\title{
Oribatid mite community structure and trophic ecology along a forest land-use gradient: effect of dead wood, time and root-trenching
}

\author{
Dissertation zur Erlangung des mathematisch- \\ naturwissenschaftlichen Doktorgrades "Doctor rerum naturalium" der \\ Georg-August-Universität Göttingen \\ im Promotionsprogramm Basisprogramm Biologie \\ der Georg-August University School of Science (GAUSS)
}

vorgelegt von

Diplom Biologe

Christian Bluhm

aus

Großburgwedel

Göttingen, April 2016 


\section{Betreuungsausschuss}

Prof. Dr. Mark Maraun, Abteilung Tierökologie, J.F. Blumenbach Institut für Zoologie und Anthropologie der Georg-August-Universität Göttingen, Berliner Str. 28, 37073 Göttingen

Prof. Dr. Stefan Scheu, Abteilung Tierökologie, J.F. Blumenbach Institut für Zoologie und Anthropologie der Georg-August-Universität Göttingen, Berliner Str. 28, 37073 Göttingen

Prof. Dr. Ulrich Brose, Abteilung Biodiversitätstheorie, Institut für Ökologie der Friedrich-Schiller-Universität Jena, Dornburger Str. 159, 07743 Jena

\section{Mitglieder der Prüfungskommission}

Referent/in: Prof. Dr. Mark Maraun, Abteilung Tierökologie, J.F. Blumenbach Institut für Zoologie und Anthropologie der Georg-August-Universität Göttingen, Berliner Str. 28, 37073, Göttingen

Koreferent/in: Prof. Dr. Stefan Scheu, Abteilung Tierökologie, J.F. Blumenbach Institut für Zoologie und Anthropologie der Georg-August-Universität Göttingen, Berliner Str. 28, 37073, Göttingen

Weitere Mitglieder der Prüfungskommission

PD Dr. Marko Rohlfs, Abteilung Tierökologie, J.F. Blumenbach Institut für Zoologie und Anthropologie der Georg-August-Universität Göttingen, Berliner Str. 28, 37073 Göttingen

Prof. Dr. Klaus Hövemeyer, J.F. Blumenbach Institut für Zoologie und Anthropologie der Georg-August-Universität Göttingen, Berliner Str. 28, 37073, Göttingen

Prof. Dr. Elvira Hörandl, Abteilung Systematik, Biodiversität und Evolution der Pflanzen, Albrecht-von-Haller-Institut für Pflanzenwissenschaften, Untere Karspüle 2, 37073, Göttingen

Prof. Dr. Holger Kreft, Abteilung Biodiversität, Makroökologie und Biogeographie, Fakultät für Forstwissenschaften und Waldökologie, Büsgenweg 1, 37077 Göttingen

Tag der mündlichen Prüfung: 29.04.2016 
Von all den Dingen die mir verloren gegangen sind, habe ich am meisten an meinem Verstand gehangen.

(Ozzy Osbourne) 
CHAPTER 1

\section{General Introduction}

1. Soil animal communities

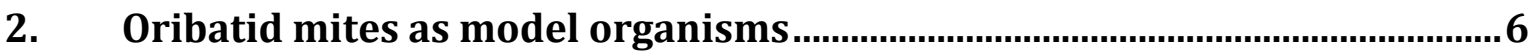

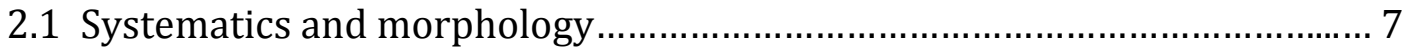

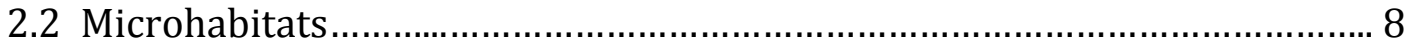

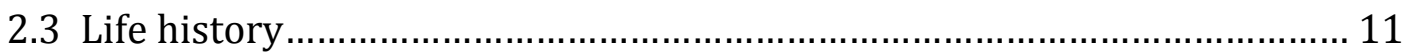

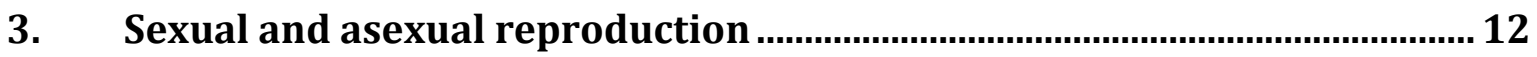

3.1 Theories on the maintenance of sexual reproduction............................... 12

3.2 Modes of parthenogenesis....................................................................... 13

3.3 Parthenogenesis in oribatid mites ..................................................... 14

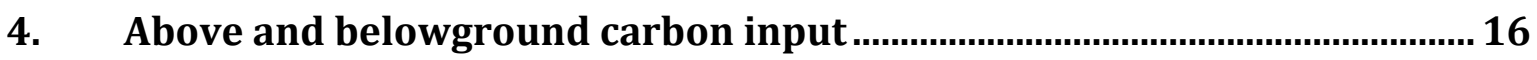

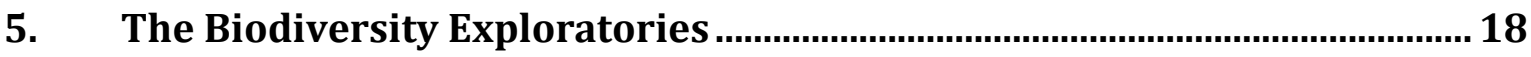

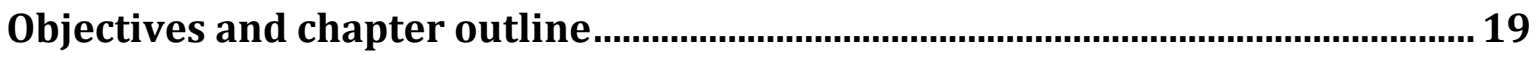

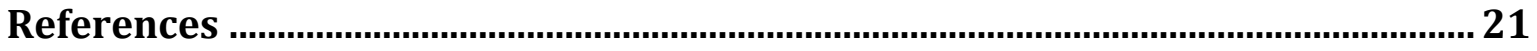

CHAPTER 2 ......................................................................................... 30

Oribatid mite communities on the bark of dead wood vary with log type, surrounding forest and regional factors

Abstract 31

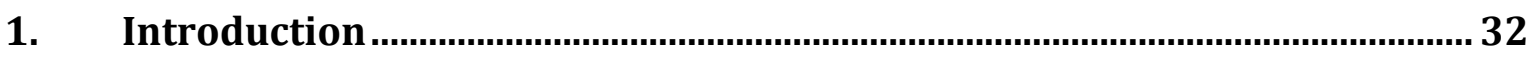

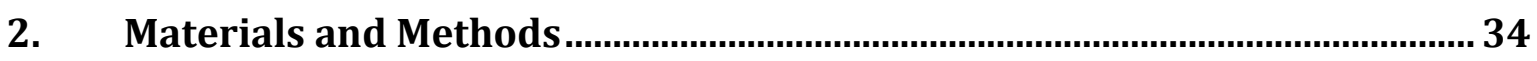

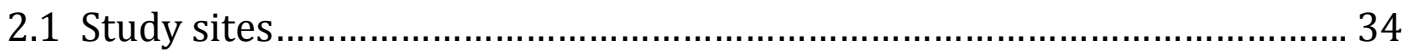

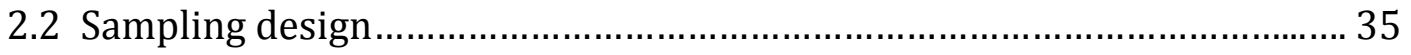

2.3 Sampling, identification of species and stable isotope analysis................. 35

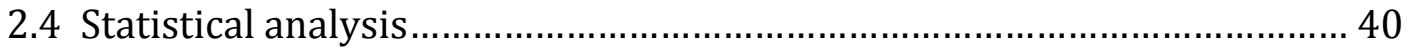

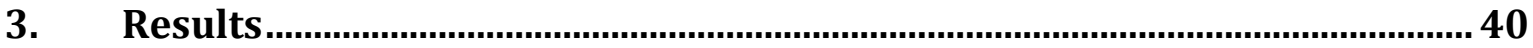

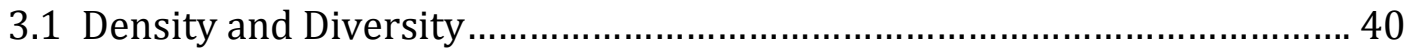

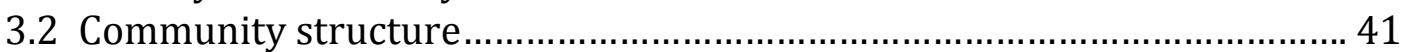

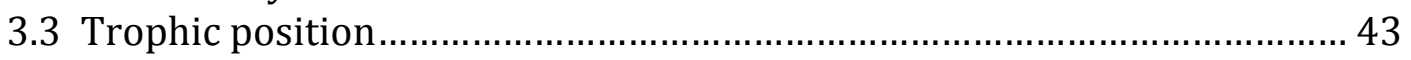

3.4 Reproductive mode.......................................................................... 44 


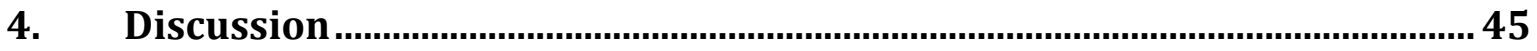

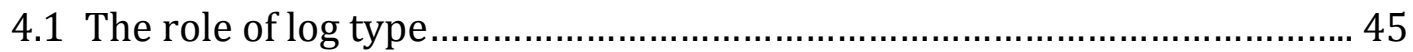

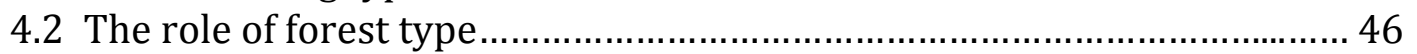

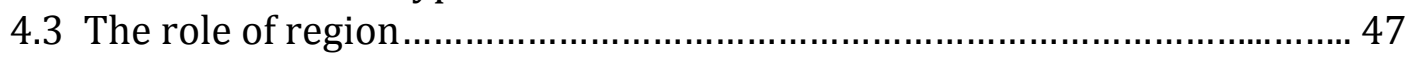

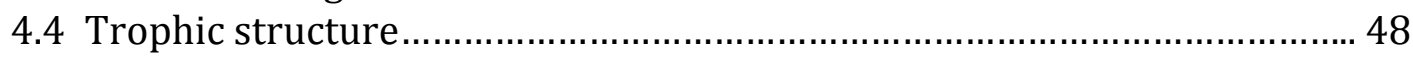

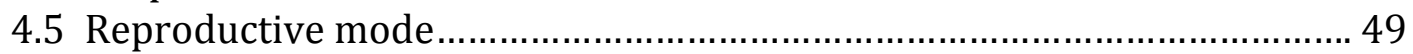

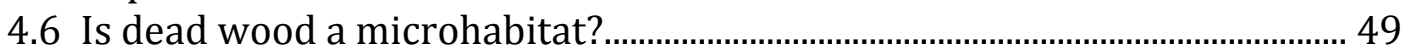

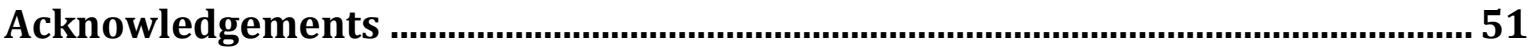

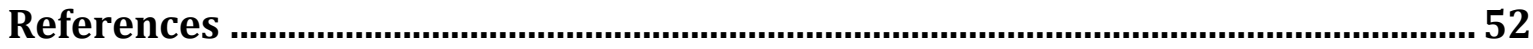

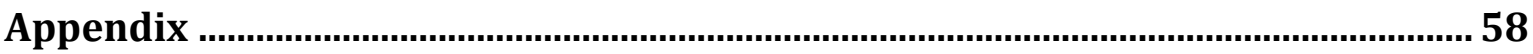

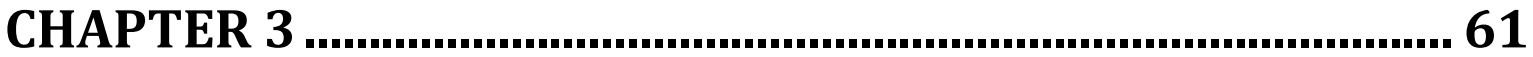

Temporal fluctuations in oribatid mites indicate that densityindependent factors favour parthenogenetic reproduction

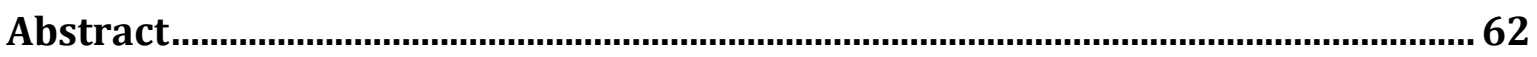

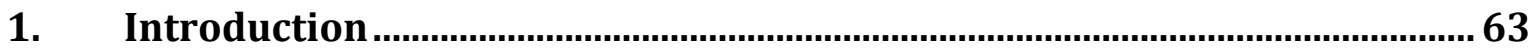

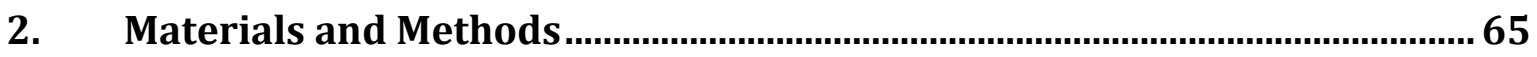

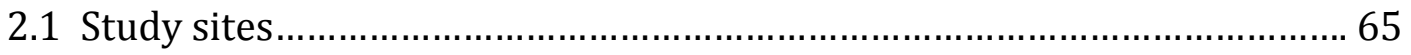

2.2 Sampling design, extraction and determination of soil animals.................66 66

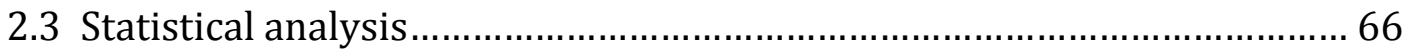

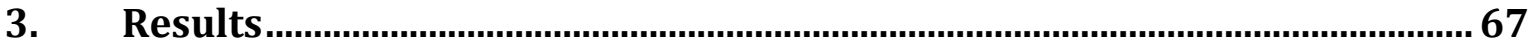

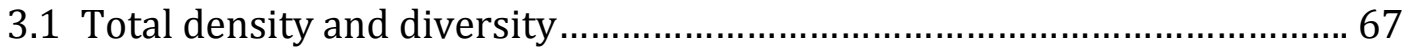

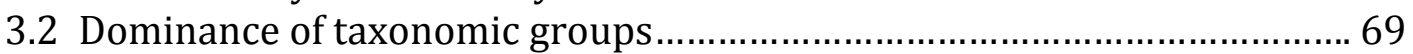

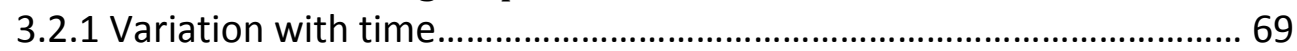

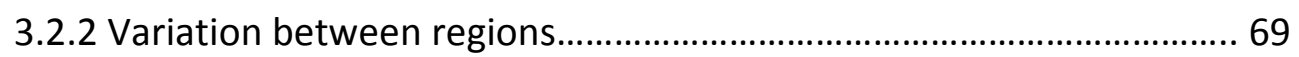

3.2.3 Variations with forest type..................................................................... 71

3.2.4 Variations with reproductive mode......................................................... 71

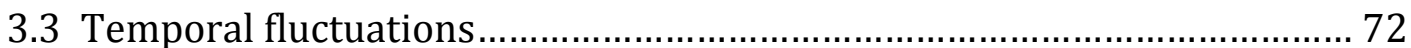

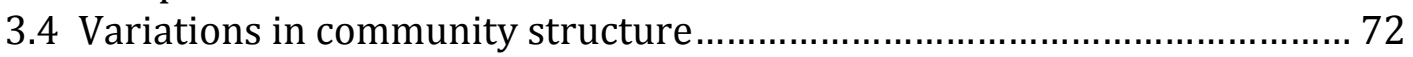

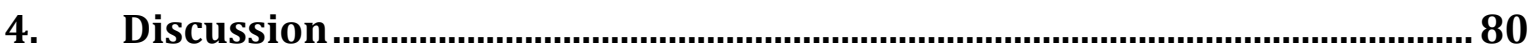

4.1 Density, species richness and community structure ............................... 80

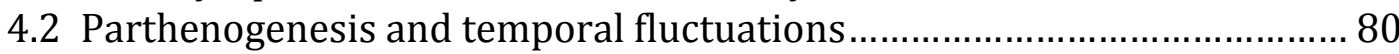

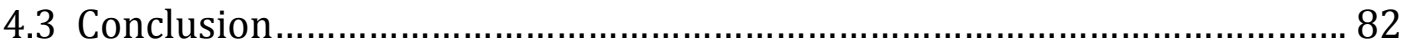

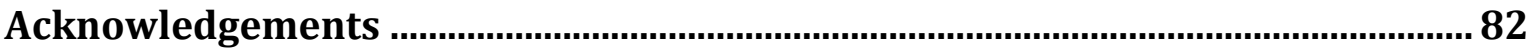

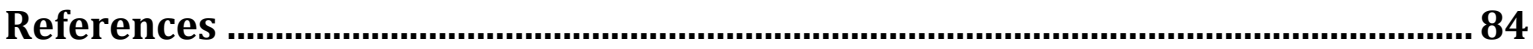


The effect of root-trenching on oribatid mite communities in temperate forests

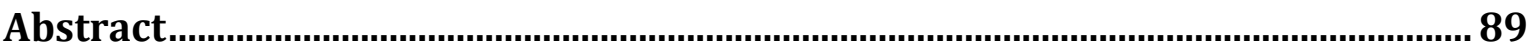

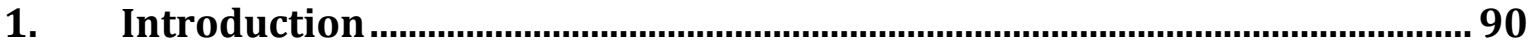

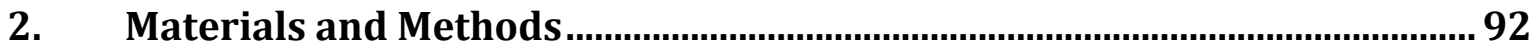

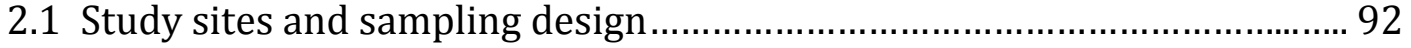

2.2 Establishment and maintenance of root-trenching plots ......................... 93

2.3 Sampling and determination of species..................................................... 93

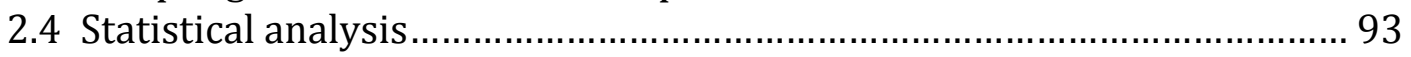

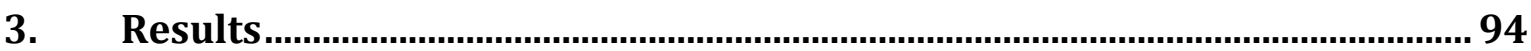

3.1 Effect of root-trenching on total oribatid mite density and species

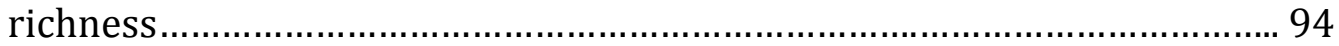

3.2 Effect of root-trenching on abundant oribatid mite species .....................99

3.3 Community composition ....................................................................... 102

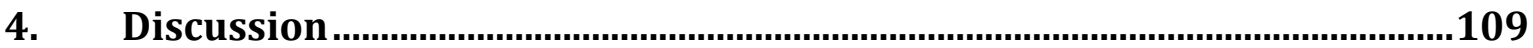

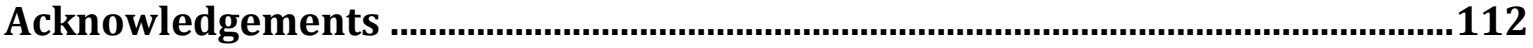

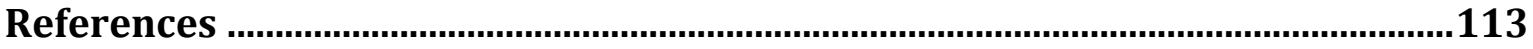

CHAPTER 5 ...............................................................................117

General Discussion

1. Factors structuring communities............................................................19

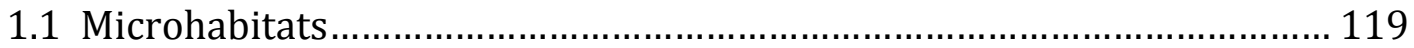

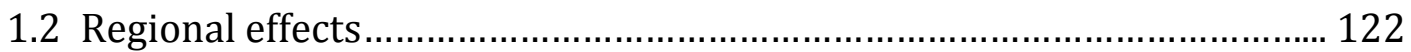

1.3 Forest type effects............................................................................. 124

2. Parthenogenesis in oribatid mites.........................................................125

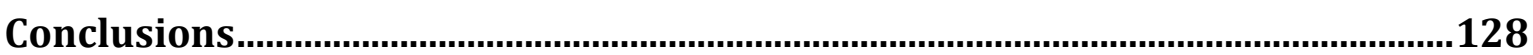

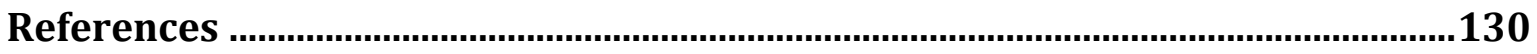

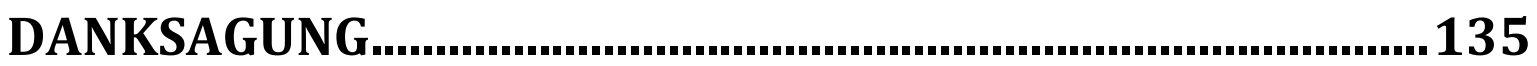

LIST OF PUBLICATIONS........................................................137

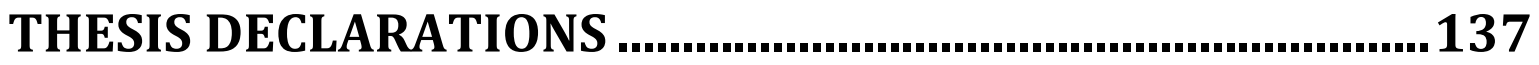




\section{SUMMARY}

Oribatid mites are involved in decomposition processes, formation of soil structure and nutrient cycling in most soils worldwide. The main habitats of oribatid mites are litter and soil but they also occur numerously on tree trunks, dead wood, marine intertidal zones and freshwater habitats. Especially in forest ecosystems they reach high local density and diversity and often dominate arthropod fauna in edaphic and arboreal habitats where they form an important part of the food web. Although oribatid mites are often regarded as a functional group of primary decomposers they feed on a wide range of food resources including lichens, mosses, algae, litter, fungi and nematodes. The exceptionally high proportion of oribatid mite species reproducing via parthenogenesis and the co-occurrence with sexual species in the same habitats make oribatid mites an interesting model group for ecological and evolutionary research.

In this thesis we investigated oribatid mite density, diversity, community structure and the proportion of parthenogenetic individuals across regions, forests types and habitats. Furthermore, we investigated the importance of root-derived resources for soil living oribatid mite communities by root-trenching, and assessed the trophic diversity on the bark of dead wood using stable isotopes.

In Chapter $\mathbf{2}$ we investigated how oribatid mite communities on the bark of early decaying dead wood are affected by log species (beech vs. oak), forest type (deciduous vs. coniferous) and region (Schorfheide-Chorin, Hainich-Dün and Schwäbische Alb). We further assessed the trophic structure of dead wood communities using stable isotopes $\left({ }^{15} \mathrm{~N}\right.$ and $\left.{ }^{13} \mathrm{C}\right)$ in one region (Hainich-Dün). The results suggest that dead wood of an early decaying stage is colonized by a mixture of edaphic and arboreal oribatid mite species and only few dead wood specialists. Stable isotope analysis provided evidence that dead wood is colonized by a community of high trophic diversity including lichen, moss, litter and fungal feeders with the latter dominating. Compared to soil, the proportion of parthenogenetic individuals on dead wood was generally low resembling arboreal communities. We showed that oribatid mite assemblages on the bark of dead wood are shaped by log species, the surrounding forest type and the region whereas density was not significantly affected by all three factors. The results indicated that oribatid mite communities on dead wood are shaped by both neutral and niche-based processes. 
In the second study (Chapter 3) we investigated oribatid mite density, community structure and the percentage of parthenogenetic individuals in four different forest types across three regions in Germany in 2008 and once again in 2011. We compared temporal (inter-annual) fluctuations in population densities between sexually and parthenogenetically reproducing species of oribatid mites. Oribatid mite community structure did not differ significantly between years but varied with forest type and region, indicating low species turnover over time. Temporal fluctuations were significantly higher in parthenogenetic as compared to sexual species. The percentage of parthenogenetic individuals was significantly higher in coniferous as compared to beech forests and significantly higher in SchorfheideChorin as compared to Hainich-Dün and Schwäbische Alb. The results indicate that parthenogenetic species flourish if populations are controlled by densityindependent factors and dominate at sites were resources are plentiful and easily available, such as coniferous forests, and in regions with more acidic soils and thick organic layers, such as Schorfheide-Chorin. However, historical factors also may have contributed to the increased dominance of parthenogenetic species in the Schorfheide-Chorin, since this region was heavily glaciated, and this may have favoured parthenogenetic species. Overall, our study supports the hypothesis that parthenogenetic species benefit from the lack of density-dependent population control whereas the opposite is true for sexual species.

In the third study (Chapter 4) we tested the significance of root-derived carbon for oribatid mite communities by interrupting the carbon flux from plants into the soil via root-trenching in two regions in Germany (Schorfheide-Chorin and Hainich-Dün). After one year, root-trenching tended to reduce total oribatid mite densities in Hainich-Dün while it had no overall effect in the Schorfheide-Chorin. Root-trenching primarily reduced densities of soil-living oribatid mites in the Hainich-Dün and primarily litter-living species in Schorfheide-Chorin. Oribatid mite community composition of both regions was not significantly affected by root-trenching. The results suggest that in contrast to previous studies only a minor part of the oribatid mite community benefits directly or indirectly from root-derived resources. The different response of oribatid mites following root-trenching in the two regions indicates that the importance of root-derived resources varies with soil structure, being more intense when litter accumulation is low. Possibly, the weak response to reduced belowground resource input was buffered by internal carbon resources of 
coarse roots being cut and also by the trophic plasticity of many oribatid mite species. 


\section{Chapter 1}

\section{General Introduction}

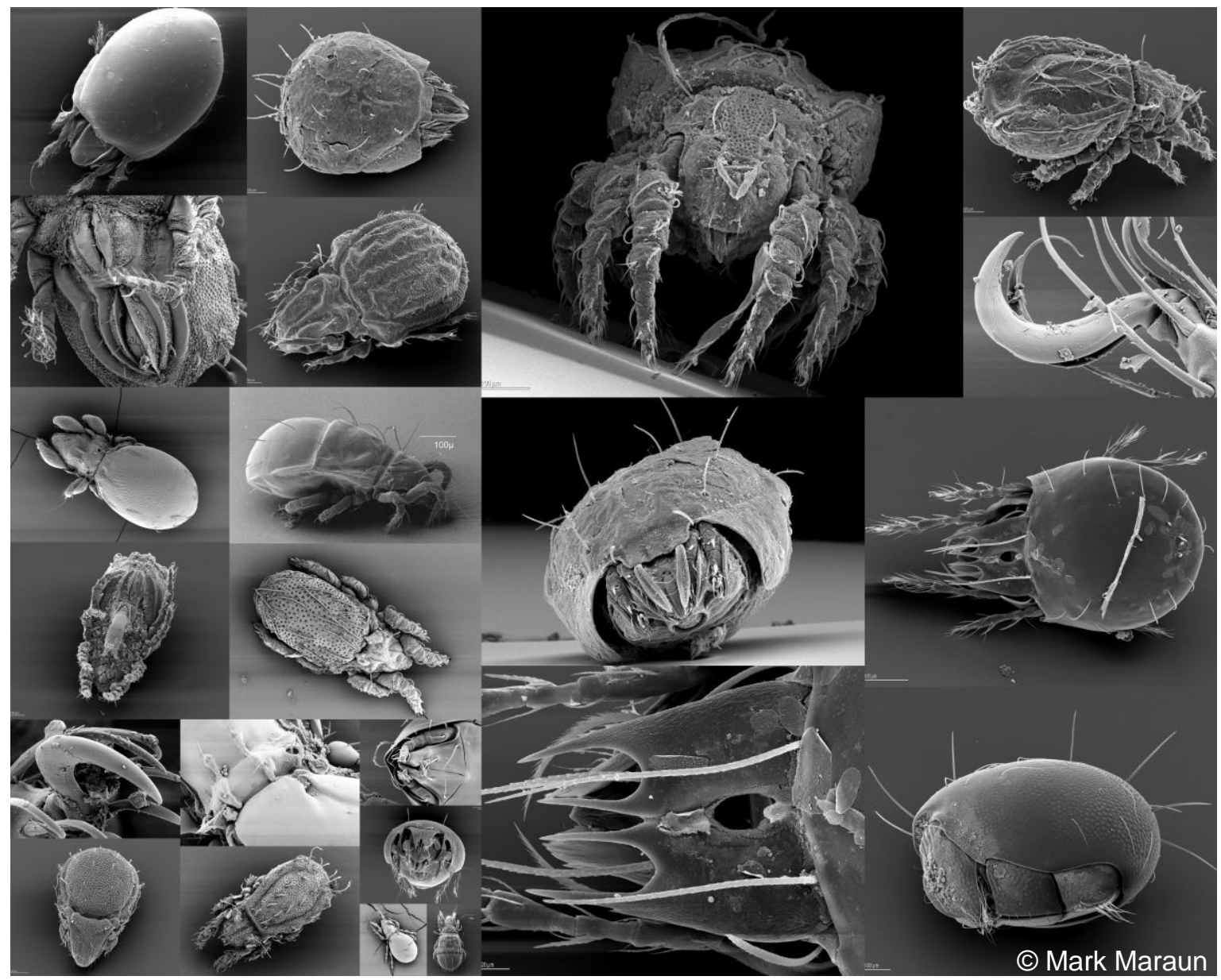




\section{Soil animal communities}

Soil is the earth's surface which comprises physically and chemically weathered inorganic parent rock material and organic remains derived from organisms living on and in it. Soils connect two important ecosystem functions: primary production of organic material and its decomposition; processes which are closely linked as they strongly depend on the presence of each other (Wardle 2002). Plants provide resources for soil organisms in form of organic matter and in return benefit from the release of nutrients due to decomposition of organic matter. Therefore, the soil represents one of the most valuable natural resource as it is the basis for all terrestrial plant life and provides habitat and resources for a variety of soil living organisms. Recently, the functional importance of the soil subsystem is increasingly appreciated and an increasing number of studies focus on belowground systems and on its connection to the aboveground world (Huhta 2007).

Due to low nutrient content and high amounts of structural compounds decomposition of organic material is a challenging task governed by a functionally diverse community of soil organisms; its species richness is assumed to exceed those of all other terrestrial systems and has been termed the "poor man's tropical rainforest" (Anderson 1975a; Giller 1996). Interactions of soil organisms are essential to sustain the recycling of organic matter and therefore play a major role in ecosystem functioning. Confronted with a densely packed three dimensional porous habitat structure, most soil dwelling organisms are rather small sized and inconspicuous and thus have been neglected in many ecological studies in the past (Usher 1985). According to their body size that affects the mobility through the porous soil environment, soil dwelling organisms are divided into microflora and micro- (<0.1 mm; Nematoda, Protozoa), meso- (0.1-2 mm; Acari, Collembola, Protura, Diplura, Pauropoda among others) and macrofauna (>2 mm; most insects, Gastropoda, Lumbricidae, Myriapoda, Isopoda among others); together, the biological entity inhabiting soil is called edaphon (Swift 1979). The microflora, comprising bacteria and fungi, are significantly involved in decomposition and mineralization processes as they possess a wide repertoire of enzymes able to break down virtually all organic substances (de Boer et al. 2005). Microorganisms excrete their enzymes into the soil environment, thereby creating the so-called "external rumen". Micro-, meso- and macrofaunal decomposers benefit from the microbial activity in that the detritus is predigested by the exoenzymes they produce. 
Additionally, the microflora serves as a food resource for many soil organisms (due to its high nutritional value) and is actively preyed by the micro- and mesofauna or passively ingested by macrofauna decomposers when litter material is consumed (Cummins 1974). However, by feeding on microorganisms, they readily disperse undigested bacteria and fungi (Renker et al. 2005). Moreover, the comminution and transformation of detritus by soil animals increases the contact surface of microorganisms (Swift 1979, Seastedt 1984; Hättenschwiler et al. 2005). Burrowing activities of so-called ecosystem engineers, particularly earthworms, markedly affect soil structure and functioning by increasing soil aeration and moisture and by allocating organic matter into deeper soil horizons (Wardle 2002).

Besides being limited by resources ("bottom up" control) primary and secondary decomposers are regulated by predation of higher level consumers ("top down" control) which potentially cascade down to lower trophic levels. However, cascades in soil food webs are generally assumed to be weak due to a high incidence of omnivory, long food chains and weak interaction strength (Strong 1992, Polis 1994). Although negative interactions such as competition and predation frequently occur among soil organism groups, they are in sum in a mutualistic relationship and collectively impact soil functioning with direct effects on primary productivity (Wardle 1999).

\section{Oribatid mites as model organisms}

Oribatid mites are an abundant and diverse, ecologically and geographically widely distributed taxon of arthropods (Peterson and Luxton 1982; Walter and Proctor 2012). They are involved in decomposition processes, formation of soil structure and nutrient cycling of most soil ecosystems worldwide (Moore et al. 1988). With a body length predominantly ranging between $0.2-1.5 \mathrm{~mm}$, they form, along with Collembola, the most important mesofauna groups. Species of oribatid mites occupy a large number of trophic niches and include primary and secondary decomposers, moss feeders, lichen feeders and predators (Luxton 1972; Siepel and de Ruiter-Dijkman 1993; Schneider et al. 2004; Maraun et al. 2011). Their species richness, trophic diversity and small size make them suitable for ecological experiments on decomposition processes and trophic interactions. Further the high number of parthenogenetic species, scattered across different phylogenetic groups, provides excellent opportunities for evolutionary research; especially as they 
sympatrically occur with sexual species (Norton et al. 1993). In the following, a more detailed view on oribatid mite systematics, evolution and ecology is provided.

\subsection{Systematics and morphology}

Mites (Acari) are the most diverse taxon of the chelicerates with about 50,000 described species, outnumbering the diversity of all known vertebrates (Wheeler 1990). Despite their superficial resemblance, the monophyly of Acari is not uniformly supported by apomorphic characters (Walter and Proctor 2012). The two distinct mite lineages Parasitiformes and Acariformes profoundly differ in morphological and behavioural characters and may be more closely related to other arachnid taxa (Dunlop and Alberti 2007; Pepato et al. 2010). The Parasitiformes contain the orders Ixodida, Holothyrida, Opilioacarida and the diverse Mesostigmata. The Acariformes are divided into the Trombidiformes and the Sarcoptiformes which is further composed of the Endeostigmata, Astigmata and the Oribatida (= "Cryptostigmata" = "Oribatei") (Krantz and Walter 2009).

Within the Acari, following the Prostigmata, the Oribatida represent the second largest phylum, currently comprising at least 10000 species (ca. 550 native to Germany), with many more undescribed awaiting classification (Schatz 2002; Weigmann 2006; Walter and Proctor 2012). The monophyly of Oribatida has been doubted by some authors based on biochemical and morphological similarities between Nothridae, a taxon of Desmonomata, and Astigmata (O'Connor 1984; Norton 1998; Sakata and Norton 2001), but this is not confirmed by molecular phylogenetic data (Maraun et al. 2004, Domes et al. 2007a).

Oribatid mites (excluding Astigmata) are characterized by (1) the presence of a prodorsal shield, (2) a sclerotized dorsal hysterosoma, consisting of at least single plates or a uniform notogaster shield, (3) a cuticula with cerotegument, (4) femora of legs without solenidia, (5) a pair of sensilli on prodorsum (with exceptions), (6) subcapitulum with broad rutella and (8) genital and anal plates are protected by a pair of sideward opening lids (Weigmann 2006).

According to their body organization, the Oribatida are commonly classified into six main subgroups of which some, however, are paraphyletic: (1) the basal, weakly sclerotized Palaeosomata, (2) the Enarthronota, in which the notogaster is subdivided in two or three shields by transversal sutures, (3) the species poor Parhyposomata, (4) the "Mixonomata" exhibiting a dichoid body form, (5) the "Desmonomata“", a group of morphological similar species exhibiting a holoid body 
form with a macropyline ventral ophistosoma region and (6) the derived monophyletic, most species rich Circumdehiscentiae (=Brachypylina), which are characterized by a holoid body form featuring a brachypyline ventral opisthosoma region (Grandjean 1969; Weigmann 2006).

The origin of oribatid mites dates back at least to the Devonian Period (about 376-379 mya) where fossils of two enarthronotan species, namely Devonacarus sellnicki and Protochthonius gilboa, have been recorded from the Gilboa Shales in the USA (Norton 1988; Dunlop and Selden 2009). Molecular-phylogenetic analyses even suggest that first oribatid mites may have evolved as early as $570 \pm 37$ million years ago (Schaefer et al. 2010). Members of the derivative group Brachypylina were first found fossilized in Southern Sweden in a sandstone formation of the early Jurassic (about 190-200 mya) as evidenced by a Hydrozetes species (Sivhed and Wallwork 1978; Krivolutsky and Druk 1986).

\subsection{Microhabitats}

Oribatid mites are among the most successful arthropods on earth, comprising species occurring on every continent and inhabit various habitats ranging from the tropical rainforests to the high latitude arctic regions (Wallwork 1973; BehanPelletier 1993; Schatz 2004; Walter and Proctor 2012). Ancestral oribatid mites are assumed to have invaded land by living in interstices in beach sand before they dwelled as detritivores in the Palaeozoic coal swamps (Labandeira et al. 1997; Feng et al. 2010). Until today, soil and litter associated habitats are the clear hotspot of abundance and diversity, but tree trunks and canopies are also habitats of notable density and diversity (Wunderle 1991; Behan-Pelletier and Walter 2000). A few genera inhabit marine intertidal zones while some other species/genera invaded freshwater habitats including ponds, streams, phytothelmata and partly submerged habitats as peat bogs (Behan-Pelletier and Bisset 1994; Behan-Pelletier and Eamer 2007; Schatz and Behan-Pelletier; Seniczak 2010). Among Acari oribatid mites are exceptional as they, despite their great diversity, did not evolve any obligate mutualism or parasitic relationships to other animals, as it is common in other suborders of the Acari (especially the closely related Astigmata).

In soil systems, oribatid mite density and diversity increase along successional stages from agricultural sites to fallow land sites/grasslands and reach its maximum when wood formation commences (Scheu and Schulz 1996, Cianciolo and Norton 2006; Zaitsev et al. 2006). In soil and litter of forest systems, oribatid mites frequently 
reach densities between tens and hundreds of thousands specimens per square meter and often numerically dominate the arthropod fauna (Schaefer and Schauermann 1990; Maraun and Scheu 2000). Exceptionally high densities are recorded from boreal forests where they occasionally exceed $300,000 \mathrm{ind} . / \mathrm{m}^{2}$ (Persson et al. 1980; Huhta et al. 1986). Although highly diverse, oribatid mite communities from tropical forest soils usually reach lower densities (Prabhoo et al. 1988; Gonzalez and Seastedt 2001; Maraun et al. 2007; Maraun et al. 2008; Illig et al. 2010). Presumably, the increase in abundance and diversity from agricultural land to forest sites is primarily attributed to the accumulation of organic material and reduced disturbance (Scheu and Schulz 1996, Zaitsev et al. 2006). In soils with a high degree of disturbance, e.g. intensively cultivated land, oribatid mite communities are depauperated, often only consisting of few euryoecious species exhibiting fast life cycles (Norton and Palmer 1991). Oribatid mite densities are usually positively correlated with the amount of organic material as it contemporaneously provides both habitat and resource. Due to habitat destruction and the reduction of resources, burrowing activities of earthworms have shown to be detrimental to oribatid mite communities (Maraun et al. 1999; McLean and Parkinson 2000; Migge-Kleian et al. 2006; Eisenhauer et al. 2007). Thus, in soils with low $\mathrm{pH}$, where earthworms are scarce, oribatid mites usually reach highest densities.

Oribatid mite communities of arboreal habitats markedly differ from those in soil and the overlap between both habitats rarely exceed 50\% (Aoki 1973; Wunderle 1992; Proctor et al. 2002; Lindo and Stevenson 2007). Although not as diverse as soil habitats, arboreal habitats are rich in species and oribatid mites frequently represent the dominant arthropod fauna in tree canopies of temperate, subtropical and tropical forests (Behan-Pelletier and Walter 2000; Walter and Proctor 2012). The majority of arboreal species belong to the Brachypylina and to a few genera of Desmonomata with many of them being restricted to this habitat (Behan-Pelletier and Walter 2000). Arboreal species are mostly associated with epiphytic cover predominantly represented by algae, bryophytes, lichens and ferns but, especially in the tropics, also with higher plants such as bromeliads and orchids (Wunderle 1992; Behan-Pelletier et al. 1993; Walter and Behan-Pelletier 1999; Behan-Pelletier et al. 2008). Other species inhabit the bark surface, insect galleries under the bark, fungal sporocarps and suspended soil but only few species colonize the phylloplane 
(Matthewman and Pielou 1971; Wunderle 1991; Erdmann et al. 2006; Maraun et al. 2014). Resource and habitat heterogeneity seems to be the main determinant for the diversity of arboreal oribatid mite assemblages (Walter and Behan-Pelletier 1999). Compared to temperate forests, the higher complexity and coverage of epiphytes on trees in tropical rainforests therefore enables a more diverse oribatid mite fauna to coexist (Behan-Pelletier et al. 1993). The type of bark may also play a role for structuring communities as it differs in microstructure, microclimate and epiphytes among tree species (Nicolai 1986, 1987, 1993). In contrast to constant conditions in soil, oribatid mites in arboreal habitats are exposed to strong climatic fluctuations and have to withstand desiccation, wind and temperature extremes. Consequently, arboreal species from many different oribatid mite taxa share behavioural and morphological similarities including the reduction of sensillus, the modification of claws, the invaginations of respiratory surfaces and sexual dimorphism and are interpreted as having convergently evolved (Aoki 1973; Pachl et al. 2012; Behan-Pelletier 2015).

In forest ecosystems dead wood represents a special habitat displaying characteristics of both the soil and the arboreal habitat. Typically, (lying) dead wood is covered by moss, lichens and algae but also litter commences to accumulate and fungi start decomposing wood substances which results in a combination of arboreal and soil resources. Additionally, on dead wood climatic conditions such as temperature and moisture fluctuations and the exposure to wind are intermediate between soil and arboreal habitats, but conditions may also vary with the stage of decay. Oribatid mite communities in dead wood are not well studied until today, but the few studies existing suggest that oribatid mite communities are diverse and species are successionally displaced by others with the stage of decay (Skubała 2008; Skubała and Maslak 2009; Huhta et al. 2012; Skubała and Marzec 2013). Highest species richness usually occurs at intermediate stages of decay, presumably due to highest resource heterogeneity (Skubała 2008; Skubała and Maslak 2009). However, it is still unclear which factors determine the acquirement of species in initial stages of decay and if dead wood communities are distinct from those of other habitats. 


\subsection{Life history}

Despite their small size and the high incidence of parthenogenetic species, most oribatid mite species are referred to as "K-strategists" exhibiting low fecundity, slow development, long adult live and iteroparity (Norton et al. 1994; Siepel 1994).

Sperm transfer is predominantly indirect via spermatophores deposited in the ambient substrate by males without female contact; in many species females reproduce via parthenogenesis without any involvement of males (for details see below) (Norton et al. 1994). In a few species mating behaviour has been observed (Schuster 1962; Estrada-Venegas et al. 1997). In general, oribatid mites lay few but large eggs that may reach half of their own body length (Sgardelis 1995). Eggs (or prelarvae in several species) are deposited individually or in small clutches once or multiple times over the year (Steinberger et al. 1990); in temperate regions often from spring to fall when temperatures are favourable for immature development. The development from egg to maturity succeeds by two larval (praelarvae, larvae) and three nymphal stages (proto-, deuto- and tritonymph) representing the presumed ancestral developmental series of Acari (Norton and Palmer 1994; Heethoff et al. 2009). Developmental time considerably differs between species ranging from 28 days in Archegozetes longisetosus (Heethoff et al. 2013) to 2-3 years in Ameronothrus lineatus (Sovik et al. 2003) but also profoundly differs with temperature (Kaneko 1988a). For example Oppiella nova develops from egg to adult in 59.5 days when reared at $15^{\circ} \mathrm{C}$ but only in 23.4 days when reared at $25^{\circ} \mathrm{C}$ (Kaneko 1988b).

The "K-strategist" view is supported by a strong sclerotization of the exoskeleton in the adult instar which functions as an effective defence mechanism thereby largely escaping predation once reached maturity (Sanders and Norton 2004; Peschel et al. 2006; Norton et al. 2007; Pachl et al. 2012). In some species, the cuticle is additionally hardened by mineralization processes by which calcium oxalate, calcium carbonate or calcium phosphate are incorporated (Norton and Behan-Pelletier 1991). Immatures are, however, weaker sclerotized and are most vulnerable to predation (Norton 1994). In many species both immature and adult instars possess defensive glands which excrete chemical substances to repel predators (Raspotnig 2006; Heethoff et al. 2012; Heethoff and Raspotnig 2012). Despite effective defence mechanism some predators such as certain beetle families (e.g. Ptiliidae, Pselaphidae, Scydmaenidae) (Park 1947; Mollemann and 
Walter 2001), some salamanders and frogs (Norton and McNamarra 1976; Simon and Toft 1991; Takada et al. 2005) as well as some species of prostigmatic and mesostigmatic mites (Walter and Kaplan 1991; Schneider and Maraun 2009) amongst others are known to prey on oribatid mites, but they are assumed to be of minor importance for the regulation of population densities. Due to scarcity of potent predators, (adult) oribatid mites are assumed to live in an "enemy free space" (Peschel et al. 2006).

The strong sclerotization of mature oribatid mites entails and contemporaneously allows slow movement, which notably contrasts with those of the predacious mesostigmatic mites. Slow movement abilities of oribatid mites hinder effective distribution and only allow dispersal on a small scale (Berthet 1964; Lehmitz et al. 2012). However, oribatid mites quickly colonize newly formed and remote habitats (Beckmann 1988; Skubała, 1995; Gjelstrup 2000; Hågvar et al. 2009). Probably dispersal by fauna (especially birds and beetles) represents a means of transportation to cover larger distances particularly when discontinuous habitats are colonized such as canopies, ponds, dead wood or islands (Norton 1980; Krivolutzky and Lebedeva 2004; Knee et al. 2013; Beaty et al. 2013; Lebedeva 2012). To a certain extent aerial and hydrochorous dispersal may also play a significant role in aiding oribatid mites to colonize new habitats (Bernini 1990; Lehmitz et al. 2011).

\section{Sexual and asexual reproduction}

\subsection{Theories on the maintenance of sexual reproduction}

As sexual reproduction is extremely common in most animal taxa, it is often overlooked that sex is not an essential feature for successful propagation. On the contrary, sexual reproduction leads to the break-up of favourable gene combinations and reduces the reproduction efficiency by the so called "two-fold costs of sex" by producing males (Maynard Smith 1978). The meaning and maintenance of sex has been a long debated and highly controversial topic since decades and has led to a multitude of theories attempting to explain its high prevalence in the animal kingdom.

Basically, the theories can be classified into ecological and mutation-based models (West et al. 1999). The ecological models agree that sexual reproduction is a useful tool to create genetic diversity, however, they differ in their explanation how this can compensate the "two-fold costs". While the 'Vicar of Bray' hypothesis suggested that by sexual recombination favourable mutations can be fixed in 
parallel, accelerating evolution and thus adaptation to changing environments (Weismann 1889; Guenther 1906; Fisher 1930; Muller 1932), the 'Red Queen' hypothesis postulates an advantage of sexual species in the coevolutionary arms race between host and parasites or predator and prey (Jaenike 1978; Hamilton 1980). The 'Tangled Bank' hypothesis attributes the dominance of sexual species to their ability to produce genetically diverse offspring able to occupy a larger variety of niches in spatially structured environments as compared to genetically more uniform offspring produced by parthenogenetic reproduction (Maynard Smith 1971; Ghiselin 1974; Bell 1982).

The mutation-based models do not point to the advantage of sexuality, rather do they highlight the disadvantage of parthenogenetic reproduction ('Mullers ratchet' and 'Kondrashov's hatchet'; Muller 1964; Kondrashov 1988). According to these theories, deleterious mutations accumulate in the genome of parthenogenetically reproducing species due to the lack of mixis leading to degeneration and eventually extinction. Consequently, they predict that asexual reproduction invariably represents an evolutionary dead end and parthenogenetic offshoots can only survive for short periods of time.

A recent model, the 'Structured Resource Theory of Sexual Reproduction' (SRTS), includes elements of the 'Tangled Bank' theory and extends them by referring the mode of reproduction to the availability of resources (Scheu and Drossel 2007). The SRTS regards parthenogenetic reproduction as strategy that is best suited to exploit habitats where resources are little structured, quickly replenished or death rates are high. On the contrary, sexual species prevail in habitats where resources are limiting or difficult to access. Based on these assumptions, the SRTS predicts that sexual species primarily occur in habitats that are limited by density-dependent factors (e.g., predation, resource competition, parasites) whereas asexual species primarily occur in habitats that are limited by density-independent factors (e.g. desiccation, frost or flooding). Hence, parthenogenetic species should exhibit temporal fluctuations that exceed those of sexual species.

\subsection{Modes of parthenogenesis}

The term parthenogenesis (from Greek for parthenos = virgin and genesis = creation) means the process in which the reproduction of progeny succeeds without female eggs being fertilized by male gametes (Hughes 1989). However, the 
underlying mechanisms how this is achieved can profoundly differ and should be separated (Bell 1982; Norton 1994). Arrhenotokous parthenogens produce female progeny by fertilized, diploid eggs and males by unfertilized, haploid eggs; thus only males are parthenogenetically produced (this form of parthenogenesis is for example found in all Hymenoptera, some Thysanoptera, some Sternorrhyncha and some Mesostigmata).

Thelytokous parthenogens only produce female progeny carrying a diploid genome (from Greek for thelys = female and tokos = birth). When meiosis is suppressed and eggs are produced by mitotic division, this form of thelytoky is referred to as apomixis. In this case, genomes of the progeny are identical with those of the mother. In automictic species, two nuclei produced by meiotic divisions immediately fuse and restore the diploid chromosome number. Due to recombination processes the female progeny are not identical with its mother. Parthenogens are further divided in those which obligatory and those which facultatively reproduce via parthenogenesis. Obligate parthenogenesis is rare in the animal kingdom and collectively comprise only about $0.1 \%$ of all species currently recognized worldwide (White 1978; Bell 1982). With approximately 8-9\% of known species reproducing parthenogenetically, oribatid mites represent an anomaly in this respect (Norton and Palmer 1991, Heethof et al. 2009).

\subsection{Parthenogenesis in oribatid mites}

Parthenogenetic oribatid mite species presumably reproduce predominantly via automictic thelytoky, but some uncertainty about the exact mechanisms exist (Taberly 1987; Taberly 1988; Heethoff et al. 2006; Heethoff et al. 2009). Although terminal fusion which usually leads to homozygous offspring has been observed for some parthenogenetic species (Taberly 1987; Heethoff et al. 2006) all investigated species exhibited fixed heterozygosity (Palmer and Norton 1992). This apparent contradiction might be solved when terminal fusion automixis of holokinetic chromosomes is combined with an inverted sequence of meiotic divisions (Wrensch et al. 1994, Heethoff et al. 2009). Mostly, evidence for parthenogenesis in oribatid mite species is rather inferential from the absence or rarity of males, but others have demonstrated to be parthenogenetic in rearing experiments (Taberly 1987a; Palmer and Norton 1990; Palmer and Norton 1991; Cianciolo and Norton 2006). Generally, species with males only representing $5 \%$ or less are assumed to reproduce parthenogenetically. Rare (spanandric) males are suggested to be atavistic relicts 
of a sexual ancestry as evidenced by sterile spermatophores (Grandjean 1941; Taberly 1988; Norton and Palmer 1991).

The majority of parthenogenetic species are phylogenetically clustered in the basal taxa Enarthronota, Mixonomata and Desmonomata but also some more recent parthenogenetic offshoots exist in the derivative Brachypylina (e.g., the genera Suctobelbella and some species of Oppiidae) (Heethoff et al. 2009). The clustered occurrence of parthenogens in several speciose monophyletic lineages indicates that they radiated while being parthenogenetic (Maraun et al. 2004). Ancient parthenogenetic lineages are exceptionally rare in the animal kingdom and are, beside oribatid mites, only found in darwinulid ostracods and bdelloid rotifers (Butlin et al. 1998; Welch and Meselson 2000). The existence of these ancient lineages violates the theory that parthenogenetic reproduction is an evolutionary dead end due to the accumulations of deleterious mutations and the inability to cope with environmental changes (Muller 1964; Kondrashov 1988); a circumstance for which the term "evolutionary/ancient asexual scandals" was coined by Maynard Smith (1978). Furthermore, the occurrence of several sexual oribatid mite species within ancient parthenogenetic clusters questions Dollo's Law which posited that complex characters once lost in evolution cannot re-evolve (Domes et al. 2007b).

Despite the plethora of theories that have been proposed on the advantages and disadvantages of sexual and parthenogenetic reproduction none of them can comprehensively explain actual distribution patterns of parthenogenetic species. The prevalence of parthenogenetic oribatid mites is not well predictable and often enough contradict theoretical assumptions. Conform with most theories, parthenogenetic oribatid mites are often found in disclimax habitats like glacial forelands, arable fields and newly formed habitats but are equally or more abundant in undisturbed forest soils (Norton and Palmer 1991; Siepel 1995). In contrast to theoretical expectations that parthenogenetic species are favoured in abiotic exposed habitats, in grassland soils and particularly on the bark of trees, where temperature and moisture regimes can vary rapidly, numbers of parthenogenetic species are generally low (BM Fischer et al. 2010; Erdmann et al. 2006; Siepel 1995). Similarly, within the soil habitat the litter layer is colonized by less parthenogenetic species than the upper soil layer where conditions are expected to be more stable (Luxton 1982, Norton and Palmer 1991). However, communities from seasonally constant tropical rain forests soils harbour lower numbers of 
parthenogenetic species than communities from boreal forest soils that are exposed to strong seasonal variations (Maraun and Scheu 2000; Maraun et al. 2013). Within the tropical rain forest soils the proportion of parthenogenetic species decreases with altitude although climate contemporaneously becomes harsher (Maraun et al. 2013). Freshwater habitats including ponds and streams and semi-limnic habitats such as peat bogs are generally rich in parthenogenetic species but marine habitats are not (Norton and Palmer 1991; Behan-Pelletier and Bisset 1994; Siepel 1995).

Solely abiotic factors seem not to be sufficient for explaining these patterns. A key factor determining the occurrence of parthenogenetic species might be the availability of resources as indicated by a positive correlation with overall oribatid mite density (Maraun et al. 2012).

\section{Above and belowground carbon input}

Only about $10 \%$ of plants primary production is consumed by herbivores (Hairston et al. 1960; Cebrian 1999). Consequently, ca. $90 \%$ of organic material produced by plants ultimately enters the so called "brown food web" as detritus, where it is degraded by the decomposer community and then propagated to higher trophic levels (Bardgett et al. 2005). It is assumed that the soil animal food web is primarily fuelled by two weakly connected trophic pathways differing in their basal resource: the litter-based and the root-based pathway.

The litter-based pathway consists mainly of hardly degradable leaf litter low in nitrogen and high in structural compounds such as cellulose, hemicellulose and lignin. The breakdown of this recalcitrant resource demands special digestive requirements from the consumers and is predominantly processed by microorganisms, especially fungi, which possess a wide repertoire of enzymes (de Boer et al. 2005). Primary decomposer animals accelerate the decomposition process by the comminution of leaf litter. Generally, due to difficulties in the degradation of this resource the energy flow in this channel is relatively slow.

The root-based pathway is driven by low molecular carbon compounds excreted belowground by plant roots (van Hees et al. 2004). These compounds are easily digestible and are rapidly incorporated by microorganisms resulting in a steep increase of microbial biomass in the vicinity of roots which is often referred to as rhizosphere effect (Hiltner 1904; Haichar et al. 2014). By preying on microorganisms and microbivores, root-carbon is channelled to higher trophic levels. Most plant roots are also associated with mycorrhizal fungi that are supplied with photosynthetic 
carbohydrates by the host (Smith and Read 2008). The high accumulation of biomass and the ubiquitous occurrence of these fungi make them suitable as a food resource for a variety of soil animals and possibly account for a high proportion of the root-derived carbon (Högberg and Högberg 2002). Laboratory food choice experiments indicate that indeed mycorrhizal fungi might be considered as a potential food resource for oribatid mites (Schneider et al. 2005). Because of limitations in the differentiation between saprotrophic and mycorrhizal fungi the importance of mycorrhiza for soil animal nutrition, however, is difficult to assess (Pollierer et al. 2012). In field experiments which reduced the abundance of mycorrhizal fungi by root-trenching or tree-girdling total oribatid mite densities were mostly negatively affected indicating beneficial effects of root derived-resources (Remén et al. 2008). However, the effect differed between species.

Evidence in support of the significance of root-derived resources also comes from recent studies using stable isotopes that demonstrated that many oribatid mites among other soil animals preferentially incorporate carbon and nitrogen from the root-based pathway (Pollierer et al 2007, 2012; Gilbert et al. 2014; S Zieger et al., unpubl. data). However, the extent to which the root-based energy channel contributes to the soil animal nutrition is still poorly understood and results are often ambiguous. Presumably, the contribution of carbon from both pathways varies with the quality of leaf litter and root exudation patterns of the involved plant species; factors which further alter with abiotic parameters, seasonality and the vigour of plant (Wardle et al. 2002; Jones et al. 2004; Kuzyakov and Blagodatskaya 2015). Therefore, the contribution of either pathway may vary between regions and between forest types of different tree species and ages. The complexity of factors being involved complicates the assessment on the importance of the root-derived pathway and requires further research. 


\section{The Biodiversity Exploratories}

The studies were conducted on the experimental sites of the large, integrative project "Biodiversity Exploratories" investigating biodiversity patterns in grassland and forest systems of different management (M Fischer et al. 2010). The project comprises three regions across Germany spanning over a distance of more than $500 \mathrm{~km}$ :

(1) The Schorfheide-Chorin is located in the lowlands of Northeast of Germany (3-140 $\mathrm{m}$ a.s.I.) and is shaped by the historic glaciation processes.

(2) The Hainich-Dün includes large, unfragmented beech forests in Thuringia, central Germany (285-550 m a.s.l.)

(3) The Schwäbische Alb is located in the alp foothills in South-west Germany on an altitude of ca. $700 \mathrm{~m}$ a.s.I.

The three regions differ in climate and soil properties. Seasonal variation in precipitation and temperature are more pronounced in the continental climate of Schorfheide-Chorin as compared to the oceanic climate of Hainich-Dün and Schwäbische Alb. The sandy soil structure of Schorfheide-Chorin profoundly differs from the calcareous soils of Hainich-Dün and Schwäbische Alb which is reflected in lower $\mathrm{pH}$-values $(3.00 \pm 0.19,4.51 \pm 0.72$ and $4.59 \pm 0.67$, respectively).

Within each region, 50 experimental forest plots of $100 \times 100 \mathrm{~m}$ of different management were selected for intensive research: young and old beech forests, planted as age class forests 30 and 70 years ago, natural beech forests, taken out of management for at least 60 years, and coniferous forests planted as age class forests 70 years ago. Coniferous forests are composed of Norway spruce (Picea abies) in Schwäbische Alb and Hainich-Dün and pine (Pinus sylvestris) in Schorfheide-Chorin. Beech forests are dominated by European beech (Fagus sylvatica) and occasionally interspersed by European ash (Fraxinus excelsior), Norway maple (Acer platanoides), sycamore maple (Acer pseudoplatanus) and Small-leaved and Large leaved lime (Tilia cordata, T. platyphyllos). 


\section{Objectives and chapter outline}

This thesis focuses on community structure, trophic ecology and ecological patterns of parthenogenetic reproduction in the Oribatida.

In Chapter 2, we investigated oribatid mite communities on the bark of young dead wood. Compared to soil arboreal habitats harbour largely distinct oribatid mite communities. Here, a dramatic switch from predominantly parthenogenetically reproducing to predominantly sexually reproducing species occur. We assumed that dead wood in an early phase of decomposition represents an intermediate habitat for soil and arboreal communities and thus also the proportion of parthenogenetic species/specimens to be intermediate. We further were interested if these communities are affected by regional factors (represented by the regions Schorfheide-Chorin, Hainich-Dün and Schwäbische Alb), by the surrounding forest type (deciduous and coniferous) and/or by the type of log represented by two different tree species (oak and beech). We assumed that the community composition is mainly driven by regional factors and to a lesser extent by the surrounding forest type since an equivalent pattern was observed for soil communities. Further, we expected that the abundance is higher on the bark of oak than on beech logs as the rough structure of the former increases habitat space which has been proven to be beneficial in litter habitats. Additionally, we were interested in the trophic structure of dead wood communities, which was analyzed by stable isotopes $\left({ }^{15} \mathrm{~N} /{ }^{13} \mathrm{C}\right)$ in one of the study regions. Arboreal habitats are mostly inhabited by species feeding on lichen, algae and moss whereas soil habitats are dominated by species that feed on litter, fungi and possibly nematodes. We expected early decaying dead wood to harbour a mixture of both feeding regimes as dead wood probably supply a mixture of these resources.

In Chapter $\mathbf{3}$ we tested predictions of the 'Structured Resource Theory of Sexual Reproduction' (SRTS) by investigating temporal patterns of parthenogenetically and sexually reproducing oribatid mites. The SRTS states that species reproducing sexually prevail in habitats where population growth is limited by the shortage or inaccessibility of resources. Species reproducing asexually consequently prevail where resources are plentiful, easy to access and replenish quickly and also in habitats where death rates are high so that available resources are not fully exploited. Accordingly, sexual species prevail at conditions where densitydependent factors predominate (e.g., predation, resource competition, parasites), 
whereas asexual species are favoured if density-independent factors prevail, such as desiccation, frost or flooding. We tested this hypothesis by comparing oribatid mite abundance, community structure and the relative proportion of parthenogenetic individuals between regions of different climate, between forest types and between years. On the basis of the SRTS we assumed that temporal fluctuations of parthenogenetically reproducing exceed those of sexually reproducing species. We further hypothesized that forest type and region affect the reproductive mode of oribatid mites with the dominance of parthenogenetic species increasing with forest disturbance and towards regions with harsher abiotic conditions.

The importance of root derived carbon for soil animal food webs increasingly attracts notice of soil biologists since recent studies displayed its relevance by the use of stable isotopes. Root-derived carbon, in contrast to the often recalcitrant litter, is an easily digestible resource and results in an increase in microbial biomass in the rhizosphere. Most trees also allocate carbohydrates gained by photosynthesis into associated mycorrhizal fungi which might serve as a food resource for various soil animals. In Chapter 4 we investigated the importance of root-derived carbon for oribatid mite communities in two regions in Germany (Schorfheide-Chorin and Hainich-Dün) in differently managed forest types by disrupting the root-carbon flow into the soil via root-trenching. We hypothesized that root-trenching reduces densities of oribatid mites relying on the root-based energy channel whereas those primarily associated with the litter-based energy channel remain unaffected. 


\section{References}

Anderson J (1975a) Succession, diversity and trophic relationships of some soil animals in decomposing leaf litter. J Anim Ecol 44:475-495

Anderson JM (1975) The enigma of soil animal species diversity. In: Vanek J (ed) Progress in soil zoology. Academia, Prague, pp 51-58

Aoki J-I (1973) Soil mites (oribatids) climbing trees. In: Daniel M, Rosicky B (eds) Proceedings of the $3^{\text {rd }}$ International Congress of Acarology, Prague. Junk B.V. Publishers, The Hague, pp 59-65

Behan-Pelletier VM (2015) Review of sexual dimorphism in brachypyline oribatid mites. Acarologia 55:127-146

Behan-Pelletier VM, Bissett B (1994) Oribatida of Canadian peatlands. Mem Entomol Soc Canada 169:73-88

Behan-Pelletier VM, Eamer B (2007) Aquatic Oribatida: Adaptations, constrains, distribution and ecology. Acarology 11:71-82

Behan-Pelletier VM, Paoletti MG, Bissett B, Stinner BR (1993) Oribatid mites of forest habitats in northern Venezuela. Trop Zool (Special Issue) 1:39-54

Behan-Pelletier VM, John MGSt, Winchester N (2008) Canopy Oribatida: Tree specific or microhabitat specific? Eur J Soil Biol 44:220-224

Behan-Pelletier VM, Walter D (2000) Biodiversity of oribatid mites (Acari: Oribatida) in tree canopies and litter. In: Coleman DC, Hendrix PF (eds) Invertebrates as Webmasters in Ecosystems. CAB International, Wallingford, UK, pp 187-202

Bell G (1982) The Masterpiece of Nature. The Evolution and Genetics of Sexuality. University of California Press, Berkeley

Bernini $F$ (1991) Oribatids and insular biogeography. Proc. Int. Symposium on biogeographical aspects of insularity, Accad. Naz. Lincei, Roma 85:23-43

Berthet PL (1964) Field study of the mobility of Oribatei (Acari), using radioactive tagging. J Anim Ecol 33:443-449

Boer Wd, Folman LB, Summerbell RC, Boddy L (2005) Living in a fungal world: impact of fungi on soil bacterial niche development. FEMS Microbiol Rev 29:795-811

Butlin R, Schön I, Martens K (1998) Asexual reproduction in nonmarine ostracods. Heredity 81:473-480

Cebrian J (1999) Patterns in the fate of production in plant communities. Am Nat $154: 449-468$

Cianciolo JM, Norton RA (2006) The ecological distribution of reproductive mode in oribatid mites, as related to biological complexity. Exp Appl Acarol 40:1-25

Cummins KW (1974) Structure and function of stream ecosystems. Bioscience 24:631-641

Domes K, Althammer M, Norton R, Scheu S, Maraun M (2007a) The phylogenetic relationship between Astigmata and Oribatida (Acari) as indicated by molecular markers. Exp Appl Acarol 42:159-71

Domes K, Norton R, Maraun M, Scheu S (2007b) Reevolution of sexuality breaks Dollo's law. Proc Natl Acad Sci USA 104:7139-44 
Dunlop JA, Selden PA (2009) Calibrating the chelicerate clock: a paleontological reply to Jeyaprakash and Hoy. Exp Appl Acarol 48:183-97

Dunlop JA, Alberti G (2008) The affinities of mites and ticks: a review. J Zool Syst Evol Res 46:1-18

Eisenhauer N, Partsch S, Parkinson D, Scheu S (2007) Invasion of a deciduous forest by earthworms: Changes in soil chemistry, microflora, microarthropods and vegetation. Soil Biol Biochem 39:1099-1110

Erdmann G, Floren A, Linsenmair KE, Scheu S, Mark M (2006) Little effect of forest age on oribatid mites on the bark of trees. Pedobiologia 50:433-441

Estrada-Venegas E, Norton RA, Moldenke AR (1997) Unusual sperm transfer in Pilogalumna sp. (Acari: Oribatida). In: Mitchell R, Horn DJ, Needham GR, Welbourn WC (eds) Acarology IX, Proceedings (IX ${ }^{\text {th }}$ Inter. Congr. Acarology), Ohio Biol. Survey, Columbus, pp 565-567

Feng Z, Wang J, Liu LJ (2010) First report of oribatid mite (arthropod) borings and coprolites in Permian woods from the Helan Mountains of northern China. Palaeogeogr Palaeoclimatol Palaeoecol 288:54-61

Fischer BM, Schatz H, Maraun M (2010) Community structure, trophic position and reproductive mode of soil and bark-living oribatid mites in an alpine grassland ecosystem. Exp Appl Acarol 52:221-237

Fischer M, Bossdorf O, Gockel S, Hänsel F, Hemp A, Hessenmöller D, Korte G, Nieschulze J, Pfeiffer S, Prati D, Renner S, Schöning I, Schuhmacher U, Wells K, Buscot F, Kalko EKV, Linsenmair KE, Schulze ED, Weisser WW (2010) Implementing large-scale and long-term functional biodiversity research: The Biodiversity Exploratories. Basic Appl Ecol 11:473-485

Fisher RA (1930) The Genetical Theory of Natural Selection. Clarendon Press, Oxford

Ghiselin MT (1974) The Economy of Nature and the Evolution of Sex. University of California Press, Berkeley, CA

Gilbert KJ, Fahey TJ, Maerz JC, Sherman RE, Bohlen P, Dombroskie JJ, Groffman PM, Yavitt JB (2014) Exploring carbon flow through the root channel in a temperate forest soil food web. Soil Biol Biochem 76:45-52

Giller PS (1996) The diversity of soil communities, the 'poor man's tropical rainforest'. Biodivers Conserv 168:135-168

Gjelstrup P (2000) Soil mites and collembolans on Surtsey, Iceland, 32 years after the eruption. Surtsey Res 11:43-50

Gonzalez G, Seastedt T (2001) Soil fauna and plant litter decomposition. Ecology 82:955-964

Grandjean F (1969) Considérations sur le classment des Oribates. Leur division en 6 groupes majeurs. Acarologia 11:127-153

Grandjean MF (1941) Statistique sexuelle et parthénogenèse chez les Oribates (Acariens). Ac Sci 212:463-467

Guenther C (1906) Darwinism and the Problems of Life. A Study of Familiar Animal Life, translated by J. McCabe. A. Owen \& Co, London 
Haichar FEZ, Santaella C, Heulin T, Achouak W (2014) Root exudates mediated interactions below ground. Soil Biol Biochem 77:69-80

Hairston NG, Smith FE, Slobodkin LB (1960) Community structure, population control, and competition. Am Nat 94:421-425

Hamilton WD 1980 Sex versus non-sex versus parasite. Oikos 35:282-290

Hättenschwiler S, Tiunov AV, Scheu S (2005) Biodiversity and Litter Decomposition in Terrestrial Ecosystems. Ann Rev Ecol Evol Syst 36:191-218

Heethoff M, Bergmann P, Norton RA (2006) Karyology and sex determination. Acarologia 46:127-131

Heethoff M, Koerner L, Norton RA, Raspotnig G (2011) Tasty but protected--first evidence of chemical defense in oribatid mites. $J$ Chem Ecol 37:1037-43

Heethoff M, Norton R, Scheu S, Maraun M (2009) Parthenogenesis in oribatid mites (Acari, Oribatida). Evolution without sex. In: Schön I, Martens K, Van Dijk P (eds) Lost sex. The Evolutionary Biology of Parthenogenesis. Springer, New York, pp 241-257

Hiltner L (1904) Über neuere Erfahrungen und Probleme auf dem Gebiet der Bodenbakteriologie und unter besonderer Berücksichtigung der Gründüngung und Brache. Arb Dtsch Landwirt Ges 98:59-78

Högberg MN, Högberg P (2002) Extramatrical ectomycorrhizal mycelium contributes one-third of microbial biomass and produces, together with associated roots, half the dissolved organic. New Phytol 154:791-795

Hughes RN (1989) A Functional Biology of Clonal Animals. Chapman and Hall, London

Huhta V (2007) The role of soil fauna in ecosystems: A historical review. Pedobiologia 50:489-495

Huhta V, Siira-Pietikäinen A, Penttinen R (2012) Importance of dead wood for soil mite (Acarina) communities in boreal old-growth forests. Soil Org 84:499-512

Illig J, Norton RA, Scheu S, Maraun M (2010) Density and community structure of soil- and bark-dwelling microarthropods along an altitudinal gradient in a tropical montane rainforest. Exp Appl Acarol 52:49-62

Jaenike $J$ (1978) A hypothesis to account for the maintenance of sex within populations. Evol Theory 3:191-194

Jones DL, Hodge A, Kuzyakov Y (2004) Plant and mycorrhizal regulation of rhizodeposition. New Phytol 163:459-480

Knee W, Forbes MR, Beaulieu F (2013) Diversity and host use of mites (Acari: Mesostigmata, Oribatida) phoretic on bark beetles (Coleoptera: Scolytinae): Global generalists, local specialists? Entomol Soc Am 106:339-350

Kondrashov AS (1988) Deleterious mutations and the evolution of sexual reproduction. Nature 336:403-405

Krivolutsky DA, Druk AY (1986) Fossil oribatid mites. Annu Rev Entomol 31:533545

Krivolutsky DA, Lebedeva NV (2004) Oribatid mites (Oribatei) in bird feathers: Passeriformes. Acta Zool Litu 14:19-38 
Kuzyakov Y, Blagodatskaya E (2015) Microbial hotspots and hot moments in soil: Concept \& review. Soil Biol Biochem 83:184-199

Labandeira CC, Phillips TL, Norton RA (1997) Oribatid mites and the decomposition of plant tissues in Paleozoic coal-swamp forests. Palaios 12:319-353

Lehmitz R, Russel D, Hohberg K, Christian A, Xylander WER (2011) Wind dispersal of oribatid mites as a mode of migration. Pedobiologia 54:201-207

Lehmitz R, Russel D, Hohberg K, Christian A, Xylander WER (2012) Active dispersal of oribatid mites into young soils. Appl Soil Ecol 55:10-19

Luxton M (1972) Studies on the oribatid mites of a Danish beech wood soil. Pedobiologia 12:434-463

Luxton M (1982) The biology of mites from beech woodland soil. Pedobiologia 23:18

Maraun M, Alphei J, Beste P, Bonkowski M, Buryn R, Migge-Kleian S, Peter M, Schaefer M, Scheu S (2001) Indirect effects of carbon and nutrient amendments on the soil meso- and microfauna of a beechwood. Biol Fertil Soils 34:222-229

Maraun M, Alphei J, Bonkowski M, Buryn R, Migge-Kleian S, Peter M, Schaefer M, Scheu S (1999) Middens of the earthworm Lumbricus terrestris (Lumbricidae): microhabitats for micro-and mesofauna in forest soil. Pedobiologia 43:276-287

Maraun M, Augustin D, Müller J, Bässler C, Scheu S (2014) Changes in the community composition and trophic structure of microarthropods in sporocarps of the wood decaying fungus Fomitopsis pinicola along an altitudinal gradient. Appl Soil Ecol 84:16-23

Maraun M, Illig J, Sandmann D, Krashevska V, Norton RA, Scheu S (2008) Soil Fauna. In: Beck E, Bendix J, Kottke I, Makeschin F, Mosandl R (eds) Gradients in a Tropical Mountain Ecosystem of Ecuador. Ecological Studies 198, Springer, Berlin, pp 181-192

Maraun M, Erdmann G, Fischer BM, Pollierer MM, Norton RA, Schneider K, Scheu $S$ (2011) Stable isotopes revisited: Their use and limits for oribatid mite trophic ecology. Soil Biol Biochem 43:877-882

Maraun M, Fronczek S, Marian F, Sandmann D, Scheu S (2013) More sex at higher altitudes: Changes in the frequency of parthenogenesis in oribatid mites in tropical montane rain forests. Pedobiologia 56:185-190

Maraun M, Heethoff M, Scheu S, Norton RA, Weigmann G, Thomas RH (2003) Radiation in sexual and parthenogenetic oribatid mites (Oribatida, Acari) as indicated by genetic divergence of closely related species. Exp Appl Acarol 29:265-77

Maraun M, Heethoff M, Schneider K, Scheu S, Weigmann G, Cianciolo JM, Thomas $\mathrm{RH}$, Norton RA (2004) Molecular phylogeny of oribatid mites (Oribatida, Acari): evidence for multiple radiations of parthenogenetic lineages. Exp Appl Acarol 33:183-201

Maraun M, Norton RA, Ehnes RB, Scheu S, Erdmann G (2012) Positive correlation between density and parthenogenetic reproduction in oribatid mites (Acari) supports the structured resource theory of sexual reproduction. Evol Ecol Res $14: 311-323$ 
Maraun M, Schatz H, Scheu S (2007) Awesome or ordinary? Global diversity patterns of oribatid mites. Ecography 30:209-216

Maraun M, Scheu S (2000) The structure of oribatid mite communities (Acari, Oribatida): patterns, mechanisms and implications for future research. Ecography 23:374-383

Matthewman W, Pielou D (1971) Arthropods inhabiting the sporophores of Fomes fomentarius (Polyporaceae) in Gatineau Park, Quebec. Can Entomol 103:775847

Maynard Smith J (1971) What use is sex? J Theor Biol 30:319-335

Maynard Smith J (1978) The Evolution of Sex. Cambridge University Press, Cambridge.

McLean MA, Parkinson D (1998) Impacts of the epigeic earthworm Dendrobaena octaedra on oribatid mite community diversity and microarthropod abundances in pine forest floor: a mesocosm study. Appl Soil Ecol 7:125-136

Migge-Kleian S, McLean MA, Maerz JC, Heneghan L (2006) The influence of invasive earthworms on indigenous fauna in ecosystems previously uninhabited by earthworms. Biol Invasions 8:1275-1285

Molleman F, Walter DE (2001) Niche segregation and can-openers: Scydmaenid beetles as predators of amoured mites in Australia. In: Halliday RB, Walter DE, Proctor HC, Norton RA and Colloff MJ (eds) Acarology: Proceedings of the $10^{\text {th }}$ International Congress. CSIRO Publishing, Melbourne, pp 283-288

Moore JC, Walter DE, Hunt HW (1988) Arthropod regulation of micro- and mesobiota in below-ground detrital food webs. Annu Rev Entomol 33:419-439

Muller HJ (1932) Some genetic aspects of sex. Am Nat 8:118-138

Muller HJ (1964) The relation of recombination to mutational advance. Mutat Res $1: 2-9$

Nicolai $V$ (1986) The bark of trees: thermal properties, microclimate and fauna. Oecologia 69:148-160

Nicolai V (1987) Anpassungen rindenbesiedelnder Arthropoden an Borkenstruktur und Feinddruck. Spixiana 10:139-145

Nicolai V (1993) The arthropod fauna on the bark of deciduous and coniferous trees in a mixed forest of the Itasca State Park, MN, USA. Spixiana 16:61-69

Norton RA (1980) Observations on phoresy by oribatid mites (Acari: Oribatei). Int J Acarol 6:121-130

Norton RA (1994) Evolutionary Aspects of Oribatid Mite Life Histories and Consequences for the Origin of the Astigmata. In: Houck M (ed) Mites. Chapman and Hall Publ., New York, pp 99-136

Norton RA, Behan-Pelletier VM (1991) Calcium carbonate and calcium oxalate as cuticular hardening agents in oribatid mites (Acari: Oribatida). Can J Zool 69:1504-1511

Norton RA, Kethley J, Johnston DE, O'Connor BM (1993) Phylogenetic perspectives on genetic systems and reproductive modes of mites. In: Wrensch DL, Ebbert MA (eds) Evolution and Diversity of Sex Ratio in Insect and Mites. Chapman and Hall Publ., New York, pp 8-99 
Norton R, Palmer SC (1991) The distribution, mechanisms and evolutionary significance of parthenogenesis in oribatid mites. In: Schuster R, Murphy PW (eds) The Acari: Reproduction, Development and Life-History Strategies. Chapman and Hall Publ., London, pp 107-136

Norton RA, MacNamara MC (1975) The common newt (Notopthalmus viridescens) as a predator of soil mites in New York. J Georgia Entomol Soc 11:89-93

Norton RA (1998) Morphological evidence for the evolutionary origin of Astigmata (Acari: Acariformes).Exp Appl Acarol 22:559-594

Norton RA (2007) Holistic acarology and ultimate causes: examples from the oribatid mites. In: Morales-Malacara JB, Behan-Pelletier V, Ueckermann E, Pérez TM, Estrada-Venegas EG and Badii M (eds) Acarology XI. Proceedings of the International Congress, pp 3-20

Norton RA, Bonamo PM, Grierson JD, Shear WA, Shear WA (1988) Oribatid mite fossils from a terrestrial devonian deposit near Gilboa, New York. J Paleo 62, 259-269

O'Connor BM (1984). Phylogenetic relationships among higher taxa in the acriformes, with particular reference to the Astigmata. In: Griffiths DA, Bowman CE (eds) Acarology VI, Volume 1. Halsted Press, New York, pp 19-27

Pachl P, Domes K, Schulz G, Norton RA, Scheu S, Schaefer I, Maraun M (2012) Convergent evolution of defense mechanisms in oribatid mites (Acari, Oribatida) shows no "ghosts of predation past". Mol Phylogenet Evol 65:412-20

Palmer SC, Norton R (1991) Taxonomic, geographic and seasonal distribution of thelytokous parthenogenesis in the Desmonomata (Acari: Oribatida). Exp Appl Acarol 12:67-81

Palmer SC, Norton RA (1990) Further experimental proof of thelytokous parthenogenesis in oribatid mites (Acari: Oribatida: Desmonomata). Exp Appl Acarol 8:149-159

Park O (1947) Observations on Batrisodes (Coleoptera: Pselaphidae), with particular reference to American species east of the Rocky Mountains. Bulletin of the Chicago Academy of Science 8:45-132

Pepato AR, Rocha EFC, Dunlop JA (2010) Phylogenetic position of the acariform mites: sensitivity to homology assessment under total evidence. BMC Evol Biol 10:1-23

Persson T, Bååth E, Clarholm M, Lundkvist H, Söderström BE, Sohlenius B (1980) Trophic structure, biomass dynamics and carbon metabolism of soil organisms in a Scots pine forest. In: Persson T (ed) Structure and function of northern coniferous forests - an ecosystem study. Ecol Bull 32:419-459

Peschel K, Norton RA, Scheu S, Maraun M (2006) Do oribatid mites live in enemyfree space? Evidence from feeding experiments with the predatory mite Pergamasus septentrionalis. Soil Biol Biochem 38:2985-2989

Petersen $\mathrm{H}$, Luxton M (1982) A comparative analysis of soil fauna populations and their role in decomposition processes. Oikos 39:288-388

Polis GA (1994) Food webs, trophic cascades and community structure. Aust J Ecol 19:121-136 
Pollierer MM, Dyckmans J, Scheu S, Haubert D (2012) Carbon flux through fungi and bacteria into the forest soil animal food web as indicated by compoundspecific ${ }^{13} \mathrm{C}$ fatty acid analysis. Funct Ecol 26:978-990

Pollierer MM, Langel R, Körner C, Maraun M, Scheu S (2007) The underestimated importance of belowground carbon input for forest soil animal food webs. Ecol Lett 10:729-736

Prabhoo NR, Pai CGA, Namboory KD (1988) Ecology of acarofauna of fire prone tropical forests in the Western Ghats in Kerala with special reference to Oribatei (Acari). In: Channabasavanna GP, Viraktamath CA (eds) Progress in acarology, Volume 1. Oxford and IBH publishing, New Delhi, pp 475-481

Proctor HC, Montgomery KM, Rosen KE, Kitching RL (2002) Are tree trunks habitats or highways? A comparison of oribatid mite assemblages from hoop-pine bark and litter. Aust J Entomol 41:294-299

Remén C, Persson T, Finlay R, Ahlström K (2008) Responses of oribatid mites to tree girdling and nutrient addition in boreal coniferous forests. Soil Biol Biochem 40:2881-2890

Renker C, Otto P, Schneider K, Zimdars B, Maraun M, Buscot F (2005) Oribatid mites as potential vectors for soil microfungi: Study of mite-associated fungal species. Microb Ecol 50:518-528

Sakata T, Norton RA (2001) Opisthonotal gland chemistry of early-derivative oribatid mites (acari) and its relevance to systematic relationships of astigmata. Int $\mathrm{J}$ Acarol 27:281-292

Sanders FH, Norton RA (2004). Anatomy and function of the ptychoid defensive mechanism in the mite Euphthiracarus cooki (Acari: Oribatida). J Morphol 259:119-54

Schaefer I, Norton RA, Scheu S, Maraun M (2010) Arthropod colonization of land-linking molecules and fossils in oribatid mites (Acari, Oribatida). Mol Phylogenet Evol 57:113-21

Schaefer M, Schauermann J (1990) The soil fauna of beech forests: comparison between a mull and a moder soil. Pedobiologia 34:299-314

Schatz H (2002) Die Oribatidenliteratur und die beschriebenen Oribatidenarten (1758-2001)—Eine Analyse. Abh Ber Natur Mus Görlitz 74:37-45

Schatz H (2004) Diversity and global distribution of oribatid mites (Acari, Oribatida) - evaluation of the present state of knowledge. Phytophaga 14:485-500

Schatz H, Behan-Pelletier VM (2008) Global diversity of oribatids (Oribatida: Acari: Arachnida). Hydrobiologia 595:323-328

Scheu S, Drossel B (2007) Sexual reproduction prevails in a world of structured resources in short supply. Proc Biol Sci 274:1225-1231

Scheu S, Schulz E (1996) Secondary succession, soil formation and development of a diverse community of oribatids and saprophagous soil macroinvertebrates. Biodivers Conserv 5:235-250

Schneider K, Maraun M (2009) Top-down control of soil microarthropods - Evidence from a laboratory experiment. Soil Biol Biochem 41:170-175 
Schneider K, Migge-Kleian S, Norton RA, Scheu S, Langel R, Reineking A, Maraun M (2004) Trophic niche differentiation in soil microarthropods (Oribatida, Acari): evidence from stable isotope ratios $\left({ }^{15} \mathrm{~N} /{ }^{14} \mathrm{~N}\right)$. Soil Biol Biochem 36:1769-1774

Schneider K, Renker C, Maraun M (2005) Oribatid mite (Acari, Oribatida) feeding on ectomycorrhizal fungi. Mycorrhiza 16:67-72

Schuster R (1962) Nachweis eines Paarungszeremoniells bei den Hommilben (Oribatei). Naturwissenschaften 49:502-503

Seastedt TR (1984) The role of microarthropods in decomposition and mineralization processes. Ann Rev Entomol 29:25-46

Seniczak A, Solhøy T, Seniczak S, Riva-Caballero A (2011) Species composition and abundance of the oribatid fauna (Acari, Oribatida) at two lakes in the Fløyen area, Bergen, Norway. Biol Lett 47:11-19

Sgardelis SP (1995) Body size, sex ratio and fecundity of soil Cryptostigmata along an altitudinal gradient. Acta Zool Fenn 196:258-259

Siepel H (1994) Life-history tactics of soil microarthropods. Biol Fertil Soils 18:263278

Siepel H (1995) Applications of microarthropod life-history tactics in nature management and ecotoxicology. Biol Fertil Soils 19:75-83

Siepel H, Ruiter-Dijkman E (1993). Feeding guilds of oribatid mites based on their carbohydrase activities. Soil Biol Biochem 25:1491-1497

Simon MP, Toft CA, Field TO (1991) Diet specialization in small vertebrates: miteeating in frogs. Oikos 61:263-278

Sivhed U, Wallwork JA (1978) An Early Jurassic oribatid mite from southern Sweden. Geol Föreningens i Stock Förhandlingar 100:65-70

Skubała P (2008) Oribatid fauna ion Norway Spruce stumps. Are there saproxylic oribatid species? In: Bertrand M, Kreiter S, Migeon A, Navajas M, Tixier MS, Vial $L$ (eds) Integrative Acarology. Proceedings of the $6^{\text {th }}$ European Congress, European Association of Acarologists, pp 250-260

Skubała P, Marzec A (2013) Importance of different types of beech dead wood for soil microarthropod fauna. Pol J Ecol 61:545-560

Skubała P, Maslak M (2009) Succession of oribatid fauna (Acari, Oribatida) in fallen spruce trees: Deadwood promotes species and functional diversity. In: Sabelis MW, Bruin J (eds) Trends in Acarology: Proceedings of the $12^{\text {th }}$ International Congress. Springer, Berlin, pp 123-128

Steinberger Y, Wallwork JA, Halimi M (1990) Sex ratios and egg production of Zygoribatula spp. (Acari, Cryptostigmata) in the Negev dessert of southern Israel. Acarologia 31:85-92

Strong DR (1992) Are trophic cascades all wet? Differentiation and donor-control in speciose ecosystems. Ecology 73:747-754

Swift MJ, Heal OW, Anderson JM (1979) Decomposition in Terrestrial Ecosystems. Blackwell Scientific Publications, Oxford 
Taberly G (1987) Recherches sur la parthéogenèse thélytoque de deux espèces d'acariens oribatides: Trypochthonius tectorum (Berlese) et Platynothrus peltifer (Koch). III. Etude anatomique, histologique et cytologique des femelles parthénogenétiques. Acarologia 28:389-403

Taberly G (1988) Recherches sur la parthénogenèse thélytoque de deux espèces d'acariens orib- atides: Trypochthonius tectorum (Berlese) et Platynothrus peltifer (Koch). IV. Observation sur les males ataviques. Acarologia 29:95-107

Takada W, Sakata T, Shimano S, Enami Y, Mori N, Nishida R, Kuwahara Y (2005) Scheloribatid mites as the source of pumiliotoxins in dendrobatid frogs. J Chem Ecol 31:2403-2415

Usher MB (1985) Population and community dynamics in the soil. In: Fitter AH, Atkinson D, Read DJ, Usher MB (eds) Ecological interactions in soil: Plants, Microbes and Animals. Blackwell Scientific Publications, Oxford, pp 243-263

Wallwork JA (1973) Zoogeography of some terrestrial micro-arthropoda in Antarctica. Biol Rev 48:233-259

Walter DE, Behan-Pelletier V (1999) Mites in forest canopies: filling the size distribution shortfall? Annu Rev Entomol 44:1-19

Walter DE, Kaplan DT (1991) Observations on Coleoscirus simplex (Acarina: Prostigmata), a predatory mite that colonizes greenhouse cultures of rootknot nematode (Meloidogyne spp.), and a review of feeding behavior in the Cunaxidae. Exp Appl Acarol 12:47-59

Wardle DA (2002) Communities and ecosystems: linking the aboveground and belowground components. Princeton University Press, Princeton

Weismann A (1889) Essays on heredity and kindred biological subjects. Oxford University Press, Oxford

Welch DM, Meselson M (2000) Evidence for the evolution of bdelloid rotifers without sexual reproduction or genetic exchange. Science 288:1211-1215

West SA, Lively C, Read A (1999) A pluralist approach to sex and recombination. J Evol Biol 12:1003-1012

Wrensch DL, Kethley JB, Norton RA (1994) Cytogenetics of Holokinetic Chromosomes and Inverted Meiosis: Keys to the Evolutionary Success of Mites, with Generalizations on Eukaryotes. In: Houck M (ed) Mites: Ecological and Evolutionary Analyses of Life-History Patterns. Chapman and Hall Publ., New York, pp 282-343

Wunderle I (1991) Life-histories and notes on the behaviour of tree-living oribatid mites. In: Dusbabek F, Bukva V (eds) Modern Acarology: Volume 2. Academia, Prague and SPB Academic Publishing by, The Hague, pp 529-535

Wunderle I (1992) Die Oribatiden-Gemeinschaften (Acari) der verschiedenen Habitate eines Buchenwaldes. Carolinea 50:79-144

Zaitsev AS, Wolters V, Waldhardt R, Dauber J (2006) Long-term succession of oribatid mites after conversion of croplands to grasslands. Appl Soil Ecol 34:230-239 


\section{CHAPTER 2}

Oribatid mite communities on the bark of dead wood vary with log type, surrounding forest and regional factors

Christian Bluhm, Stefan Scheu, Mark Maraun

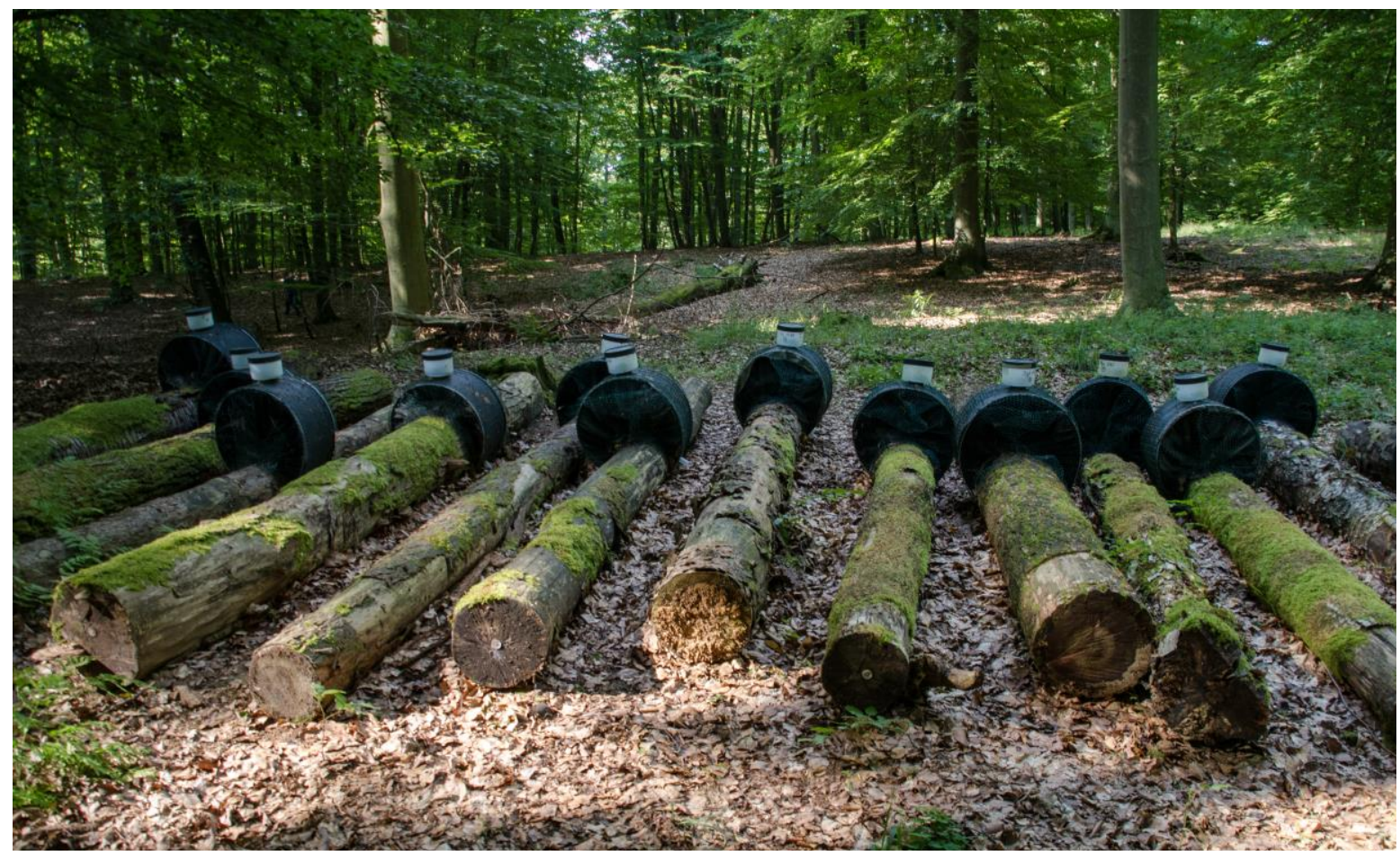

Published in:

Bluhm C, Scheu S, Maraun M (2015) Oribatid mite communities on the bark of dead wood vary with log type, surrounding forest and regional factors. Appl Soil Ecol 89:102-112 


\begin{abstract}
Dead wood is a crucial component of natural and semi-natural forest ecosystems. It is of eminent importance as habitat for a variety of animal species but its importance for microarthropods, a diverse group of small forest animals, has been little studied. We investigated how oribatid mite density, species richness, community structure and the proportion of parthenogenetic individuals on the bark of dead wood are affected by log type (beech, oak) and surrounding forest type (deciduous, coniferous) in three regions in Germany (Schorfheide-Chorin, HainichDün, Schwäbische Alb). Additionally, we analyzed the trophic structure of oribatid mites from the bark of dead wood in one region (Hainich-Dün) using stable isotope ratios $\left({ }^{15} \mathrm{~N} /{ }^{14} \mathrm{~N},{ }^{13} \mathrm{C} /{ }^{12} \mathrm{C}\right)$. Oribatid mite richness and community structure were significantly affected by log type, forest type and region. Oribatid mite communities comprised mainly soil and arboreal species but only few dead wood specialists indicating that dead wood in an early stage of decay functions as transitory habitat rather than specific microhabitat. However, some oribatid mites likely are adapted to dead wood as habitat by living phoretically on bark beetles (e.g., Siculobata leontonycha) or endophagous in fungi associated with dead wood (e.g., juvenile Carabodes species). The proportion of parthenogenetic oribatid mite individuals was rather low ( $8 \%$ ) suggesting that oribatid mites on dead wood predominantly rely on living food resources resembling arboreal communities but not those in soil. Natural variations in stable isotope ratios indicate that oribatid mites on the bark of dead wood span at least three trophic levels including lichens feeders, moss feeders, decomposers and fungal feeders with fungal feeders dominating.
\end{abstract}

Key-words: oribatid mites, dead wood, fungi, parthenogenesis 


\section{Introduction}

Dead wood is an important component of forest ecosystems. However, in most European forests dead wood does not accumulate on the forest floor since trees typically are harvested. Further, dead wood is assumed to function as a source of diseases and is often removed to prevent, e.g. bark beetle infestations; under natural conditions it is decomposed by a complex community of microorganisms and invertebrates (Jonsell et al 1998; Wermelinger, 2004; Lassauce et al., 2011). The importance of dead wood for biodiversity is increasingly appreciated and forests in Europe are allowed to age more naturally resulting in increasing amounts of dead wood on the forest floor (Müller-Using and Bartsch, 2003; Jonsson et al. 2005).

Dead wood harbors a large number of arthropod species temporarily or permanently colonizing this habitat, thus contributing considerably to total forest diversity. Especially beetle communities in dead wood are well investigated due to their economic importance and their high diversity (Peltonen et al., 1998; Eidmann, 1992; Ehnström, 2001; Similä et al., 2003; Müller et al., 2008; Gossner et al., 2013). However, dead wood also provides habitat for many other arthropod taxa, including Diptera, Hymenoptera and Isopoda, which use it as a food resource, for breeding or shelter (Stokland et al. 2012). Furthermore, dead wood is inhabited by a variety of fungi, mosses and lichens which partly also occur in soil but some being restricted to dead wood. Especially basidiomycete fungi benefit from the accumulation of dead wood as they are the most important wood decomposers able to break down recalcitrant wood compounds including lignin. A large number of animal species benefit from the presence of fungi by feeding on fungal hyphae or sporocarps or using fungal sporocarps as habitat (Matthewman and Pielou, 1971; Maraun et al., 2014).

While insect and fungal communities in dead wood are well investigated only few studies investigated mite communities in dead wood. Mites (Acari) represent a diverse taxon with an estimated total species number of up to one million (Walter and Proctor, 1999). Oribatid mites (Oribatida) are a species rich and abundant taxon of mites occurring in soil of virtually all terrestrial ecosystems but also in microhabitats such as tree trunks, stumps, logs, lichens, mosses, fungal sporocarps and even fresh and salt water (Aoki, 1967; Schuster, 1979; Materna, 2000; BehanPelletier and Walter, 2000; Lindo and Winchester, 2006). On dead wood they are 
among the most numerous arthropod taxon (Abbott and Crossley, 1982; Seastedt et al., 1989).

Oribatid mite communities on bark overlap only little with those in soil thereby the bark of trees represents a distinct habitat (Wunderle, 1992; Proctor et al., 2002; Erdmann et al., 2006; B.M. Fischer et al., 2010). However, it is little studied if oribatid mite communities from dead wood on the forest floor resemble those of the soil or those of the bark of trees or if dead wood is colonized by a specific oribatid mite community (but see Skubała and Maślak, 2009, Huhta et al., 2012).

Unraveling the feeding habits of oribatid mites from dead wood may contribute to the understanding of their community structure. It has been shown that oribatid mites in soil mostly feed on litter and fungi, whereas oribatid mites on the bark of trees often feed on lichens or mosses (Schuster, 1956; Luxton, 1972; Siepel and de Ruiter-Dijkman, 1993; Erdmann et al., 2007; B.M. Fischer et al., 2010; Maraun et al. 2011). However, the trophic ecology of oribatid mite from dead wood has never been studied.

Another key for understanding the specific composition of oribatid mite communities may be their reproductive mode. It has been hypothesized that a high percentage of parthenogenetic individuals in oribatid mite communities points to the availability of resources whereas a high percentage of sexual species indicates resource limitation (Scheu and Drossel, 2007; Maraun et al., 2012). This is based on the assumption that the advantage of having genetically different progeny diminishes when resources are not limited and thus favors faster reproducing asexual species. The percentage of parthenogenetic individuals in soil is high ( 50$80 \%$ ) compared to the bark of living trees ( 5-10\%) (B.M. Fischer et al., 2010; Maraun et al., 2012). How the ratio between parthenogenetic and sexual oribatid mites changes after death of trees and how dead wood is colonized by soil living oribatid mite species is unknown.

Generally, animal and plant communities are structured either by niche-based or neutral processes (Hutchinson, 1959, Hubbell, 2001). Oribatid mite community structure is affected by regional factors such as soil type, $\mathrm{pH}$ or climate that operate on the landscape level which points to the importance of niche-based processes (Erdmann et al., 2012, Mori et al., 2013). However, Caruso et al. (2012) emphasized that stochasticity also explains a considerable fraction of the variation in oribatid mite community structure. 
Moreover, the surrounding habitat modifies local animal community composition (Tscharntke et al. 2012) and this also applies to soil animals such as oribatid mites (Erdmann et al. 2012). Due to low dispersal capabilities of oribatid mites (Lehmitz et al., 2011) this might be of particular importance for the colonization of dead wood. However, oribatid mite community structure is also likely to vary with the species of dead wood either by differences in shelter opportunities or specific food sources, such as certain species of fungi or lichens.

We investigated the diversity, community structure, reproductive mode and trophic niches of oribatid mites on the bark of dead wood of two log types (beech and oak) in two different forest types (deciduous, coniferous) in three geographically separated regions in Germany (Hainich-Dün, Schwäbische Alb, SchorfheideChorin). Our aim was to separate effects of log type, forest type and region on oribatid mite communities of dead wood. Additionally, we investigated trophic niches of oribatid mites on the bark of dead wood in the Hainich-Dün. Generally, we expected the role of region in structuring oribatid mite communities to exceed that of log type and forest type since turnover of oribatid mite species in space has been shown to be high (Erdmann et al. 2012).

We hypothesized that log type (beech, oak) little affects oribatid mite community composition but rather oribatid mite density, with the more structured bark of oak resulting in higher densities than the little structured bark of beech. Furthermore, we expected the surrounding forest type to affect oribatid mite community structure by functioning as source for the colonization of tree logs. Finally, we hypothesized that region affects the species composition of dead wood since the climate differs strongly between the three study sites. The Schorfheide-Chorin is characterized by continental climate with cold winters and hot summers whereas the climate at the Schwäbische Alb and Hainich-Dün is more atlantic with mild winters and wet summers.

\section{Materials and Methods}

\subsection{Study sites}

The study formed part of a long term dead wood experiment in the framework of the "Biodiversity Exploratories" (M. Fischer et al., 2010), a large scale biodiversity project in three regions in Germany including coniferous (Picea abies in the HainichDün and Schwäbische Alb, Pinus sylvestris in the Schorfheide-Chorin) and 
deciduous forests (Fagus sylvatica). The geographical regions included (1) the Schorfheide-Chorin in the north-east of Germany (3-140 m a.s.I.), (2) the HainichDün a hilly region in central Germany (285-550 m a.s.I.), and (3) the Schwäbische Alb a low-mountain range in south-west Germany (460-860 m a.s.l), spanning an overall latitudinal gradient of about $500 \mathrm{~km}$. Mean annual temperatures for Schorfheide-Chorin, Hainich-Dün and Schwäbische Alb are 8-8.5, 6.5-8 and 6-7 ${ }^{\circ} \mathrm{C}$ with mean annual precipitation of 500-600, 500-800 and 700-1000 mm, respectively. More details on the study sites are given in M. Fischer et al. (2010).

\subsection{Sampling design}

In 2009, logs of 13 tree species (Picea abies, Pinus sylvestris, Pseudotsuga menziesii, Larix decidua., Fagus sylvatica, Fraxinus excelsior, Acer pseudoplatanus, Carpinus betulus, Betula pendula, Populus sp., Tilia sp., Quercus sp., Prunus avium; $\sim 4 \mathrm{~m}$ in length, $\sim 32 \mathrm{~cm}$ in diameter) were placed in three coniferous and six deciduous forests in each region, where each log type was replicated in three subplots. The logs of each subplot were arranged in one row with a distance of approximately $1 \mathrm{~m}$ in between. All logs were cut from fresh standing trees. Only trunks were used for the study with the lower trunk region being excluded. For the present study we sampled beech and oak logs from one subplot in each of the nine forests (deciduous and coniferous) in three regions, resulting in a total of 54 samples.

\subsection{Sampling, identification of species and stable isotope analysis}

In November 2011, two years after the logs were placed in the forests, a bark sample of $30 \times 30 \mathrm{~cm}$ of each plot was taken from the upper side of the logs, using a hand saw and a chisel. The bark on the logs was largely intact but started to detach from the wood beneath. In comparison with bark from living trees the bark was inhabited by fungi from both the upper and lower side. The wood underneath the bark was still virtually undecomposed. Bark samples were broken into smaller pieces and turned upside down in the extraction vessels. Animals were extracted by heat (Macfadyen, 1961) and stored in $70 \%$ ethanol until determination. Oribatid mites were identified to species level using Weigmann (2006) except for Brachychthoniidae, Suctobelbella and Phthiracarus which were determined to family or genus level. Juvenile oribatid mites were counted but not determined. The reproductive mode of oribatid mite species was taken from literature data (Palmer 
and Norton, 1991; Norton et al., 1993; Cianciolo and Norton, 2006; Domes et al., 2007; B.M. Fischer et al, 2010; Table 1).

For analysis of natural variations in stable isotope ratios $\left({ }^{15} \mathrm{~N} /{ }^{14} \mathrm{~N},{ }^{13} \mathrm{C} /{ }^{12} \mathrm{C}\right)$ oribatid mites were extracted from bark samples taken in April 2013 from beech and oak logs in the Hainich-Dün. Due to low numbers of oribatid mite individuals per species we pooled all individuals from oak and beech logs and also from the different forest types. Oribatid mites were determined to species level and transferred into tin capsules. One to 110 individuals were combined per sample to obtain the amount of tissue necessary for stable isotope analysis (see Table 1). The samples were dried at $60^{\circ} \mathrm{C}$ for $24 \mathrm{~h}$ and weighed. ${ }^{15} \mathrm{~N} /{ }^{14} \mathrm{~N}$ and ${ }^{13} \mathrm{C} /{ }^{12} \mathrm{C}$ ratios were determined by a coupled system of an elemental analyzer (NA 1500, Carlo Erba, Milan) and a mass spectrometer (MAT 251, Finnigan) (Reineking et al. 1993; Langel and Dyckmans, 2014).

Nitrogen and carbon isotope composition is reported in $\delta$ notation with $\delta^{15} \mathrm{~N}$, respectively $\delta^{13} \mathrm{C}(\%)=\left(R_{\text {sample }}-R_{\text {standard }}\right) / R_{\text {standard }} \times 1000$. $R_{\text {sample }}$ and $R_{\text {standard }}$ represent the ${ }^{15} \mathrm{~N} /{ }^{14} \mathrm{~N}$, respectively ${ }^{13} \mathrm{C} /{ }^{12} \mathrm{C}$ ratios of the sample and standard. For ${ }^{15} \mathrm{~N}$ atmospheric nitrogen served as primary standard and acetanilide $\left(\mathrm{C}_{8} \mathrm{H}_{9} \mathrm{NO}\right.$, Merck, Darmstadt) was used for internal calibration. For ${ }^{13} \mathrm{C}$ Vienna Pee Dee Belemnite (V-PDB) served as the primary standard. Platynothrus peltifer was used as the baseline to separate the trophic levels since this species is known for its stable signature and since the typical baseline signature, i.e. leaf litter, was not available for dead wood (Schneider et al., 2004; Maraun et al., 2011). 


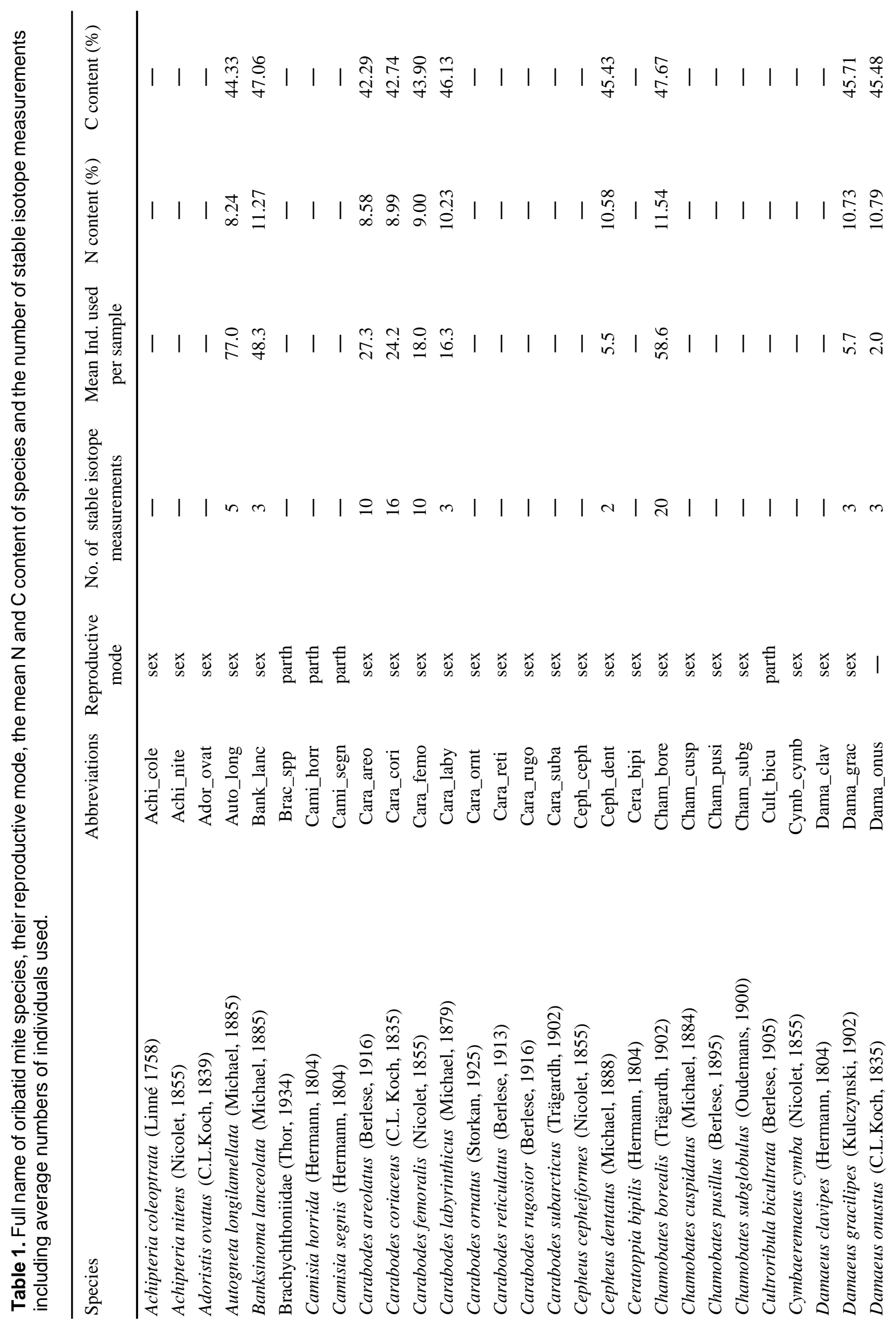




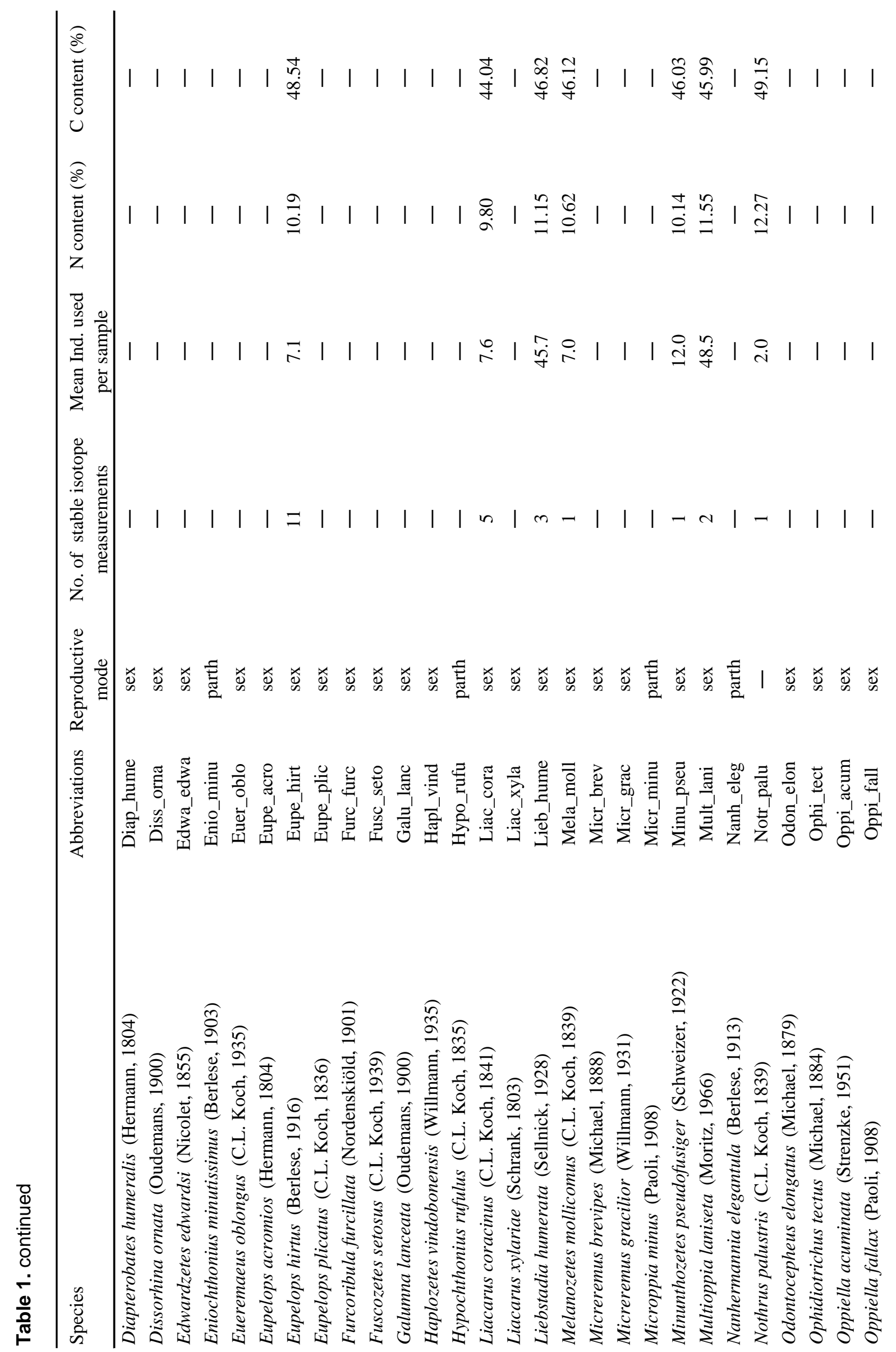




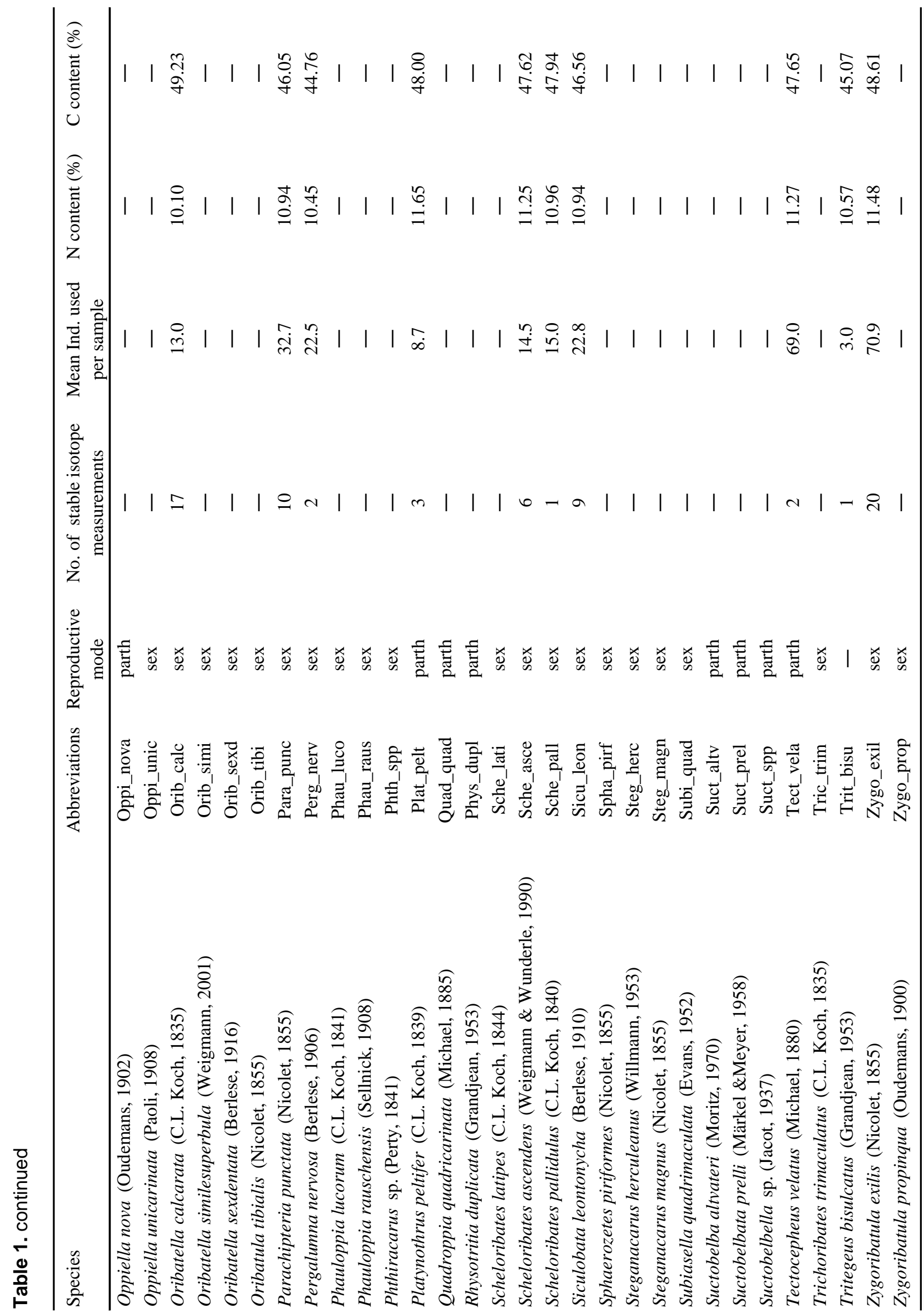




\subsection{Statistical analysis}

Oribatid mite density, diversity and reproductive mode were analyzed by threefactorial analysis of variance (ANOVA) with the fixed factors region (Schwäbische Alb, Hainich-Dün, Schorfheide-Chorin), forest type (coniferous, deciduous) and log type (beech, oak) using R version 2.14.1 (R Development Core Team 2011). Data on oribatid mite density were log-transformed to improve homoscedasticity.

To evaluate the significance of the three fixed factors for oribatid mite community composition the multivariate dataset consisting of 83 species was reduced to five dimensions using non-metric multidimensional scaling (NMDS) in CANOCO 5 (Microcomputer Power, Ithaca, New York; Šmilauer and Lepš, 2014). The NMDS serves to reduce the number of variables (83 species) and contains the condensed information of our original dataset. The stress values for the NMDS were: axis $1=$ 0.39 , axis $2=0.23$, axis $3=0.16$, axis $4=0.12$, axis $5=0.09$. Five axes were a compromise between compression and loss of information. Those five axes were used as dependant variables in the MANOVA in SAS 9.3 for Windows (SAS Institute Inc., Cary, NC) to identify treatment effects. Finally, principal component analysis (PCA) with all 83 species was performed using CANOCO 5 to relate the structure of oribatid mite communities to the factors region, forest type and log type. For the analysis data were log transformed.

\section{Results}

\subsection{Density and Diversity}

In total 35,631 oribatid mites were counted of which 22,064 were adults. Oribatid mite densities from the bark of the logs did not differ significantly between HainichDün (8520 \pm 7109 ind. $\left./ \mathrm{m}^{2}\right)$, Schorfheide-Chorin (7563 \pm 5404 ind. $/ \mathrm{m}^{2}$ ) and Schwäbische Alb $\left(5911 \pm 4901\right.$ ind. $\left./ \mathrm{m}^{2} ; F_{2,42}=1.40, \mathrm{P}=0.26\right)$. Further, their densities neither differed significantly between coniferous $\left(7828 \pm 3939 \mathrm{ind} . / \mathrm{m}^{2}\right)$ and deciduous forests $\left(7083 \pm 6668\right.$ ind. $\left./ \mathrm{m}^{2}, \mathrm{~F}_{1,42}=2.03, \mathrm{P}=0.16\right)$ nor between beech $\left(7339 \pm 6231 \mathrm{ind} . / \mathrm{m}^{2}\right)$ and oak logs $\left(7324 \pm 5606 \mathrm{ind} . / \mathrm{m}^{2} ; F_{1,42}=0.03, P=0.88\right)$ (Appendix A).

Overall, 83 species were recorded, 44 in Schwäbische Alb, 46 in Hainich-Dün and 56 in Schorfheide-Chorin. Only 22 species occurred in all three regions but these species represented more than $63 \%$ of all individuals. Some species were exclusively found in one region (11, 10 and 20 for the Schwäbische Alb, Hainich- 
Dün and Schorfheide-Chorin, respectively). More than half of the species were found in both forest types (42), 27 species exclusively in deciduous and 14 in coniferous forests. The majority of species colonized both log types (52). Only 18 species were unique to oak and 13 to beech logs, but none of them had high densities.

Species richness (average number of oribatid mite species per sample) significantly differed between regions, increasing from Schwäbische Alb $(9.2 \pm 3.8)$ to Hainich-Dün $(12.4 \pm 3.5)$ to Schorfheide-Chorin $\left(15.3 \pm 4.2 ; \mathrm{F}_{2,42}=14.45, \mathrm{P}<\right.$ $0.0001)$, and also between forest types with a higher diversity in coniferous (14.7 \pm 4.2) than in deciduous forests $\left(11.1 \pm 4.3 ; F_{1,42}=13.02, P<0.001\right)$. Further, species richness was significantly higher on oak $(13.4 \pm 4.6)$ than on beech logs $(11.2 \pm 4.3$; $\left.F_{1,42}=6.11, P=0.018\right)$.

\subsection{Community structure}

Oribatid mite communities differed significantly between the three regions (MANOVA; Wilks' lambda 0.08, $F_{10,76}=20.02, P<0.0001$ ). Further, they differed significantly between the two forest types (MANOVA; Wilks' lambda $0.65, F_{5,38}=$ 4.12, $P=0.0043$ ) as well as between the two log types (MANOVA; Wilks' lambda $\left.0.39, F_{5,38}=11.77, P<0.0001\right)$. However, the effect of log type differed between regions; in Hainich-Dün the oribatid mite communities on the two log types were similar whereas they differed markedly in Schwäbische Alb and Schorfheide-Chorin (MANOVA; significant log type $\times$ region interaction; Wilks' lambda $0.57, F_{10,76}=2.43$, $P=0.0142)$.

The first axis of the PCA separated the three regions, in particular the Schorfheide-Chorin from the Schwäbische Alb and Hainich-Dün (Fig. 1). The five most abundant species of each region accounted for more than half of all individuals (82, 60 and $58 \%$ of total in the Hainich-Dün, Schorfheide-Chorin and Schwäbische Alb, respectively). They were represented by Zygoribatula exilis (37.9\%), Siculobata leontonycha (17.6\%), Chamobates borealis (12.8\%), Liebstadia humerata (8.9\%) and Autogneta longilamellata $(5.2 \%)$ in the Hainich-Dün, by Chamobates cuspidatus (28.0\%), Autogneta longilamellata (10.5\%), Oppiella unicarinata (8.7\%), Tectocepheus velatus $(7.1 \%)$, Pergalumna nervosa $(6.0 \%)$ in the SchorfheideChorin and by Autogneta longilamellata (17.3\%), Siculobata leontonycha (15.9\%), Parachipteria punctata (11.6\%), Banksinoma lanceolata (7.5\%), Liebstadia humerata (5.6\%) in the Schwäbische Alb (Appendix A). Parthenogenetic species, 
such as Platynothrus peltifer, Tectocepheus velatus, Quadroppia quadricarinata, Oppiella nova and Suctobelbella sp., predominantly occurred in SchorfheideChorin.

The second axis represented the type of forest and log. Typical taxa of coniferous forests were Adoristes ovatus, Chamobates borealis, Pergalumna nervosa, Suctobelbella sp. and Parachipteria punctata whereas Liebstadia humerata, Chamobates pusillus and Oppiella unicarinata mainly occurred in deciduous forests. The genus Carabodes mainly occurred on oak logs, but occurrence of the different Carabodes species differed between the regions. Carabodes ornatus, Carabodes areolatus and Carabodes subarcticus reached highest densities in the SchorfheideChorin, Carabodes femoralis and Carabodes coriaceus in the Hainich-Dün and Carabodes labyrinthicus and Carabodes reticulatus in the Schwäbische Alb. Fuscozetes setosus, Tectocepheus velatus and Parachipteria punctata also mainly occurred on oak logs. The oribatid mite community on beech logs was characterized by Liebstadia humerata and Siculobata leontonycha. Species known to live as primary decomposers, e.g. Platynothrus peltifer, Tectocepheus velatus and Phthiracarus sp. (Schneider et al., 2004), predominantly occurred in coniferous forests especially on oak logs. 


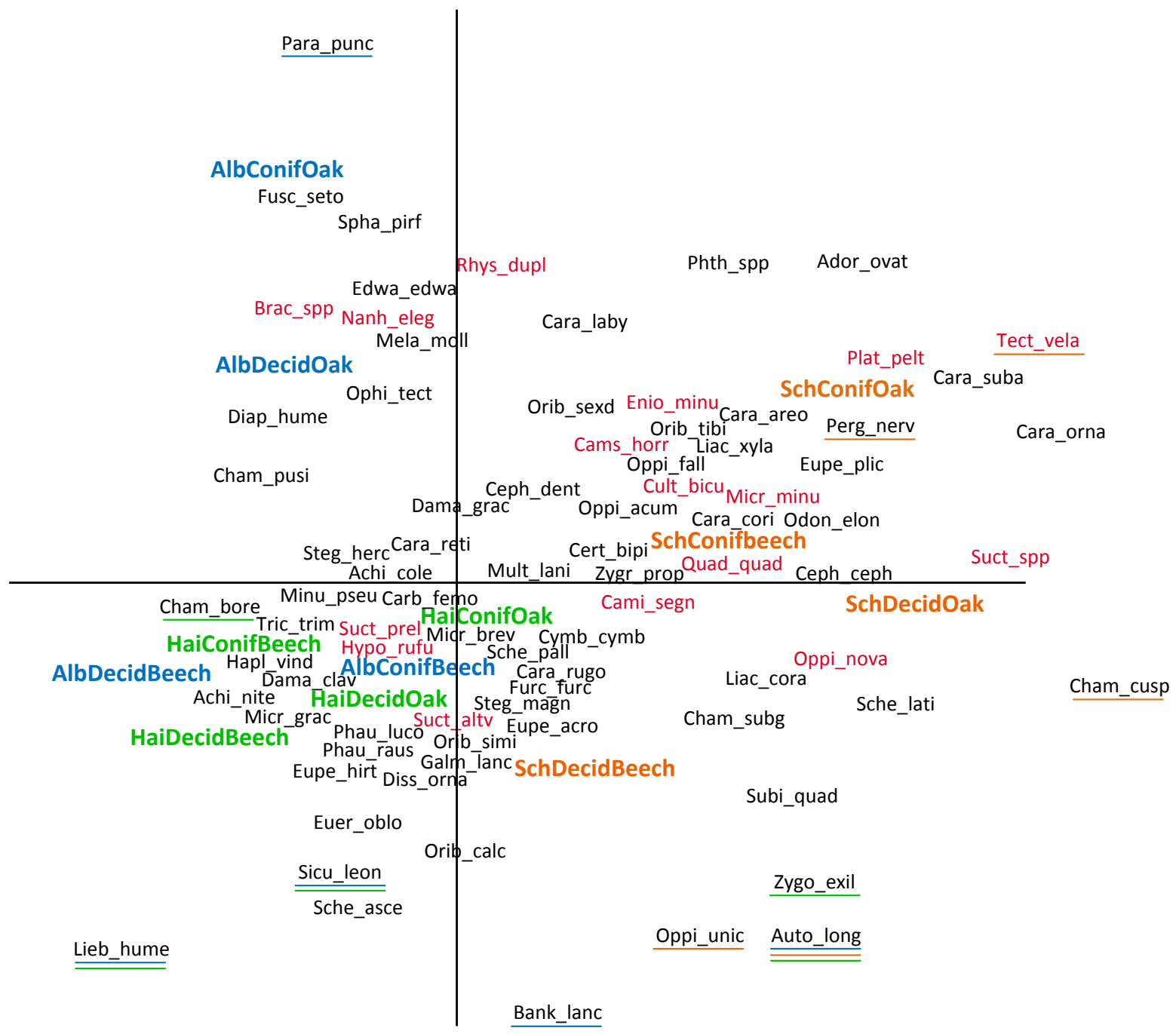

Fig. 1. Principal components analysis (PCA) of oribatid mites on different log types exposed in deciduous and coniferous forests in three regions in Germany. Parthenogenetic species are marked red; the five most abundant species of each region are underlined with the color of the respective region. Length of gradient 3.9; eigenvalues of 0.20 and 0.11 for the first and second axis, respectively. Alb = Schwäbische Alb; Hai = Hainich-Dün; Sch = Schorfheide-Chorin; Decid = deciduous forest; Conif $=$ coniferous forest; Beech = beech log; Oak = oak log. For full names of species see Table 1.

\subsection{Trophic position}

$\delta^{15} \mathrm{~N}$ signatures of oribatid mites from the Hainich-Dün spanned over $7.6 \delta$ units being highest in Tritegeus bisulcatus (1.58) and lowest in Carabodes labyrinthicus (-5.92; Fig. 2). $\delta^{13} \mathrm{C}$ signatures spanned over $8.3 \delta$ units being highest in Carabodes femoralis (-22.0) and lowest in Melanozetes mollicomus (-30.3). Stable isotope signatures were lowest in Tectocepheus velatus, Nothrus palustris, Parachipteria punctata and Platynothrus peltifer with $\delta^{15} \mathrm{~N}$ signatures ranging between -4.9 and 5.3 and $\delta^{13} \mathrm{C}$ signatures between -25.4 and -27.2 . The $\delta^{13} \mathrm{C}$ signature of Carabodes labyrinthicus (-25.1) was similar to these species but its $\delta^{15} \mathrm{~N}$ signature was more depleted (-5.9). In Melanozetes mollicomus the $\delta^{15} \mathrm{~N}$ signature was little higher 
(- 3.7) but its $\delta^{13} \mathrm{C}$ signature was markedly more depleted $(-30.3)$. The $\delta^{15} \mathrm{~N}$ signature of the majority of species ranged between -2.5 and 1.6 and the $\delta^{13} \mathrm{C}$ signature between-25.8 and -22.5. Carabodes species (except $C$. labyrinthicus) and Liacarus coracinus had intermediate $\delta^{15} \mathrm{~N}$ signatures (between -4.2 and -2.5 ) but high $\delta^{13} \mathrm{C}$ signatures (between -23.2 and -21.9).

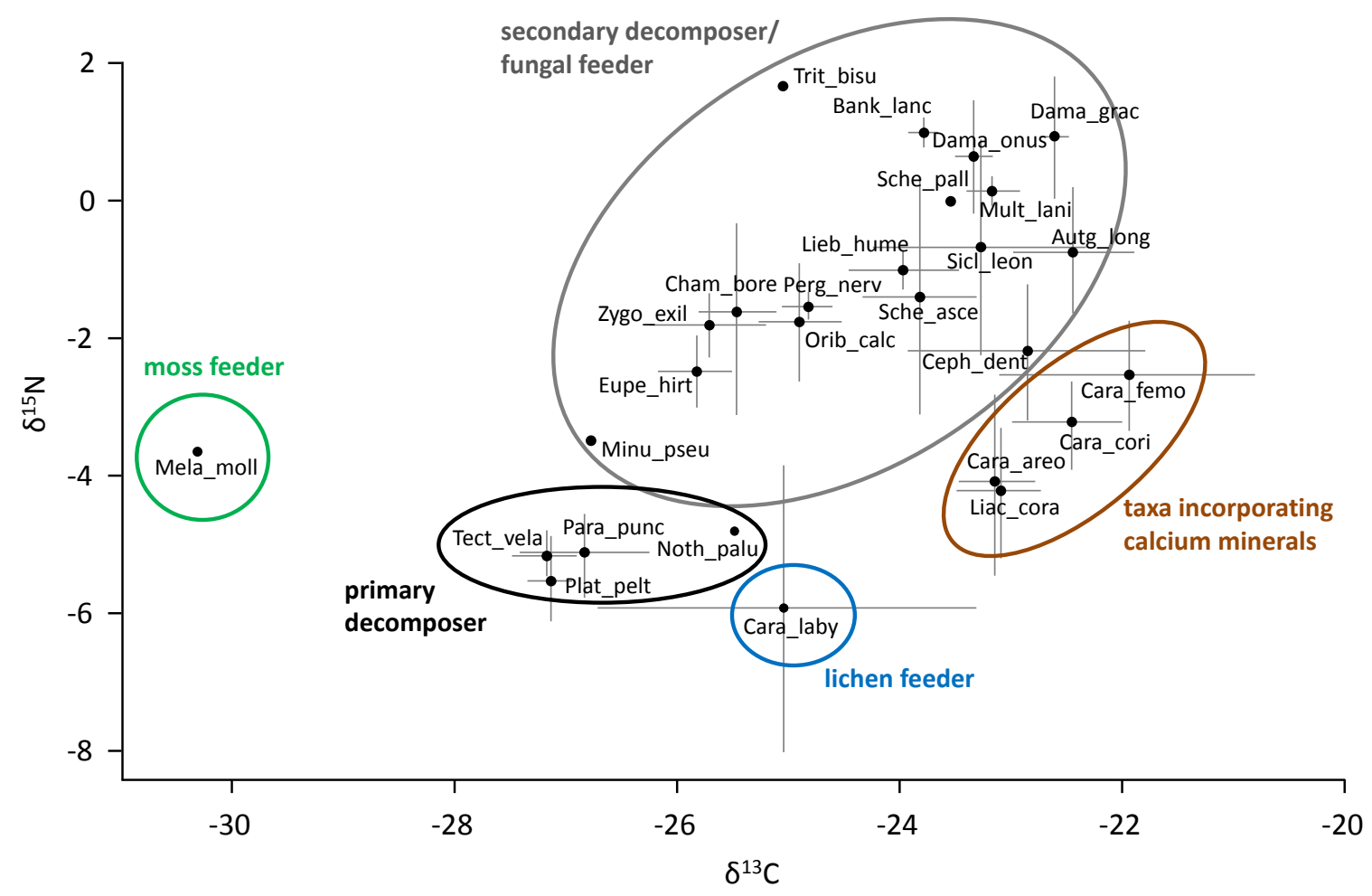

Fig. 2. Mean $( \pm S D)$ stable isotope ratios $\left({ }^{15} \mathrm{~N} /{ }^{14} \mathrm{~N},{ }^{13} \mathrm{C} /{ }^{12} \mathrm{C}\right)$ of oribatid mites on the bark of dead wood in Hainich-Dün. For full names of species and number of replicates measured see Table 1.

\subsection{Reproductive mode}

The percentages of parthenogenetic individuals (of total) was significantly higher in the Schorfheide-Chorin $(12.9 \pm 14.6 \%)$ and Schwäbische Alb $(7.5 \pm 11.7 \%)$ than in the Hainich-Dün $\left(3.6 \pm 3.6 \% ; F_{2,42}=4.26, P=0.021\right)$ and also higher in coniferous $(13.8 \pm 13.6 \%)$ than in deciduous forests $\left(5.2 \pm 9.1 \% ; F_{1,42}=9.80, P=0.0032\right)$. However, differences between forest types tended to vary between regions. In the Schwäbische Alb and Schorfheide-Chorin there were more parthenogenetic individuals in coniferous (16.7 $\pm 16.3 \%$ and $21.6 \pm 11.9 \%$, respectively) as compared to deciduous forests $(2.9 \pm 4.6 \%$ and $8.6 \pm 14.3 \%$, respectively), whereas in the Hainich-Dün the percentages of parthenogenetic individuals was similar in coniferous and deciduous forests $(3.1 \pm 2.1 \%$ and $3.9 \pm 4.3 \%$, 
respectively; $F_{2,42}=2.92, P=0.065 ;$ Fig. 3 ). Log type did not significantly affect the reproductive mode but it tended to be higher on oak than on beech logs $(10.3 \pm 13.0$ $\%$ and $5.7 \pm 9.4 \%$, respectively; $F_{1,42}=3.15, P=0.083$ ).

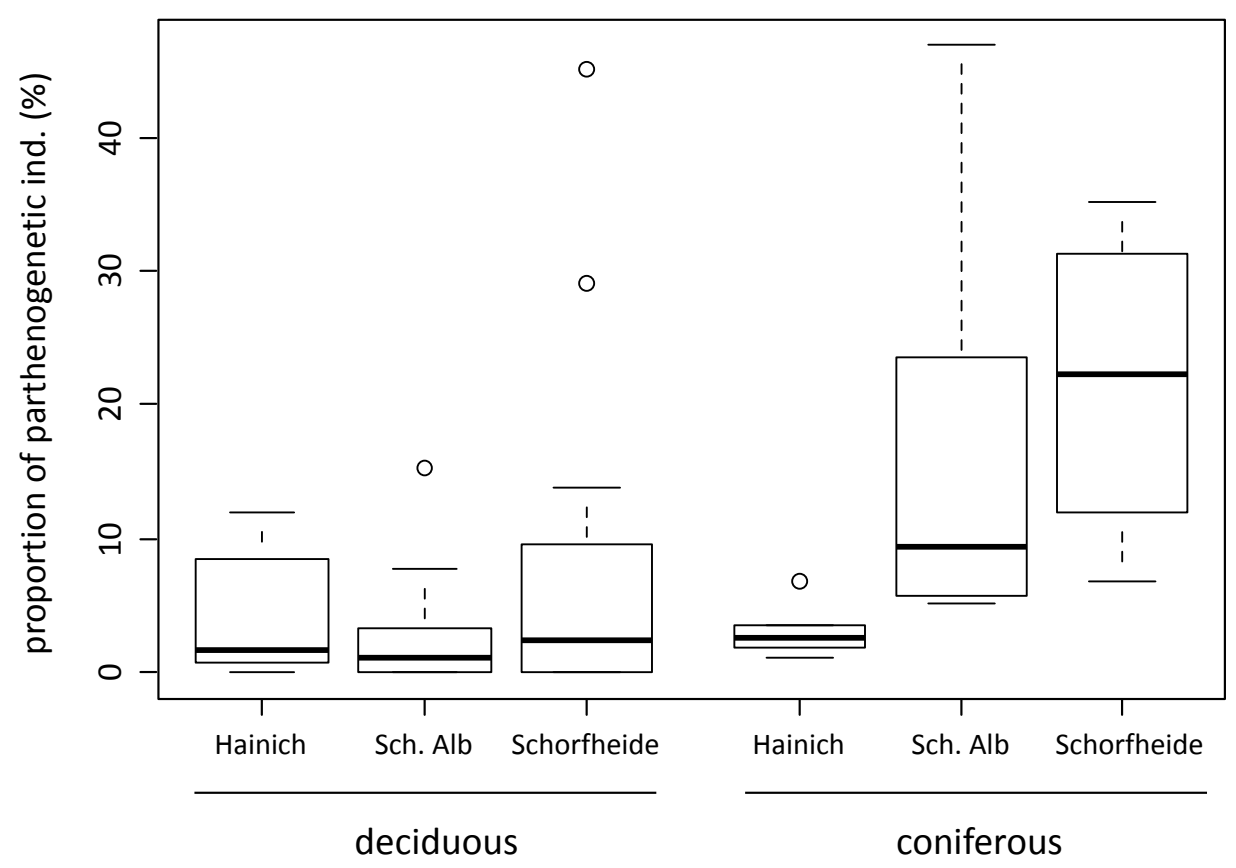

Fig. 3. Proportion of parthenogenetic individuals on the bark of dead wood in coniferous and deciduous forests across three regions in Germany. Sch. Alb = Schwäbische Alb; Hainich = Hainich-Dün; Schorfheide = Schorfheide-Chorin; deciduous $=$ deciduous forest ; coniferous $=$ coniferous forest.

\section{Discussion}

Results of our study indicate that the bark on dead wood is not colonized by specialist oribatid mite species occurring exclusively in this microhabitat. Rather, the communities are formed by a combination of arboreal and soil species. However, our findings indicate that oribatid mite communities of dead wood in an early stage of decay are affected by log type, forest type and region.

\subsection{The role of log type}

In contrast to our hypothesis, the more complex surface structure of the bark of oak logs did not increase the density of oribatid mites. This is surprising since structural complexity is among the most important factors affecting animal density in soil (Peterson and Luxton, 1982; Schaefer and Schauermann, 1990, Hansen, 2000). Hence, on the bark of dead wood space limitation (which is also 
intercorrelated with structural complexity) presumably is less important for oribatid mite communities as compared to soil.

In contrast to density, oribatid mite species richness was significantly higher on oak than on beech logs, and community structure also differed between log species. This suggests that tree identity, i.e. structural complexity of the bark habitat, is an important factor for structuring oribatid mite communities on dead wood. However, differences between log species varied between regions. Differences in the community structure presumably are related to differences in bark structure and differences in the accumulation of organic matter which is favored by the wrinkled bark of oak. Especially in coniferous forests needles accumulate in bark crevices forming a soil-like habitat. Concomitantly, typical decomposer taxa of oribatid mites colonized oak bark such as Platynothrus peltifer, Tectocepheus velatus and Phthiracarus spp. (Maraun et al., 2011). These taxa frequently occur in soil but are virtually absent on the bark of living trees. In addition, some other species especially Liebstadia humerata almost exclusively occurred on beech logs whereas species of the genus Carabodes mainly occurred on oak logs. Most oribatid mite species are fungal feeders (see below), and Schneider and Maraun (2005) demonstrated that preferences of oribatid mite species for fungal species as food differ. Additionally, juveniles of the genus Carabodes are associated with basidiomycete fungi growing on dead wood (Maraun et al. 2014; Hagvar and Steen, 2013). This suggests that fungal species consumed by species such as Liebstadia humerata are more abundant on beech logs whereas fungal species that are used by Carabodes species, especially Basidiomycetes, are more abundant on oak logs.

Several oribatid mite species mainly occurred on one log type, e.g. Siculobata leontonycha and Diapterobates humeralis were abundant on beech logs but were rare or absent on oak logs. Presumably, this is due to the fact that these phoretic species are dispersed by bark beetles (Penttinen et al., 2013) which typically have narrow host ranges (Knee et al., 2013). The density of a number of oribatid mite species, e.g. Autogneta longilamellata, Zygoribatula exilis, Chamobates borealis, $C$. cuspidatus did not differ between beech and oak logs suggesting that they are rather generalistic in respect to habitat characteristics.

\subsection{The role of forest type}

Oribatid mite density on the bark of dead wood was similar in beech and spruce forests contrasting the density in soil which typically is higher in coniferous than in 
deciduous forests (Maraun and Scheu, 2000; Sylvain and Buddle, 2010; Erdmann et al., 2012). Similar results were found in forests in Finland where oribatid mite densities in soil and dead wood of pine, spruce and birch forests were studied (SiiraPietikäinen et al., 2008).

In contrast to results of the study of Siira-Pietikiäinen et al. (2008) oribatid mite communities at our study sites were significantly affected by the type of the forest they were exposed in. Presumably, coniferous needles accumulating on the rough bark of oak logs contributed to the high number of oribatid mites on logs exposed in coniferous forests (see above). Some oribatid mite species, e.g. Adoristes ovatus that tunnel in needles (Lions and Gourbière, 1988) obligatory rely on needle litter explaining their absence on logs exposed in beech forests.

\subsection{The role of region}

The most important factor affecting oribatid mite communities on dead wood was the region. Similarly, investigating oribatid mite communities in soil in the same regions as in the present study, Erdmann et al. (2012) found oribatid mite communities to vary mainly between regions suggesting that regional factors such as climate are of major importance. Oribatid mite communities on the bark of dead wood exposed in the Schorfheide-Chorin region separated from the other two regions presumably due to the more continental climate but the low soil pH may also have contributed to this variation. Oribatid mite species reaching high densities in acidic forests, e.g. Pergalumna nervosa, Eniochthonius minutissimus, Carabodes ornatus, Cepheus cepheiformis and Carabodes subarcticus, also reached high density on the bark of logs in the Schorfheide-Chorin characterized by sandy soils of low $\mathrm{pH}$.

Oribatid mite communities in the Hainich-Dün and Schwäbische Alb were similar reflecting the similar climatic conditions and soil characteristics of these regions. Especially abundant species, such as Autogneta Iongilamellata, Siculobata leontonycha, Liebstadia humerata, Chamobates borealis, Banksinoma lanceolata and Multioppia laniseta, were present in both regions. Despite many species occurred in both regions several species only or predominantly occurred in one of the regions. In the Hainich-Dün a group of mainly arboreal species, including Phauloppia lucorum, Phauloppia rauschensis, Cymbaeremaeus cymba, Scheloribates ascendens, Trichoribates trimaculatus and Micreremus brevipes, frequently occurred on the logs. As many of these species have been assumed to 
feed on lichens (Seyd and Seaward, 1984; Meier et al., 2002; Erdmann et al., 2007; B.M. Fischer et al., 2010), their occurrence in the Hainich-Dün may be due to high abundance of lichens on the bark of dead wood. In the Schwäbische Alb oribatid mite communities on beech and oak logs were characterized by Fuscozetes setosus, Steganacarus herculeanus, Sphaerozetes piriformis, Edwardzetes edwardsi and Suctobelba altvateri. Typically, these species occur in montane regions (Schuster, 1960; Borcard et al., 1995; Materna, 2000; Schatz and Wilhalm, 2013; Weigmann, 2006) and their preferential occurrence in this region therefore likely is related to the fact that the study sites of the Schwäbische Alb are located at higher altitude ( $700 \mathrm{~m}$ a.s.I.) than those of the two other two regions (Hainich-Dün $\sim 400 \mathrm{~m}$ a.s.I., Schorfheide-Chorin $\sim 100 \mathrm{~m}$ a.s.I.).

\subsection{Trophic structure}

Samples for stable isotopes were taken about one and a half years after the first sampling. However, as oribatid mite communities at both sampling dates resembled each other the stable isotope data presumably also reflect the trophic organization of oribatid mite communities at the first sampling.

Stable isotopes signatures of oribatid mites spanned 7.6 delta units in ${ }^{15} \mathrm{~N}$ and 8.3 delta units in ${ }^{13} \mathrm{C}$ indicating that oribatid mite species from dead wood occupy more than two trophic levels and a wide range of trophic niches. Generally, fungal feeders dominated among oribatid mites suggesting that the most important food resource for oribatid mites on the bark of dead wood are fungi. The results further suggest that fungal feeding species separate into those relying on basidiomycete fungi, e.g. Carabodes femoralis, Carabodes areolatus, Carabodes coriaceus, Liacarus coracinus and Cepheus dentatus, typically occurring in sporocarps of basidiomycetes (Maraun et al. 2014) and from those predominantly feeding on ascomycete fungi, e.g. Chamobates borealis, Eupelops hirtus and Oribatella calcarata, dominating in the litter layer of forests (Visser and Parkinson, 1975; Shanthi and Vittal, 2010).

Notably, oribatid mite species feeding on mosses, such as Melanozetes mollicomus, lichens, such as Carabodes labyrinthicus, Phauloppia lucorum, Phauloppia rauschenesis, Micreremus brevipes and Cymbaeremaeus cymba, and those living as detritivores, such as Platynothrus peltifer, Tectocepheus velatus, Parachipteria punctata and Phthiracarus sp. (Maraun et al., 2011) were rare on the bark of logs. The former are usually part of arboreal oribatid mite communities 
whereas the latter occur numerously in soil indicating that tree logs form a transitional habitat for oribatid mites. Overall, the results suggest that decomposer species did not colonize the bark of dead wood in high density, presumably because the logs were at an early stage of decay. Moss and lichen feeders also were rare, suggesting that lichens and mosses did not yet intensively colonize the logs.

A group of oribatid mite species (Carabodes sp.; Liacarus coracinus) was less depleted in ${ }^{13} \mathrm{C}$ than the other species indicating that those taxa incorporate calcium minerals to harden their cuticle (Cromack et al., 1977; Norton and Behan-Pelletier, 1991).

\subsection{Reproductive mode}

In general, the low frequency of parthenogenetic individuals and species on the bark of dead wood (ca. 8\%) found in this study resembled that of the bark of living trees (Erdmann et al., 2006; B.M. Fischer et al.,2010) but contrasted that in soil of temperate forests (Maraun et al., 2012). The dominance of sexual species on bark of dead wood agrees with the hypothesis that animal taxa that feed on living resources reproduce sexually. In our study most of the oribatid mite species fed on living resources such as fungi, lichens and mosses. Scheu and Drossel (2007) stated that sexual species outcompete parthenogenetic species in habitats of short resource supply because the progeny is able to exploit varying resources more effectively. Resources on the bark of dead wood indeed might be in short supply considering the high density of oribatid mites resembling that in soil. Further, fungi, lichens and mosses may defend themselves against consumers by chemical defense mechanisms therefore hampering full exploitation by consumers (Rohlfs et al., 2007; Rohlfs and Churchill, 2011).

The proportion of parthenogenetic individuals was higher in coniferous than in deciduous forests and also higher in Schorfheide-Chorin than in Schwäbische Alb and Hainich-Dün. This pattern is similar to that in soil (Maraun et al., 2012) supporting the importance of source populations from the surrounding forest type and region for structuring oribatid mite communities on the bark of dead wood.

\subsection{Is dead wood a microhabitat?}

Dead wood of an early decaying stage is colonized by a specific oribatid mite community of high trophic diversity including lichen, moss, fungal and litter feeders. However, only few species exclusively occur in this habitat. Most oribatid mite 
species from dead wood also occur on the bark of living trees or occur in soil indicating that dead wood forms a transitional habitat. Of the 83 species found in this study less than 10 species exclusively occur on dead wood including species associated with bark beetles (Siculobata leontonycha) or species with endophagous juveniles tunneling in decaying wood or fungi (Carabodes spp., Odontocepheus elongatus). Another dead wood specialist was Autogneta longilamellata which is only found in this habitat (Skubała and Duras, 2008; Penttinen et al., 2008; SiiraPietikäinen et al., 2008; Déchêne and Buddle, 2009; Skubała and Marzec, 2013), however, the factors restricting the occurrence of this species to dead wood are little understood. Possibly, the scarcity of specialized species in our study is related to the rather young dead wood we sampled and might change in later stages of decay (see Skubała and Duras, 2008; Skubała and Maślak, 2009; Huhta et al., 2012; Skubała and Marzec, 2013)

Many other species which are typically found in dead wood are linked to epiphytes covering the bark and not to the dead wood itself. In a meta-study, Wunderle (1992) summarized that Zygoribatula exilis, Minunthozetes pseudofusiger, Tectocepheus velatus, Carabodes labyrinthicus, Melanozetes mollicomus and Parachipteria punctata dominate oribatid mite assemblages in mosses in forest ecosystems. Since dead wood provides beneficial microclimatic conditions for mosses, species of this assemblage are mostly found in dead wood samples.

Compared to earlier studies (Skubała and Duras, 2008; Siira-Pietikäinen et al., 2008; Déchêne and Buddle, 2009; Skubała and Marzec, 2013) we investigated dead wood at an early stage of decay explaining the high abundance of typical arboreal species, such as Zygoribatula exilis, Micreremus brevipes, Carabodes labyrinthicus, Cymbaeremaeus cymba and Phauloppia sp. (Seyd and Seaward, 1984; Erdmann et al., 2006, B.M. Fischer et al. 2010).

Overall, results of the present study show that dead wood is colonized by a large number of oribatid mite species also occurring on the forest floor. Many of them are ubiquists such as Oppiella nova and Tectocepheus velatus occurring in a variety of habitats in virtually all regions of the world. Only very few species such as Siculobata leontonycha are dead wood specialists. The mixture of soil-living and arboreal species occurring on the logs indicates that the bark of dead wood functions as transitory habitat for oribatid mites, thereby contributing little to oribatid mite diversity 
in forest ecosystems. Assemblage of species predominantly is driven by the type of forest the logs are located in, and the region the forest is located (random assemblage of species). However, the structure of bark and the type of tree logs also affected the oribatid mite community structure (deterministic niche-based species assemblage). Hence, our data support the conclusion that similar to the soil (Caruso et al., 2012; Ingimarsdóttir et al., 2012) oribatid mite communities on the bark of dead wood are assembled by both neutral and niche based processes.

\section{Acknowledgements}

We thank the managers of the three Exploratories, Swen Renner, Sonja Gockel, Kerstin Wiesner, and Martin Gorke for their work in maintaining the plot and project infrastructure; Simone Pfeiffer and Christiane Fischer giving support through the central office, Michael Owonibi for managing the central data base, and Markus Fischer, Eduard Linsenmair, Dominik Hessenmöller, Jens Nieschulze, Daniel Prati, Ingo Schöning, François Buscot, Ernst-Detlef Schulze, Wolfgang W. Weisser and the late Elisabeth Kalko for their role in setting up the Biodiversity Exploratories project. The work has been (partly) funded by the DFG Priority Program 1374 "Infrastructure-Biodiversity-Exploratories". Field work permits were issued by the responsible state environmental offices of Baden-Württemberg, Thüringen, and Brandenburg (according to $\S 72$ BbgNatSchG). We thank Nils Peter and Sarah Zieger for help in the field and Georgia Erdmann for help during sample processing. 


\section{References}

Abbott, D.T., Crossley, D.A., 1982. Woody litter decomposition following clearcutting. Ecology 63, 35-42.

Aoki, J., 1967. Microhabitats of oribatid mites on a forest floor. Bull. Natl. Sci. Mus. $10,132-138$.

Behan-Pelletier, V., Walter, D., 2000. Biodiversity of Oribatid Mites (Acari: Oribatida) in Tree Canopies and Litter, in: Coleman, D.C., Hendrix, P.F. (Eds), Invertebrates as Webmasters in Ecosystems. CAB International, Wallingford, pp. 187-202.

Borcard, D., Geiger, W., Matthey, W., 1995. Oribatid mite assemblages in a contact zone between a peat-bog and a meadow in the Swiss Jura (Acari, Oribatei): influence of landscape structures and historical processes. Pedobiologia 39, 318-330.

Caruso, T., Taormina, M., Migliorini, M., 2012. Relative role of deterministic and stochastic determinants of soil animal community: a spatially explicit analysis of oribatid mites. J. Anim. Ecol. 81, 214-221.

Cianciolo, J.M., Norton, R.A., 2006. The ecological distribution of reproductive mode in oribatid mites, as related to biological complexity. Exp. Appl. Acarol. 40, 125.

Cromack, K. Jr., Sollins, P., Todd, R.L., Crossley, D.A., Fender, W.M., Fogel, R., Todd, A.W., 1977. Soil microorganism-arthropod interactions: Fungi as major calcium and sodium sources, in: Mattson, W.J. (Ed.), The Role of Arthropods in Forest Ecosystems. Springer Verlag, New York, pp. 78-84.

Déchêne, A.D., Buddle, C.M., 2009. Decomposing logs increase oribatid mite assemblage diversity in mixedwood boreal forest. Biodivers. Conserv. 19, 237256.

Domes, K., Scheu, S., Maraun, M., 2007. Resources and sex: Soil re-colonization by sexual and parthenogenetic oribatid mites. Pedobiologia 51, 1-11.

Ehnström, B., 2001. Leaving dead wood for insects in boreal forests - Suggestions for the future. Scand. J. For. Res. 16, 91-98.

Eidmann, H.H., 1992 Impact on bark beetles on forest and forestry in Sweden. J. Appl. Ent. 114, 193-200.

Erdmann, G., Floren, A., Linsenmair, K.E., Scheu, S., Maraun, M., 2006. Little effect of forest age on oribatid mites on the bark of trees. Pedobiologia 50, 433-441.

Erdmann, G., Otte, V., Langel, R., Scheu, S., Maraun, M., 2007. The trophic structure of bark-living oribatid mite communities analysed with stable isotopes $\left({ }^{15} \mathrm{~N},{ }^{13} \mathrm{C}\right)$ indicates strong niche differentiation. Exp. Appl. Acarol. 41, 1-10.

Erdmann, G., Scheu, S., Maraun, M., 2012. Regional factors rather than forest type drive the community structure of soil living oribatid mites (Acari, Oribatida). Exp. Appl. Acarol. 57, 157-169.

Fischer, B.M., Schatz, H., Maraun, M., 2010. Community structure, trophic position and reproductive mode of soil and bark-living oribatid mites in an alpine grassland ecosystem. Exp. Appl. Acarol. 52, 221-237. 
Fischer, M., Bossdorf, O., Gockel, S., Hänsel, F., Hemp, A., Hessenmöller, D., Korte, G., Nieschulze, J., Pfeiffer, S., Prati, D., Renner, S., Schöning, I., Schumacher, U., Wells, K., Buscot, F., Kalko, E.K.V., Linsenmair, K.E., Schulze, E.-D., Weisser, W.W., 2010. Implementing large-scale and long-term functional biodiversity research: The Biodiversity Exploratories. Basic Appl. Ecol. 11, 473-485.

Gossner, M.M., Lachat, T., Brunet, J., Isacsson, G., Bouget, C., Brustel, H., Brandl, R., Weisser, W.W., Müller, J., 2013. Current near-to-nature forest management effects on functional trait composition of saproxylic beetles in beech forests. Conserv. Biol. 27, 605-614.

Hågvar, S., Steen, R., 2013. Succession of beetles (genus Cis) and oribatid mites (genus Carabodes) in dead sporocarps of the red-banded polypore fungus Fomitopsis pinicola. Scand. J. For. Res. 28, 436-444.

Hansen, R.A., 2000. Effects of habitat complexity and composition on a diverse litter microarthropod assemblage. Ecology 81, 1120-1132.

Hubbell, S.P., 2001. The Unified Neutral Theory of Biodiversity and Biogeography, Princeton University Press, Princeton.

Huhta, V., Siira-Pietikäinen, A., Penttinen, R., 2012. Importance of dead wood for soil mite (Acarina) communities in boreal old-growth forests. Soil Org. 84, 499512.

Hutchinson, G.E., 1959. Homage to santa rosalia or why are there so many animals? Am. Nat. 93, 145-159.

Ingimarsdóttir, M., Caruso, T., Ripa, J., Magnúsdóttir, Ó.B., Migliorini, M., Hedlund, K., 2012. Primary assembly of soil communities: disentangling the effect of dispersal and local environment. Oecologia 170, 745-754.

Jonsell, M., Weslien, J., Ehnström, B., 1998. Substrate requirements of red-listed saproxylic invertebrates in Sweden. Biodivers. Conserv. 7, 749-764.

Jonsson, B., Kruys, N., Ranius, T., 2005. Ecology of species living on dead woodlessons for dead wood management. Silva Fenn. 39, 289-309.

Knee, W., Forbes, M.R., Beaulieu, F., 2013. Diversity and host use of mites ( Acari: Mesostigmata, Oribatida) Phoretic on Bark Beetles (Coleoptera: Scolytinae ): Global Generalists, Local Specialists? Entomol. Soc. Am. 106, 339-350.

Langel, R., Dyckmans, J., 2014. Combined ${ }^{13} \mathrm{C}$ and ${ }^{15} \mathrm{~N}$ isotope analysis on small samples using a near-conventional elemental analyzer/isotope ratio mass spectrometer setup. Rapid Commun. Mass Spectrom. 28, 1019-1022.

Lassauce, A., Paillet, Y., Jactel, H., Bouget, C., 2011. Deadwood as a surrogate for forest biodiversity: meta-analysis of correlations between deadwood volume and species richness of saproxylic organisms. Ecol. Indic. 11, 1027-1039.

Lehmitz, R., Russell, D., Hohberg, K., Christian, A., Xylander, W.E.R., 2011. Wind dispersal of oribatid mites as a mode of migration. Pedobiologia 54, 201-207.

Lindo, Z., Winchester, N.N., 2006. A comparison of microarthropod assemblages with emphasis on oribatid mites in canopy suspended soils and forest floors associated with ancient Western Red Cedar trees. Pedobiologia 50, 31-41. 
Lions, J.C., Gourbière, F., 1988. Populations adultes et immatures d'Adoristes ovatus (Acarien, Oribate) dans les aiguilles de la litière d'Albies alba. Rev. Écol. Biol. Sol 25, 343-352.

Luxton, M., 1972. Studies on the oribatid mites of a Danish beech wood soil. Pedobiologia 12, 434-463.

Macfadyen, A., 1961. Improved funnel-type extractors for soil arthropods. J. Anim. Ecol. 30, 171-181.

Maraun, M., Augustin, D., Müller, J., Bässler, C., Scheu, S., 2014. Changes in the community composition and trophic structure of microarthropods in sporocarps of the wood decaying fungus Fomitopsis pinicola along an altitudinal gradient. Appl. Soil. Ecol. 84, 16-23.

Maraun, M., Erdmann, G., Fischer, B.M., Pollierer, M.M., Norton, R.A., Schneider, K., Scheu, S., 2011. Stable isotopes revisited: Their use and limits for oribatid mite trophic ecology. Soil Biol. Biochem. 43, 877-882.

Maraun, M., Norton, R.A., Ehnes, R., Scheu, S., Erdmann, G., 2012. Positive correlation between density and parthenogenetic reproduction in oribatid mites (Acari) supports the structured resource theory of sexual reproduction. Evol. Ecol. Res. 14, 311-323.

Maraun, M., Scheu, S., 2000. The structure of oribatid mite communities (Acari, Oribatida): patterns, mechanisms and implications for future research. Ecography 23, 374-383.

Materna, J., 2000. Oribatid communities (Acari: Oribatida) inhabiting saxicolous mosses and lichens in the Krkonoše Mts. (Czech Republic). Pedobiologia 44, 40-62.

Matthewman, W., Pielou, D., 1971. Arthropods inhabiting the sporophores of Fomes fomentarius (Polyporaceae) in Gatineau Park, Quebec. Can. Entomol. 103, 775-847

Meier, F. a., Scherrer, S., Honegger, R., 2002. Faecal pellets of lichenivorous mites contain viable cells of the lichen-forming ascomycete Xanthoria parietina and its green algal photobiont, Trebouxia arboricola. Biol. J. Linn. Soc. 76, 259-268.

Mori, A.S., Shiono, T., Koide, D., Kitagawa, R., Ota, A.T., Mizumachi, E., 2013. Community assembly processes shape an altitudinal gradient of forest biodiversity. Glob. Ecol. Biogeogr. 22, 878-888.

Müller, J., Bußler, H., Goßner, M., Rettelbach, T., Duelli, P., 2008. The European spruce bark beetle Ips typographus in a national park: from pest to keystone species. Biodivers. Conserv. 17, 2979-3001.

Müller-Using, S., Bartsch, N., 2003. Totholzdynamik eines Buchenbestandes (Fagus sylvatica L.) im Solling: Nachlieferung, Ursache und Zersetzung von Totholz. Allg. Forst- und Jgd.-Ztg. 174, 122-130

Norton, R.A., Behan-Pelletier, V.M., 1991. Calcium carbonate and calcium oxalate as cuticular hardening agents in oribatid mites (Acari: Oribatida). Can. J. Zool. $69,1504-1511$. 
Norton, R.A., Kethley, J., Johnston, D.E., OConnor, B.M., 1993. Phylogenetic perspectives on genetic systems and reproductive modes of mites, in: Wrensch, D.L., Ebbert, M.A. (Eds.), Evolution and Diversity of Sex Ratio in Insects and Mites. Chapman \& Hall Publ., New York, pp. 8-99.

Palmer, S., Norton, R.A., 1991. Taxonomic, geographic and seasonal distribution of thelytokous parthenogenesis in the Desmonomata (Acari: Oribatida). Exp. Appl. Acarol. 12, 67-81.

Peltonen, M., Heliövaara, K., Väisänen, R., Keronen, J., 1998. Bark beetle diversity at different spatial scales. Ecography 5, 510-517.

Penttinen, R., Siira-Pietikäinen, A., Huhta, V., 2008. Oribatid mites in eleven different habitats in Finland. Integr. Acarology 2, 237-244.

Penttinen, R., Viiri, H., Moser, J.C., 2013. The mites (Acari) associated with bark beetles in the Koli National Park in Finland. Acarologia 53, 3-15.

Petersen, H., Luxton, M., 1982. A comparative analysis of soil fauna populations and their role in decomposition processes. Oikos 39, 288-388.

Proctor, H.C., Montgomery, K.M., Rosen, K.E., Kitching, R.L., 2002. Are tree trunks habitats or highways? A comparison of oribatid mite assemblages from hooppine bark and litter. Aust. J. Entomol. 41, 294-299.

Reineking, A., Langel, R., Schikowski, J., $1993 .{ }^{15} \mathrm{~N},{ }^{13} \mathrm{C}$-on-line measurements with an elemental analyser (Carlo Erba, NA 1500), a modified trapping box and a gas isotope mass spectrometer (Finnigan, MAT 251). Isot. Isot. Environ. Heal. Stud. 29, 169-174.

Rohlfs, M., Albert, M., Keller, N.P., Kempken, F., 2007. Secondary chemicals protect mould from fungivory. Biol. Lett. 3, 523-525.

Rohlfs, M., Churchill, A.C.L., 2011. Fungal secondary metabolites as modulators of interactions with insects and other arthropods. Fungal Genet. Biol. 48, 23-34.

Schaefer, M., Schauermann, J., 1990. The soil fauna of beech forests: comparison between a mull and a moder soil. Pedobiologia 314, 299-314.

Schatz, H., Wilhalm, T., 2013. Tag der Artenvielfalt 2012 in Ridnaun ( Gemeinde Ratschings, Südtirol, Italien ). Gredleriana 13, 139-194.

Scheu, S., Drossel, B., 2007. Sexual reproduction prevails in a world of structured resources in short supply. Proc. Biol. Sci. 274, 1225-1231.

Schneider, K., Maraun, M., 2005. Feeding preferences among dark pigmented fungal taxa ("Dematiacea") indicate limited trophic niche differentiation of oribatid mites (Oribatida, Acari). Pedobiologia 49, 61-67.

Schneider, K., Migge, S., Norton, R.A., Scheu, S., Langel, R., Reineking, A., Maraun, M., 2004. Trophic niche differentiation in soil microarthropods (Oribatida, Acari): evidence from stable isotope ratios $\left({ }^{15} \mathrm{~N} /{ }^{14} \mathrm{~N}\right)$. Soil Biol. Biochem. 36, 1769-1774.

Schuster, R., 1956. Der Anteil der Oribatiden an den Zersetzungsvorgängen im Boden. Z. Morphol. Oekol. Tiere 45, 1-33.

Schuster, R., 1960. Über die Ökologie und Verbreitung von Bodenmilben (Oribatei) am Alpen-Ostrand, insbesondere der Steiermark. Mitteilungen des Naturwissenschaftlichen Vereines der Steiermark 90, 132-149. 
Schuster, R., 1979. Soil mites in the marine environment. Recent Adv. Acarol. 1, 593-602.

Seastedt, T.R., Reddy, M.V., Cline, S.P., 1989. Microarthropods in decaying wood from temperate coniferous and deciduous forests. Pedobiologia 33, 69-77.

Seyd, E., Seaward, M., 1984. The association of oribatid mites with lichens. Zool. J. Linn. Soc. 80, 369-420.

Shanthi, S., Vittal, B.P.R., 2010. Fungi associated with decomposing leaf litter of cashew (Anacardium occidentale). Mycology 1, 121-129.

Siepel, H, de Ruiter-Dijkman, E.M., 1993. Feeding guilds of oribatid mites based on their carbohydrase activities. Soil Biol. Biochem. 25, 1491-1497.

Siira-Pietikäinen, A., Penttinen, R., Huhta, V., 2008. Oribatid mites (Acari: Oribatida) in boreal forest floor and decaying wood. Pedobiologia 52, 111-118.

Similä, M., Kouki, J., Martikainen, P., 2003. Saproxylic beetles in managed and seminatural Scots pine forests: quality of dead wood matters. For. Ecol. Manag. 174, 365-381.

Skubała, P., Duras, M., 2008. Do decaying logs represent habitat islands? Oribatid mite communities in dead wood. Ann. Zool. 58, 453-466.

Skubała, P., Marzec, A., 2013. Importance of different types of beech dead wood for soil microarthropod fauna. Pol. J. Ecol. 61, 545-560.

Skubała P., Maślak M. 2009. Succession of oribatid fauna (Acari, Oribatida) in fallen spruce trees: Deadwood promotes species and functional diversity, in: Sabelis, M.W., Bruin, J. (Eds.), Trends in Acarology. Springer, Dordrecht, pp. 123-128.

Stokland, J.N., Siitonen, J., Jonsson, B.G., 2012. Biodiversity in Dead Wood, Cambridge University Press, Cambridge

Sylvain, Z. A., Buddle, C.M., 2010. Effects of forest stand type on oribatid mite (Acari: Oribatida) assemblages in a southwestern Quebec forest. Pedobiologia $53,321-325$.

Šmilauer, P., Lepš, J., 2014. Multivariate Analysis of Ecological Data using CANOCO 5, Cambridge University Press, Cambridge

Tscharntke, T., Tylianakis, J.M., Rand, T. a, Didham, R.K., Fahrig, L., Batáry, P., Bengtsson, J., Clough, Y., Crist, T.O., Dormann, C.F., Ewers, R.M., Fründ, J., Holt, R.D., Holzschuh, A., Klein, A.M., Kleijn, D., Kremen, C., Landis, D. a, Laurance, W., Lindenmayer, D., Scherber, C., Sodhi, N., Steffan-Dewenter, I., Thies, C., van der Putten, W.H., Westphal, C., 2012. Landscape moderation of biodiversity patterns and processes - eight hypotheses. Biol. Rev. Camb. Philos. Soc. 87, 661-685.

Visser S, Parkinson D., 1975. Fungal succession on aspen poplar leaf litter. Can. J. Bot. 53, 1640-1657.

Walter, D., Proctor, H., 1999. Mites: Ecology, Evolution, and Behaviour, CAB International, Wallingford

Weigmann, G., 2006. Hornmilben (Oribatida), in: Dahl, F. (Ed.), Die Tierwelt Deutschlands 76. Goecke \& Evers, Keltern, pp. 1-520.

Wermelinger, B., 2004. Ecology and management of the spruce bark beetle Ips typographus-a review of recent research. For. Ecol. Manag. 202, 67-82. 
Wunderle, I., 1992. Die Oribatiden-Gemeinschaften (Acari) der verschiedenen Habitate eines Buchenwaldes. Carolinea 50, 79-144. 


\section{Appendix}

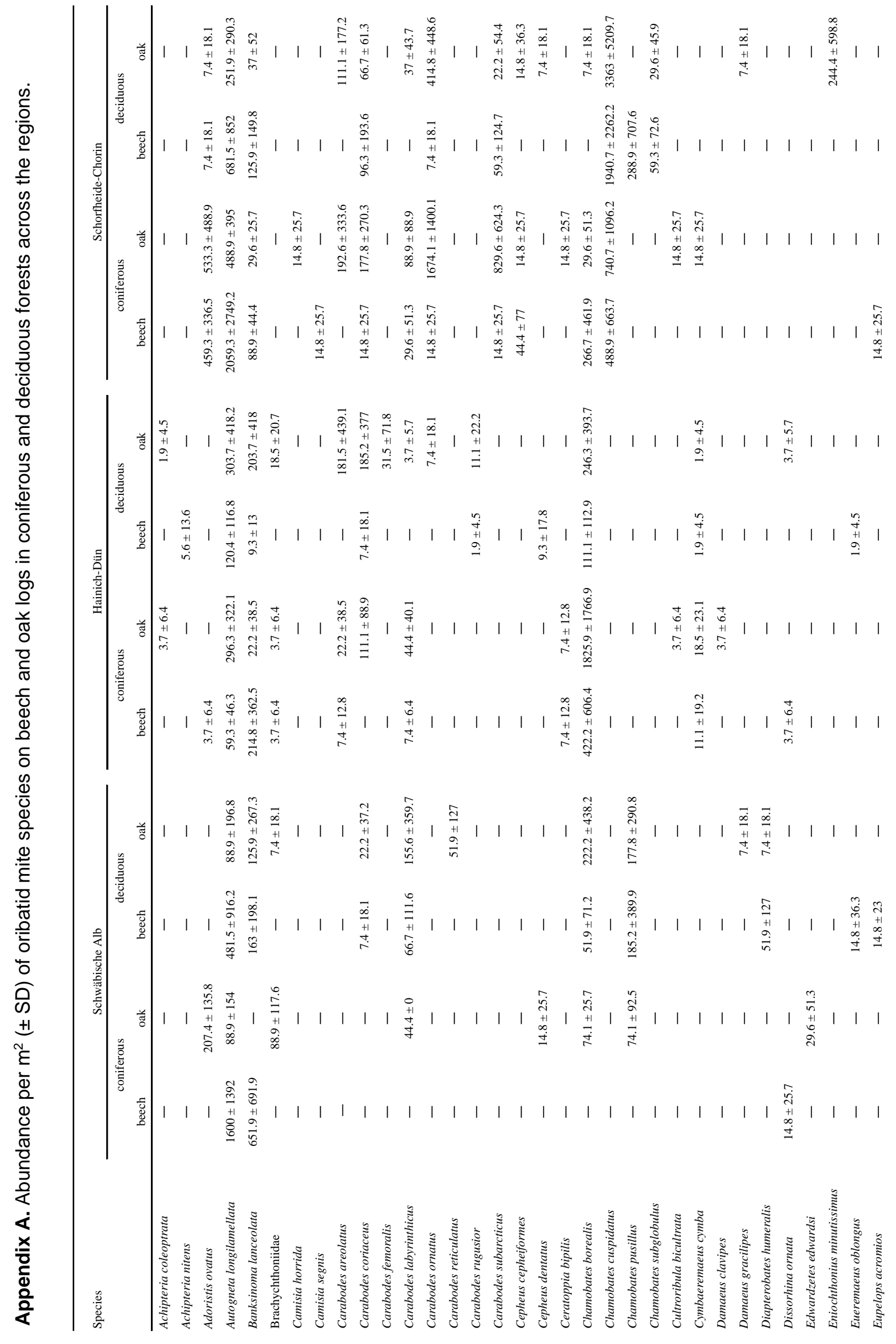




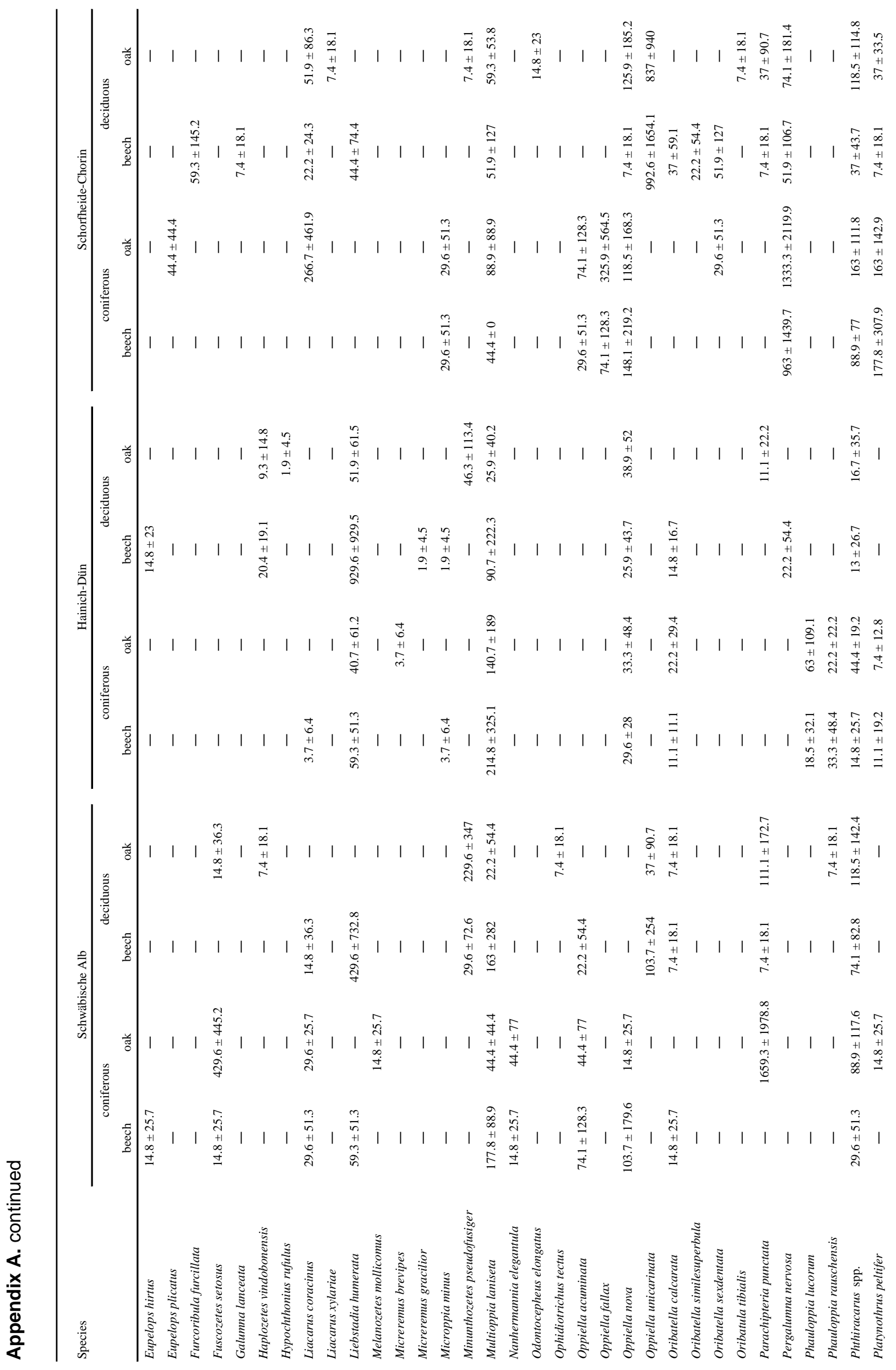




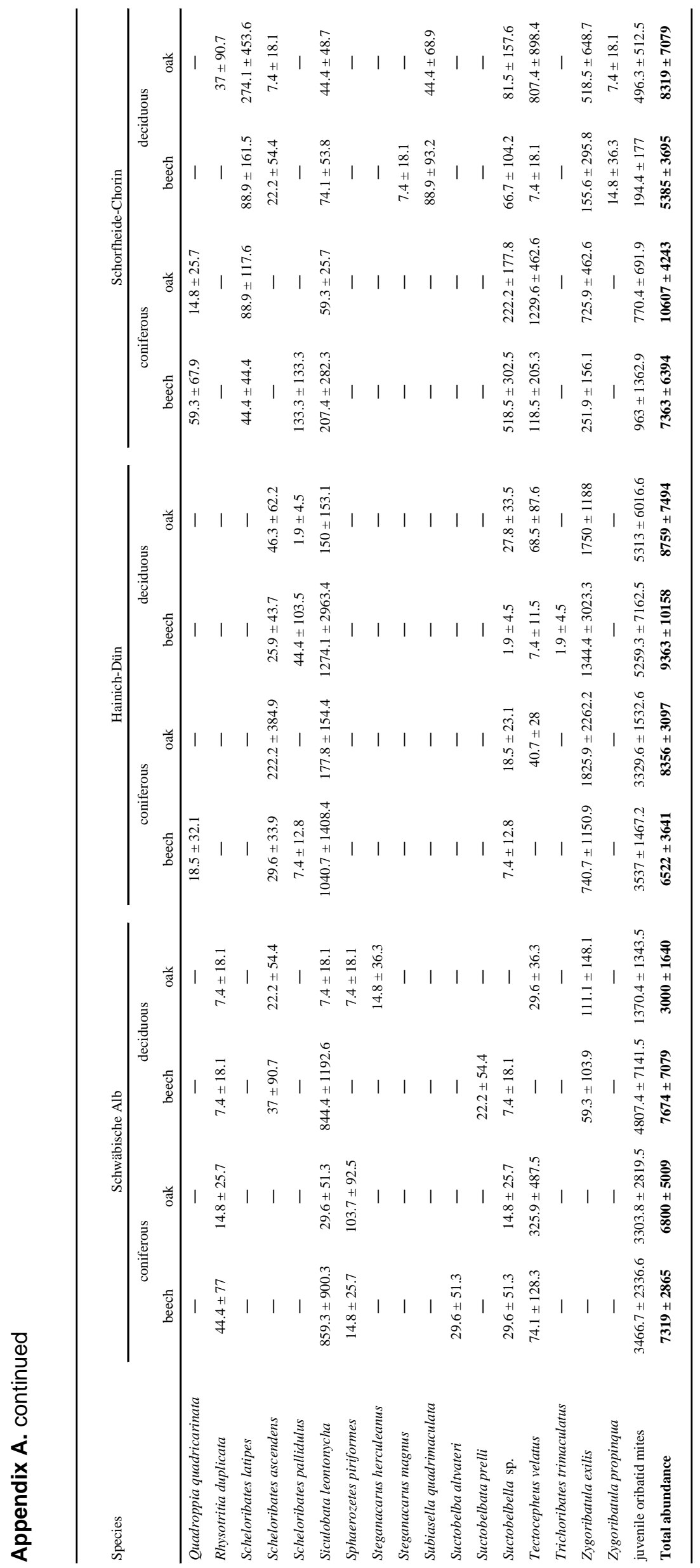




\section{CHAPTER 3}

Temporal fluctuations in oribatid mites indicate that densityindependent factors favour parthenogenetic reproduction

Christian Bluhm, Stefan Scheu, Mark Maraun

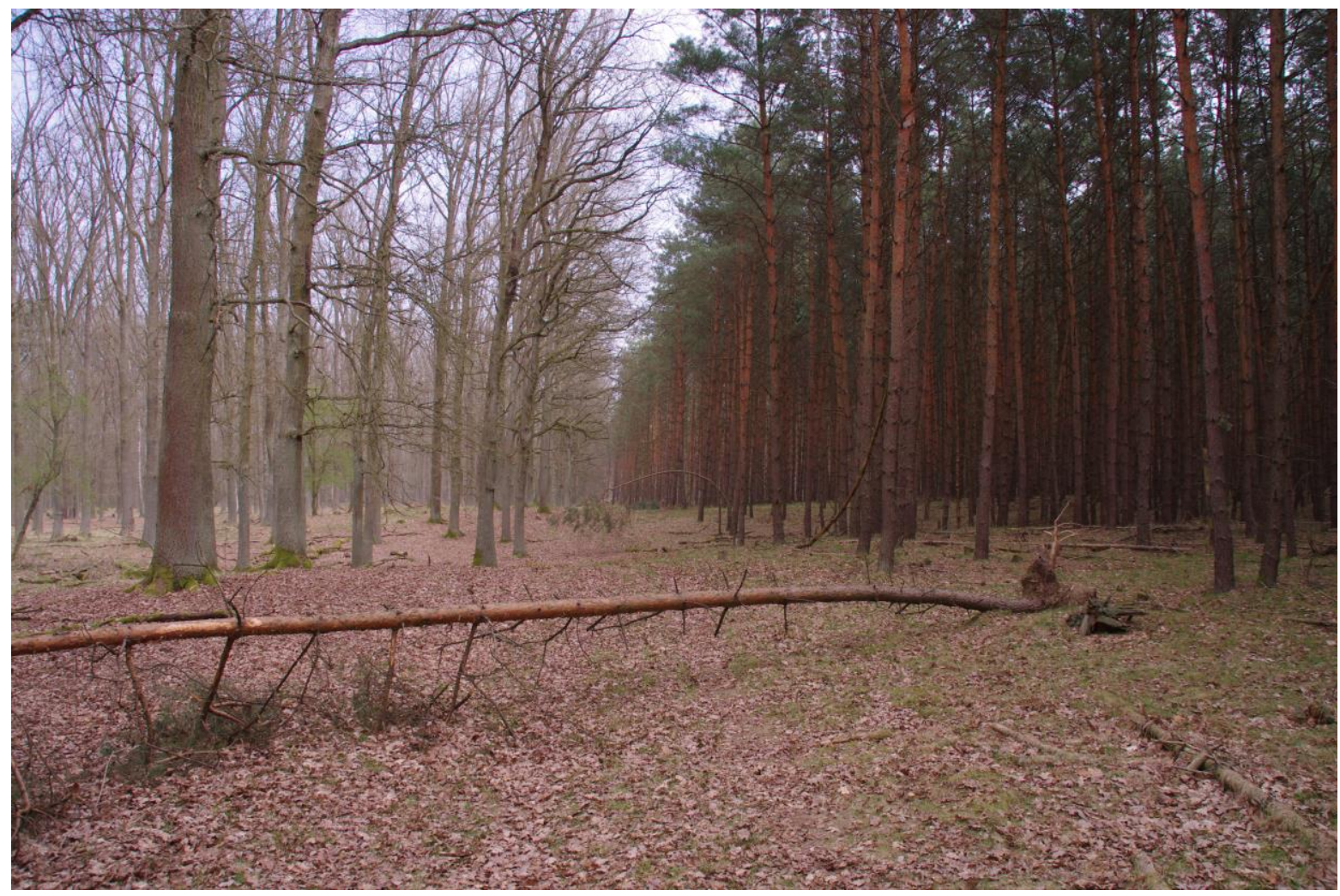

Published in:

Bluhm C, Scheu S, Maraun M (2016) Temporal fluctuations in oribatid mites indicate that density-independent factors favour parthenogenetic reproduction. Exp Appl Acarol 68:387-407 


\begin{abstract}
We investigated the oribatid mite density, community structure and the percentage of parthenogenetic individuals in four different forest types across three regions in Germany in 2008 and once again in 2011. We compared temporal (interannual) fluctuations in population densities between sexually and parthenogenetically reproducing species of oribatid mites. We hypothesized that population densities in parthenogenetic oribatid mite species fluctuate more than in sexual ones. Further, we expected species composition and dominance of parthenogenetic species to differ between forest types and regions. Oribatid mite community structure did not differ between years but varied with forest type and region, indicating low species turnover in time. As hypothesized, temporal fluctuations were more pronounced in parthenogenetic as compared to sexual species. The percentage of parthenogenetic individuals was significantly higher in coniferous as compared to beech forests and significantly higher in SchorfheideChorin as compared to Hainich-Dün and Schwäbische Alb. The results indicate that parthenogenetic species flourish if populations are controlled by densityindependent factors and dominate at sites were resources are plentiful and easily available, such as coniferous forests, and in regions with more acidic soils and thick organic layers, such as Schorfheide-Chorin. However, historical factors also may have contributed to the increased dominance of parthenogenetic species in the Schorfheide-Chorin, since this region was more heavily glaciated and this may have favoured parthenogenetic species. Overall, our study supports the hypothesis that parthenogenetic species benefit from the lack of density-dependent population control whereas the opposite is true for sexual species.
\end{abstract}

Key-words: Oribatida, parthenogenesis, temporal fluctuations, temperate forests 


\section{Introduction}

Understanding the reasons for the evolution and maintenance of sexual reproduction and its dominance in the animal kingdom for long poses a challenge for ecologists and evolutionary biologists (e.g., Weismann 1889; Fisher 1930; Muller 1964; Maynard Smith 1968; Hamilton 1980; Bell 1982; Scheu and Drossel 2007). Despite the "twofold costs of sex" due to producing males, sexual reproduction is widespread with about $99.9 \%$ of animal species reproducing sexually (White 1978; Bell 1982).

A number of ecological and evolutionary theories have been proposed to explain how sexual reproduction outweighs this twofold disadvantage. The Red Queen Hypothesis postulates a coevolutionary arms race between host and parasites or predator and prey (Jaenike 1978; Hamilton 1980). It states that species have to evolve continuously to survive in a temporally changing environment conferring sexuality an advantage over asexuality. The Tangled Bank Hypothesis attributes the prevalence of sexual taxa to their ability to produce genetically diverse offspring able to occupy a larger variety of niches in spatially structured environments as compared to genetically more uniform offspring produced by parthenogenetic reproduction (Maynard Smith 1971; Bell 1982). Building on the latter, the 'Structured Resource Theory of Sexual Reproduction' (SRTS) assumes that sexual taxa outcompete asexual ones in habitats where resources are in short supply or are difficult to access (Scheu and Drossel 2007). In contrast, asexual taxa prevail in environments where resources are easily available, little structured or replenish quickly. Additionally, asexuals dominate in habitats where death rates are so high that available resources are not fully exploited. Hence, the SRTS predicts that sexual species prevail at conditions where density-dependent factors predominate (e.g., predation, resource competition, parasites), whereas asexual species are favoured if density-independent factors prevail, such as desiccation, frost or flooding. This implies that temporal fluctuations should be more pronounced in parthenogenetic than in sexual species; this hypothesis, however, has never been tested until today.

Testing the different theories on the advantage of sexual reproduction is difficult, in part as they are making similar predictions (Bell 1982), but also due to the scarcity of taxa that include closely related parthenogenetic and sexual species. Moreover, parthenogenetically reproducing species tend to form singular terminal offshoots in 
phylogenetic trees, whereas clusters of species rarely occur. The few existing clusters of species reproducing parthenogenetically often exhibit very different ecological characteristics to those reproducing sexually and do not allow straightforward comparisons. For example, the parthenogenetically reproducing bdelloid rotifers live very different to the (predominantly) sexually reproducing monogonont rotifers and are difficult to compare in respect to forces regulating their populations (Segers 2008).

A promising group allowing straightforward comparison of sexually and parthenogenetically reproducing species of similar ecology are oribatid mites (Oribatida, Acari; Maraun et al. 2003; Heethoff et al. 2007; Schaefer et al. 2010). Oribatid mites are a diverse cosmopolitan taxon often numerically dominating soil animal communities (Walter and Proctor 2013). To date more than 10,000 species have been described of which approximately $8-9 \%$ reproduce via thelytokous parthenogenesis scattered across phylogenetic distinct groups (Norton and Palmer 1991; Palmer and Norton 1991). Additionally, sexual and asexual species co-occur in the same habitat and therefore their population dynamics can be compared.

Parthenogenetically reproducing oribatid mite species are not evenly distributed over different ecosystems but dominate in freshwater, in agricultural systems and in acidic habitats such as peat bogs or boreal forest soils (Karg 1967; Norton and Sillman 1985; Beckmann 1988; Behan-Pelletier 1989; Behan-Pelletier and Bissett 1994), whereas they rarely occur on the bark of trees (Erdmann et al. 2006) or in montane tropical forest soils (Illig et al. 2010). The incidence of parthenogenesis is generally high in forest soils, but it markedly differs between forest types (e.g., coniferous vs. deciduous), suggesting that environmental conditions and niches differ in these ecosystems (Erdmann et al.2012; Maraun et al. 2012). On a larger scale, regional factors may also affect the reproductive mode of soil animals due to differences in climate, landscape history and pedogenic processes, e.g. different parent rock, which affect the $\mathrm{pH}$ of the respective systems (Maraun et al. 2012; Zaitsev et al. 2013).

Recently, evidence supporting the SRTS has been provided in showing that the proportion of parthenogenetic individuals correlates with overall oribatid mite density indicating that ample resources favour asexual reproduction (Maraun et al. 2012). Further, in tropical as well as temperate regions sexual oribatid mite taxa have been shown to dominate at higher altitudes (Maraun et al. 2013; BM Fischer et al. 2014). 
Since resource quality (as indicated by high litter $\mathrm{C} / \mathrm{N}$ ratio) decreases with increasing altitude (Wilcke et al. 2008) this supports the hypothesis that poor accessibility of resources promotes sexual reproduction.

We investigated if community structure and the relative density (dominance) of parthenogenetic individuals differ between regions of different climate, between forest types (beech vs. coniferous) and between years (2008 vs. 2011). We further analysed if temporal fluctuations differ between sexual and parthenogenetic taxa of oribatid mites. We hypothesized that population fluctuations in parthenogenetic species exceed those of sexual species, since the former flourish if populations are controlled by density-independent factors. We further hypothesized that forest type and region affect the dominance of parthenogenetic species with the dominance of parthenogenetic species increasing with forest disturbance and in regions with harsher abiotic conditions.

\section{Materials and Methods}

\subsection{Study sites}

The study was carried out in three regions of Germany at the experimental forest sites of the "Biodiversity Exploratories", an integrative ecosystem research project (M Fischer et al. 2010). The three regions included (1) the Schorfheide-Chorin (3$140 \mathrm{~m}$ a.s.I.), situated in the lowlands of North-east Germany and characterized by a young glacial landscape with sandy soils and many wetlands, (2) the Hainich-Dün (285-550 $\mathrm{m}$ a.s.l.), located in the hilly lands of central Germany featuring large unfragmented beech forests, and (3) the Schwäbische Alb (460-860 m a.s.I.), located in the low mountain ranges of South-west Germany. Mean annual precipitation in the Schorfheide-Chorin, Hainich-Dün and Schwäbische Alb are 500$600,500-800$ and $700-1000 \mathrm{~mm}$ with mean annual temperatures of 8.0-8.5, 6.5-8.0 and $6.0-7.0^{\circ} \mathrm{C}$, respectively. Soils mainly comprise Cambisols and Luvisols in the Schorfheide-Chorin and Hainich-Dün, and Cambisols and Leptosols in the Schwäbische Alb. Bedrock is glacial till in the Schorfheide-Chorin, Triassic limestone in the Hainich-Dün and Jurassic shell limestone in the Schwäbische Alb. Soil pH ranges from $3.00 \pm 0.19$ to $4.51 \pm 0.72$ to $4.59 \pm 0.67$ in the SchorfheideChorin, the Schwäbische Alb and the Hainich-Dün, respectively. For more details on the study sites see M Fischer et al. (2010). 


\subsection{Sampling design, extraction and determination of soil animals}

Within each region, four different forest types were selected: managed young and old beech (Fagus sylvatica) forests with an average tree age of 30 (young beech) and 70 (old beech) years, respectively, unmanaged beech forests taken out of management for at least 60 years (natural beech), with mature trees being 120 to 150 years old, and old managed coniferous forests (coniferous) with an average tree age of 70 years (Pinus sylvestris in Schorfheide-Chorin and Picea abies in Hainich-Dün and Schwäbische Alb). All managed forests were planted as age class forests. The forest types were replicated four times in each of the three regions resulting in a total of 48 forest plots.

Soil samples were taken from April to May in 2008 and 2011. At each date, two soil samples per plot were taken from a $5 \mathrm{~m}^{2}$ subplot using a soil corer $(\varnothing 5 \mathrm{~cm})$; as we focus on temporal variability, those samples were pooled for statistical analysis. Soil animals were extracted by heat (Macfadyen 1961) and subsequently transferred into $70 \%$ ethanol. Oribatid mites were determined to species level, except for Brachychthoniidae, Suctobelbella and Phthiracarus, which were determined to family or genus level, using the key of Weigmann (2006). Juvenile oribatid mites were counted but not determined. Data on the reproductive mode of oribatid mite species were taken from Palmer and Norton (1991), Norton et al. (1993), Cianciolo and Norton (2006), Domes et al. (2007) and BM Fischer et al. (2010). We classified oribatid mite species on the basis of known information on their ecology into the subgroups Enarthronota, Desmonomata, Phthiracaroidea, Tectocepheidae, sexual Oppiidae, parthenogenetic Oppiidae, Suctobelbidae, Poronota and 'Others' (including all oribatid mites not included to any of the groups above). Species of the respective groups share similar life history characteristics and are therefore assumed to respond in a similar way to changing environmental factors (Maraun and Scheu 2000; Norton and Behan-Pelletier 2009).

\subsection{Statistical analysis}

Oribatid mite density, diversity and the proportion of parthenogenetic individuals and taxonomical subgroups were analysed by repeated measures analysis of variance (ANOVA) with the fixed factors region (Schwäbische Alb, Hainich-Dün, Schorfheide-Chorin) and forest type (coniferous, young beech, old beech, natural beech), and time $(2008,2011)$ as a repeated factor using $R$ version 2.14.1 ( $R$ 
Development Core Team 2011). Data on oribatid mite density were log-transformed to improve homoscedasticity.

To investigate the fluctuations of oribatid mite communities, the density of sexual and parthenogenetic species, and also for Enarthronota, Desmonomata, Phthiracaroidea, Tectocepheidae, sexual Oppiidae, parthenogenetic Oppiidae, Suctobelbidae, Poronota and 'Others' of the dataset of 2008 were subtracted from those of 2011 for each of the 48 plots. Algebraic signs were ignored since only the difference between the two years was of relevance for this study, i.e. all values were positive. These differences were then expressed as percentage of the mean of the respective group or taxon, i.e. sexual vs. parthenogenetic species, and of the respective taxonomical groups. These percentages were analysed by three-factorial analysis of variance (ANOVA) with the fixed factors region (Schorfheide-Chorin, Hainich-Dün, Schwäbische Alb), forest type (coniferous, young beech, old beech, natural beech) and reproductive mode (sex, parthenogenesis) or taxonomic group (Enarthronota, Desmonomata, Phthiracaroidea, Tectocepheidae, sexual Oppiidae, parthenogenetic Oppiidae, Suctobelbidae, Poronota, Others).

The relationship between oribatid mite communities and the factors region, forest type and time was analysed by principal components analysis (PCA) with species occurring in more than five samples using CANOCO 5 (Microcomputer Power, Ithaca, New York; Šmilauer and Lepš 2014). No rotation was used for the PCA. Subsequently, the coordinates 1-4 of the PCA were used in STATISTICA 11 (Statsoft, Tulsa, USA) for Discriminant Function Analyses (DFA) to inspect differences between treatment levels.

\section{Results}

\subsection{Total density and diversity}

Oribatid mite densities were similar in 2008 and 2011 in the Hainich-Dün and in the Schwäbische Alb, but in the Schorfheide-Chorin significantly lower in 2011 than in 2008 (region $\times$ time interaction; Fig. 1a, Table 1). Generally, oribatid mite densities were higher in coniferous forests $\left(89,967 \pm 68,877 \mathrm{ind} . / \mathrm{m}^{2}\right)$ than in the three beech forests $\left(51,855 \pm 39,195 \mathrm{ind} . / \mathrm{m}^{2}, 44,767 \pm 43,085 \mathrm{ind} . / \mathrm{m}^{2}\right.$ and 44,678 $\pm 32,070$ ind. $/ \mathrm{m}^{2}$ in young, old and natural beech forests, respectively) with differences being most pronounced in the Schwäbische Alb. Moreover, oribatid mite densities 
decreased in young and old beech forests and in coniferous forests but increased in natural beech forests from 2008 to 2011 (forest $\times$ type time interaction; Fig. 1b).
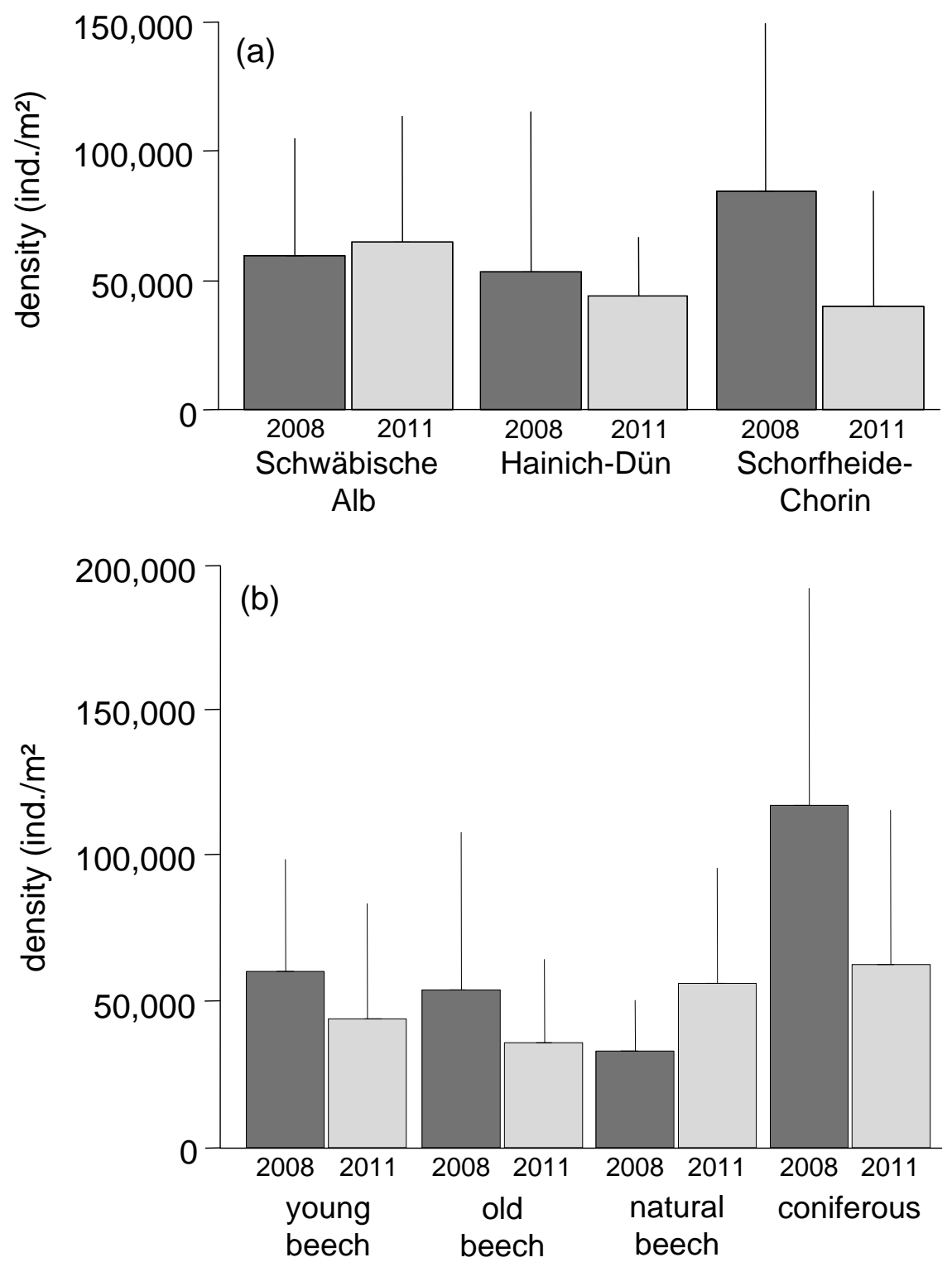

Fig. 1. Oribatid mite densities ( \pm SD) in 2008 and 2011 in (a) three regions in Germany (Schwäbische Alb, Hainich-Dün, Schorfheide-Chorin) and (b) the four management types, young managed beech forest (young beech), old managed beech forest (old beech), unmanaged natural beech forest (natural beech) and coniferous forest (coniferous).

Overall, 116 species of oribatid mites were recorded, 98 at each sampling date. Total species number decreased from Schwäbische Alb (87) to Schorfheide-Chorin (68) to Hainich-Dün (61) with on average 85 species in young beech, 82 in coniferous, 69 in natural and 63 in old beech forests. 
Average species number per sample was lower in 2011 than in 2008 in the Hainich-Dün (16.8 \pm 4.4 and $19 \pm 4.8$, respectively) and in the Schorfheide-Chorin (13.3 \pm 5.0 and $18.1 \pm 4.7$, respectively) but higher in the Schwäbische Alb (20.3 \pm 5.0 and $17.9 \pm 4.5$, respectively; region $\times$ time interaction, Table 1 ). Average species number per sample was higher in coniferous than in beech forests in the Schwäbische Alb $(23.9 \pm 3.5 \%, 16 \pm 2.7 \%, 16.3 \pm 3.8 \%$ and $20.3 \pm 4.8 \%$ in coniferous and young, old and natural beech forests, respectively) and SchorfheideChorin $(19.1 \pm 4.9 \%, 17.5 \pm 6.0 \%, 13.9 \pm 4.6 \%$ and $12.3 \pm 3.7$ in coniferous and young, old and natural beech forests, respectively), whereas in the Hainich-Dün the number of species was higher in beech as compared to coniferous forests (13.9 \pm $3.4,21.5 \pm 5.0,17.4 \pm 3.6$ and $18.8 \pm 3.6$ in coniferous and young, old and natural beech forests, respectively; region $\times$ forest type interaction).

\subsection{Dominance of taxonomic groups}

\subsubsection{Variation with time}

Dominance of most taxonomic groups did not vary significantly between the two sampling dates except for Poronota and Desmonomata which were more dominant in $2011(17.0 \pm 15.5 \%$ and $6.9 \pm 8.8 \%$, respectively) than in $2008(11.2 \pm 8.0 \%$ and $3.6 \pm 5.5 \%$, respectively; Table 1 ), and Suctobelbidae which were less dominant in the Schorfheide-Chorin in $2011(12.8 \pm 9.1 \%)$ than in $2008(25.0 \pm 13.3 \%$; time $\times$ region interaction)

\subsubsection{Variation between regions}

Overall, Oppiidae represented the most abundant taxon of oribatid mites in each of the three regions, but their dominance was significantly lower in the SchorfheideChorin $(26.8 \pm 23.1 \%)$ than in the Hainich-Dün $(40.6 \pm 15.4 \%)$ and the Schwäbische Alb (44.9 $\pm 18.8 \%$; Table 1$)$. The dominance of sexually reproducing Oppiidae was significantly lower $(1.4 \pm 2.9 \%, 27.7 \pm 15.6 \%$ and $34.1 \pm 19.8 \%$, respectively) and that of parthenogenetically reproducing Oppiidae was significantly higher in the Schorfheide-Chorin than in the Hainich-Dün and Schwäbische Alb $(25.5 \pm 23.4 \%$, $12.9 \pm 12.1 \%$ and $10.9 \pm 9.6 \%$, respectively). The dominance of Enarthronota significantly increased from the Schwäbische Alb $(3.7 \pm 4.7 \%)$ to the SchorfheideChorin $(8.6 \pm 9.4 \%)$ and the Hainich-Dün $(12.1 \pm 15.5 \%)$, whereas proportions of Desmonomata were significantly higher in Schorfheide-Chorin (11.0 $\pm 9.5 \%)$ than in the Schwäbische Alb $(2.1 \pm 4.3 \%)$ and Hainich-Dün $(2.7 \pm 3.6 \%)$. 


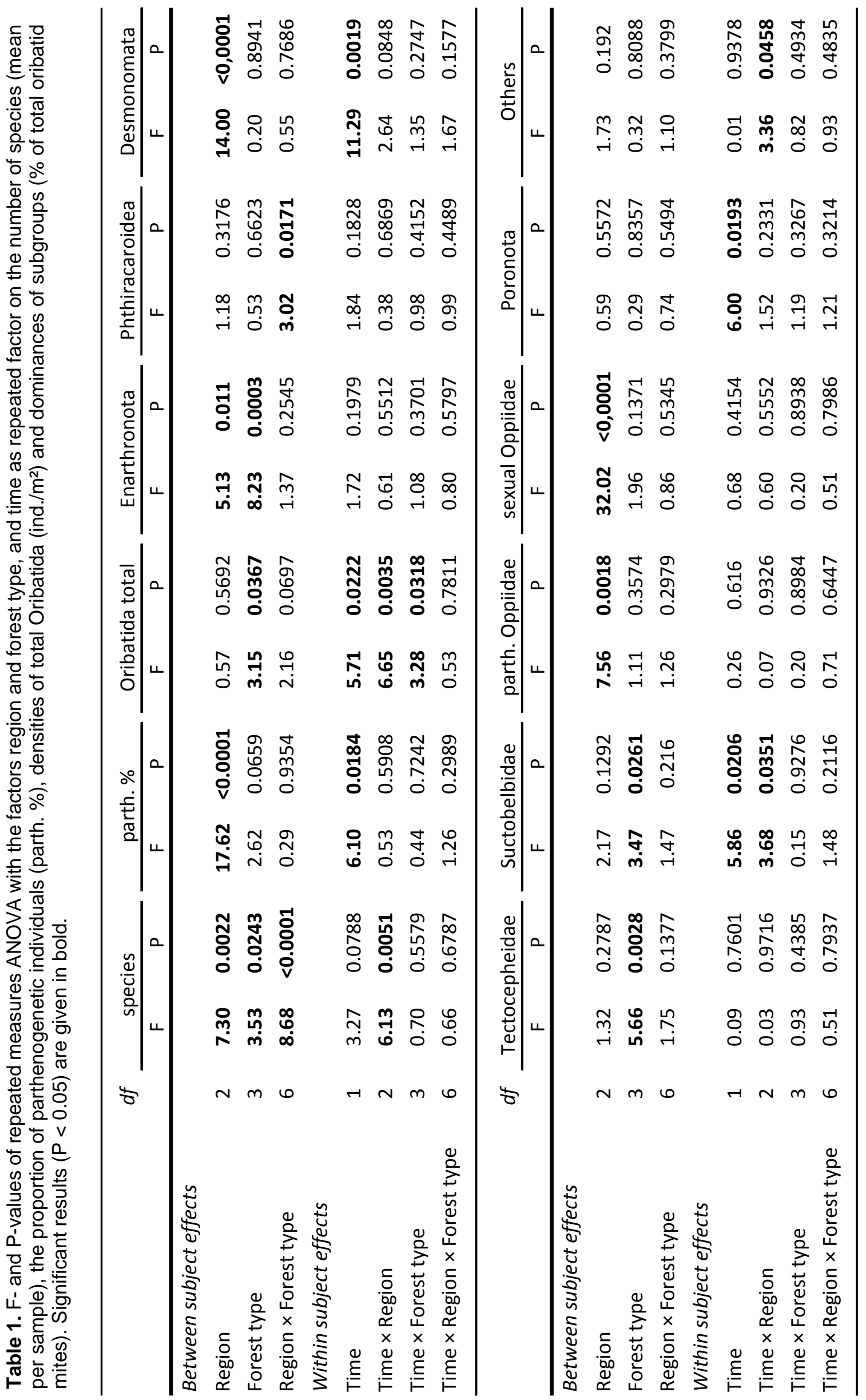




\subsubsection{Variations with forest type}

The dominance of Oppiidae was significantly lower in coniferous (25.6 $\pm 17.4 \%)$ as compared to the three beech forests ( $39.2 \pm 18.1 \%, 40.3 \pm 19.6 \%$ and $44.7 \pm$ $23.0 \%$ in young, old and natural beech forests, respectively), and this was mainly due to sexual species $(14.0 \pm 16.4 \%, 23.1 \pm 20.7 \%, 21.8 \pm 21.4 \%$ and $25.4 \pm 21.7 \%$ in coniferous and young, old and natural beech forests, respectively; Table 1). In contrast, the dominance of Enarthronota $(17.1 \pm 17.1 \%, 6.8 \pm 7.8 \%, 5.7 \pm 6.2 \%$ and $2.9 \pm 3.1 \%$ in coniferous and young, old and natural beech forests, respectively) and Tectocepheidae $(7.2 \pm 8.2 \%, 1.7 \pm 2.9 \%, 1.1 \pm 2.8 \%$ and $2.6 \pm 5.8 \%$ in coniferous and young, old and natural beech forests, respectively) was considerably higher in coniferous as compared to the three beech forests. The dominance of Suctobelbidae also differed between forest types and decreased from coniferous $(20.9 \pm 9.8 \%)$ to young $(18.9 \pm 10.1 \%)$ to old $(14.9 \pm 9.8 \%)$ to natural beech forests $(13.6 \pm 12.4 \%)$. Also, the dominance of Phthiracaroidea differed between forest types, but this varied between regions; in the Schwäbische Alb it was highest in old beech forests $(7.2 \pm 5.2 \%, 13.5 \pm 10.8 \%, 23.3 \pm 10.4 \%$ and $7.1 \pm 7.9 \%$ in coniferous and young, old and natural beech forests, respectively), in the Hainich-Dün in natural beech forests $(6.1 \pm 8.8 \%, 9.9 \pm 7.2 \%, 7.5 \pm 7.7 \%, 16.6 \pm 12.3 \%$ in coniferous and young, old and natural beech forests, respectively) and in the SchorfheideChorin in coniferous forests $(13.4 \pm 17.4 \%, 6.2 \pm 6.2 \%, 6.9 \pm 6.8 \%$ and $8.9 \pm 4.6 \%$ in coniferous and young, old and natural beech forests, respectively; region $\times$ forest type interaction).

\subsubsection{Variations with reproductive mode}

The percentage of parthenogenetic individuals was significantly higher in Schorfheide-Chorin than in Hainich-Dün and Schwäbische Alb (Fig. 2a, Table 1), and significantly lower in 2011 than in 2008 (53.6 $\pm 23.2 \%$ and $62.3 \pm 21.5 \%$, respectively). Further, the percentage of parthenogenetic individuals significantly differed between forest types with a higher percentage in coniferous forests than in the three beech forests (Fig. 2b). 

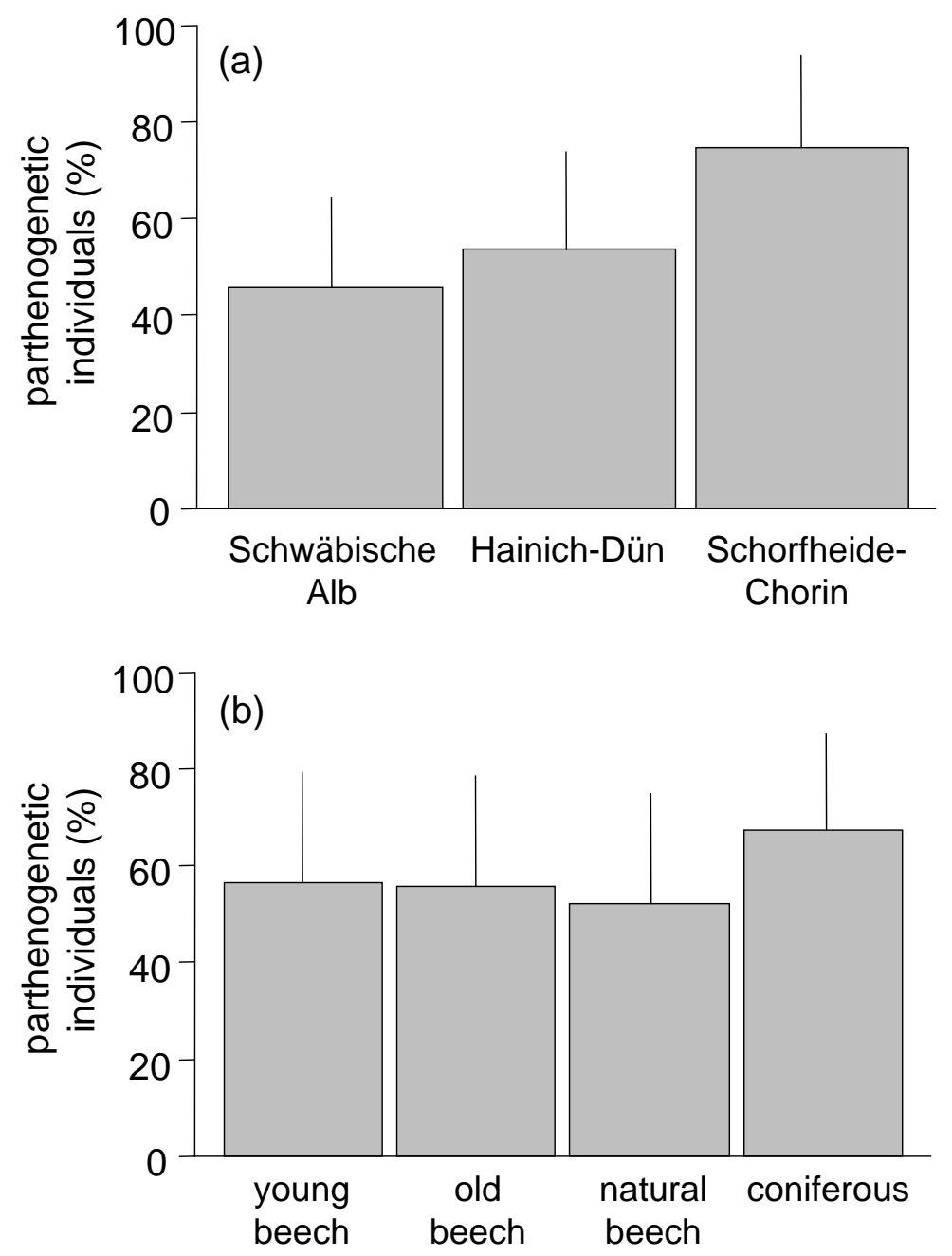

Fig. 2. Relative density (\% of total $\pm S D$ ) of parthenogenetic species in (a) three regions in Germany (Schwäbische Alb, Hainich-Dün, Schorfheide-Chorin), and (b) the four forest types, young managed beech forest (young beech), old managed beech forest (old beech), unmanaged natural beech forest (natural beech) and coniferous forest (coniferous).

\subsection{Temporal fluctuations}

Temporal fluctuations did not significantly differ between the taxonomic groups $\left(\mathrm{F}_{8,324}=1.39, \mathrm{P}=0.20\right)$, but were significantly higher in parthenogenetic $(98.0 \pm$ $100.7 \%)$ than in sexual species $\left(61.1 \pm 55 \% ; F_{1,72}=4.61, P=0.035\right)$. Further, temporal fluctuations of oribatid mites were positively correlated with the percentage of parthenogenetic individuals (linear regression; $r^{2}=0.18$, $t$-value $=3.17, F_{1,46}=$ 10.02, $P=0.0028)$.

\subsection{Variations in community structure}

Oribatid mite communities differed significantly between each of the three regions (DFA: Wilk's Lambda $=0.20, F_{18,180}=27.95, P<0.0001$; Mahalanobis Distance 
between Schorfheide-Chorin and Schwäbische Alb 13.38, $F_{4,90}=51.78, P<0.0001$, between Schorfheide-Chorin and Hainich-Dün 8.81, $F_{4,90}=34.12, P<0.0001$, and between Hainich-Dün and Schwäbische Alb 3.24, F4,90=12.55, P $<0.0001$; Fig. 3).

Oribatid mite communities also significantly differed between the forest types separating coniferous from the three beech forests (DFA: Wilk's Lambda $=0.43$, $F_{12,235}=7.47, P<0.0001 ;$ Mahalanobis Distance between coniferous and young beech 4.65, $F_{4,89}=13.49, P<0.0001$, coniferous and old beech 6.40, $F_{4,89}=18.56$, $\mathrm{P}<0.0001$, coniferous and natural beech 8.49, $\mathrm{F}_{4,89}=24.63, \mathrm{P}<0.0001$ ).

Oribatid mite communities did not differ between 2008 and 2011 (DFA: Wilk's Lambda $\left.=0.95, F_{4,91}=1.13, P=0.35\right)$.

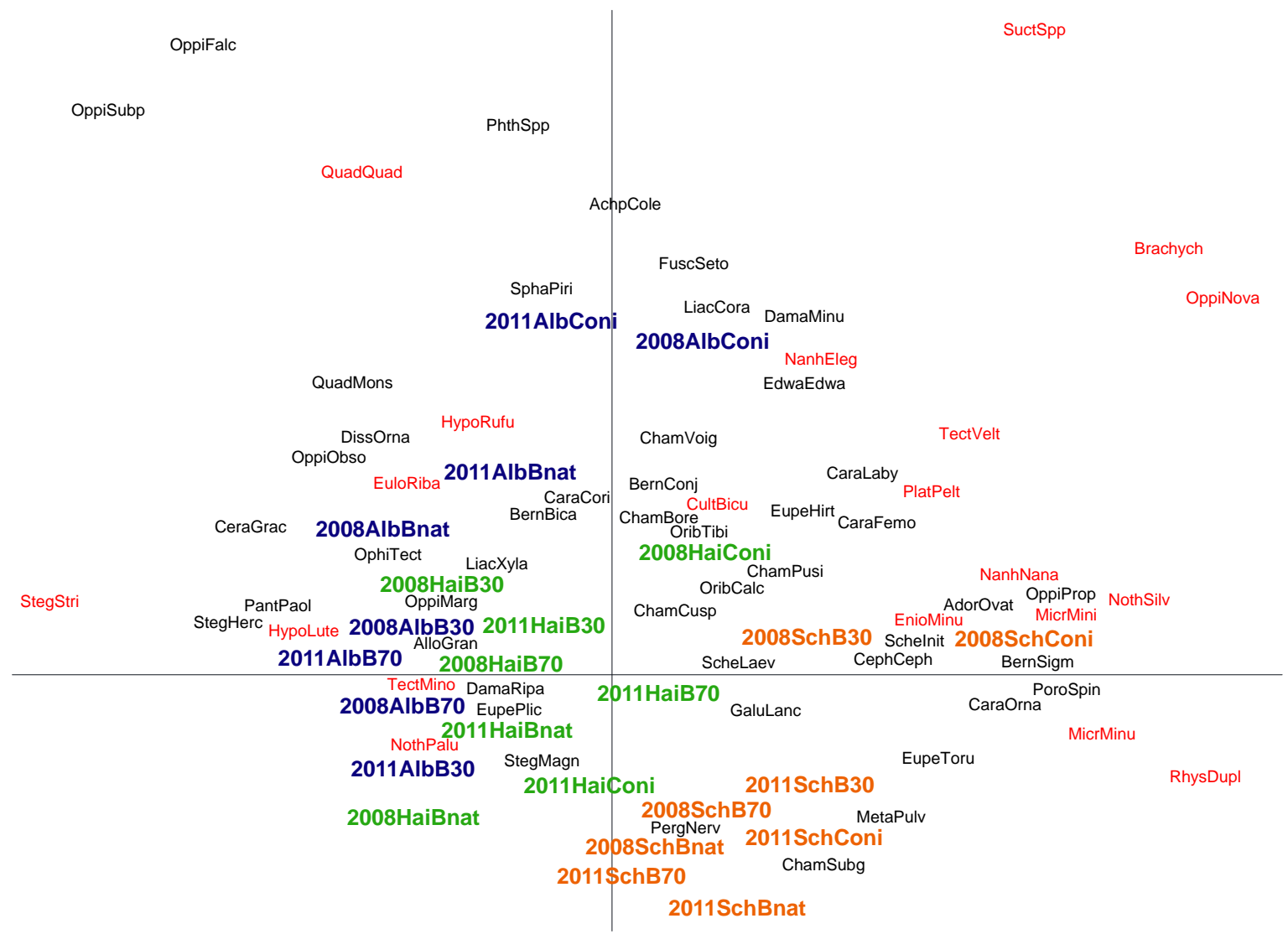

Fig. 3: Principal components analysis (PCA) of oribatid mite species in different forest types in three regions in Germany in 2008 and 2011. Length of gradient 2.7; eigenvalues of 0.23 and 0.20 for the first and second axis, respectively. Alb = Schwäbische Alb; Hai = Hainich-Dün; Sch = SchorfheideChorin; B30 = young managed beech forest; $\mathrm{B} 70=$ old managed beech forest; $B$ nat $=$ unmanaged natural beech forest; Conif = coniferous forest. Parthenogenetic species are marked red. For full names of species and their abbreviations see Table 2. 


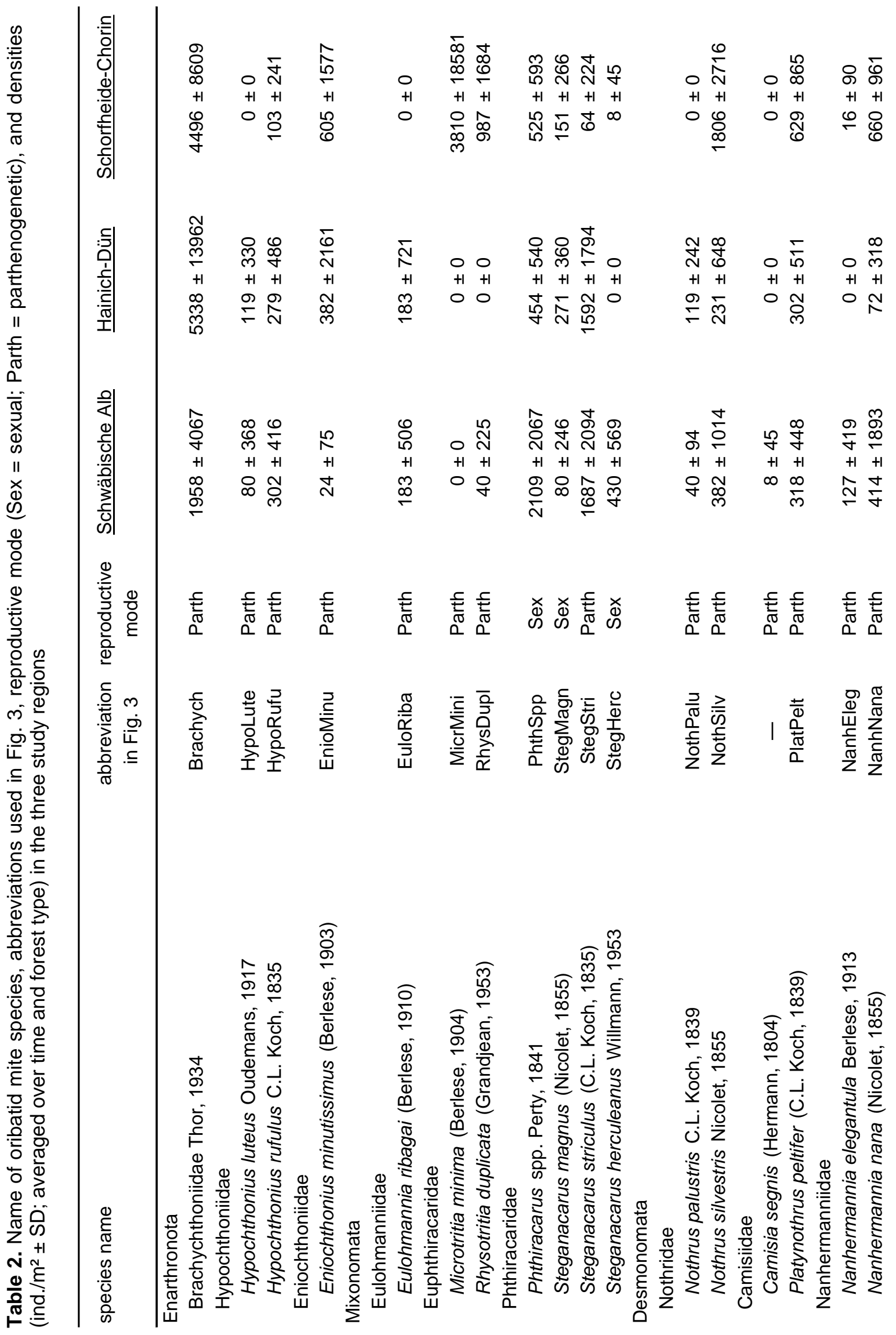




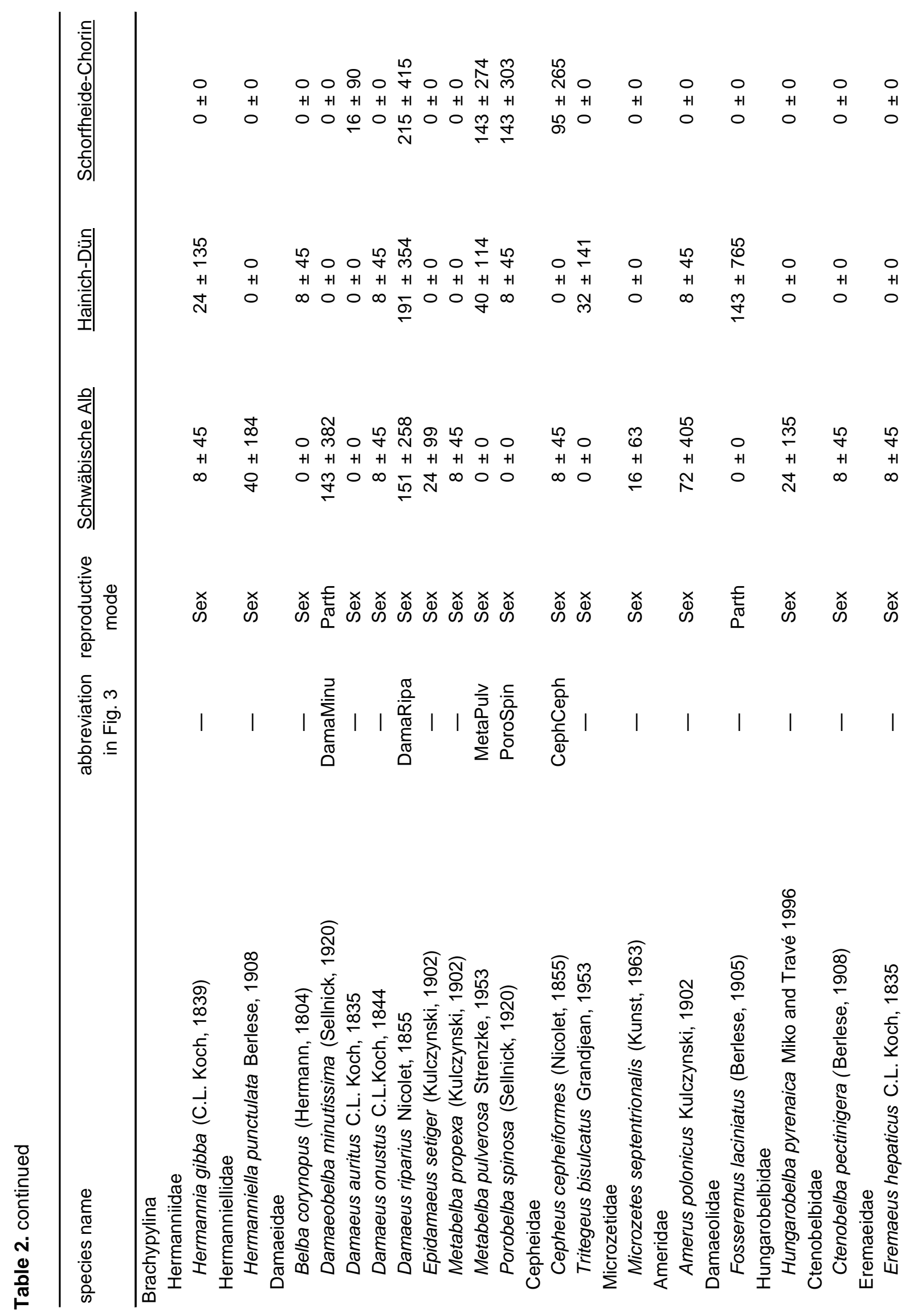




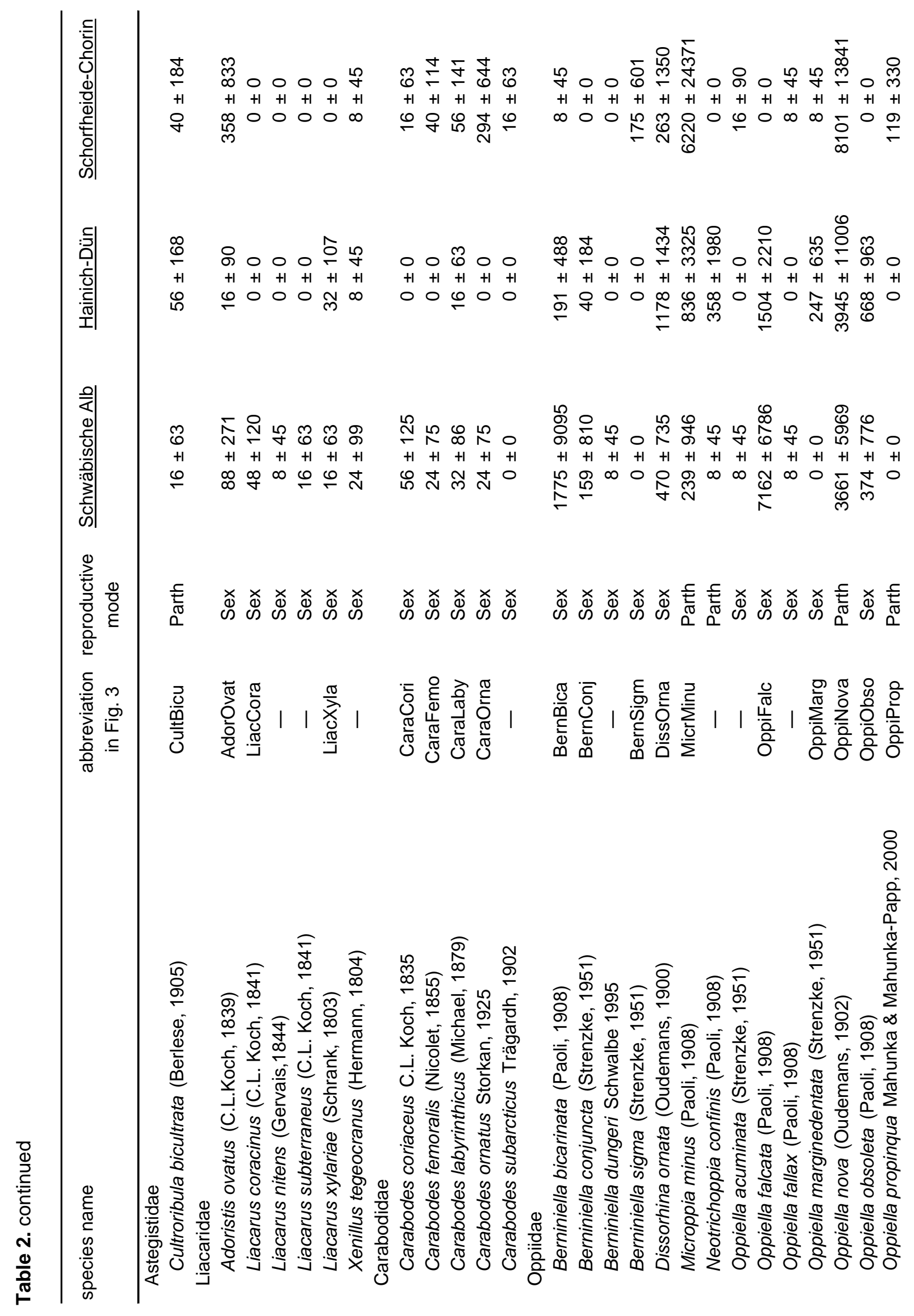




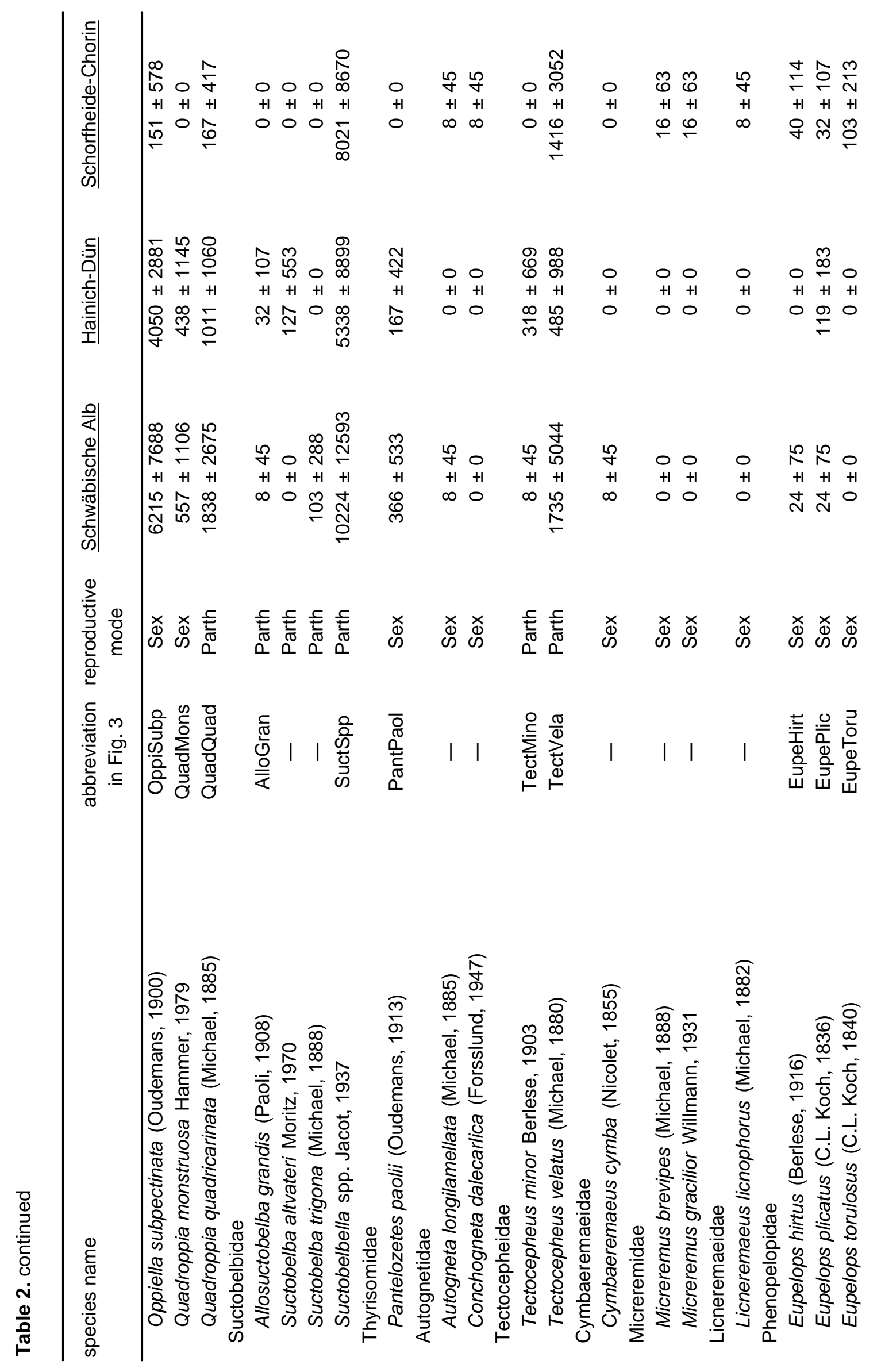




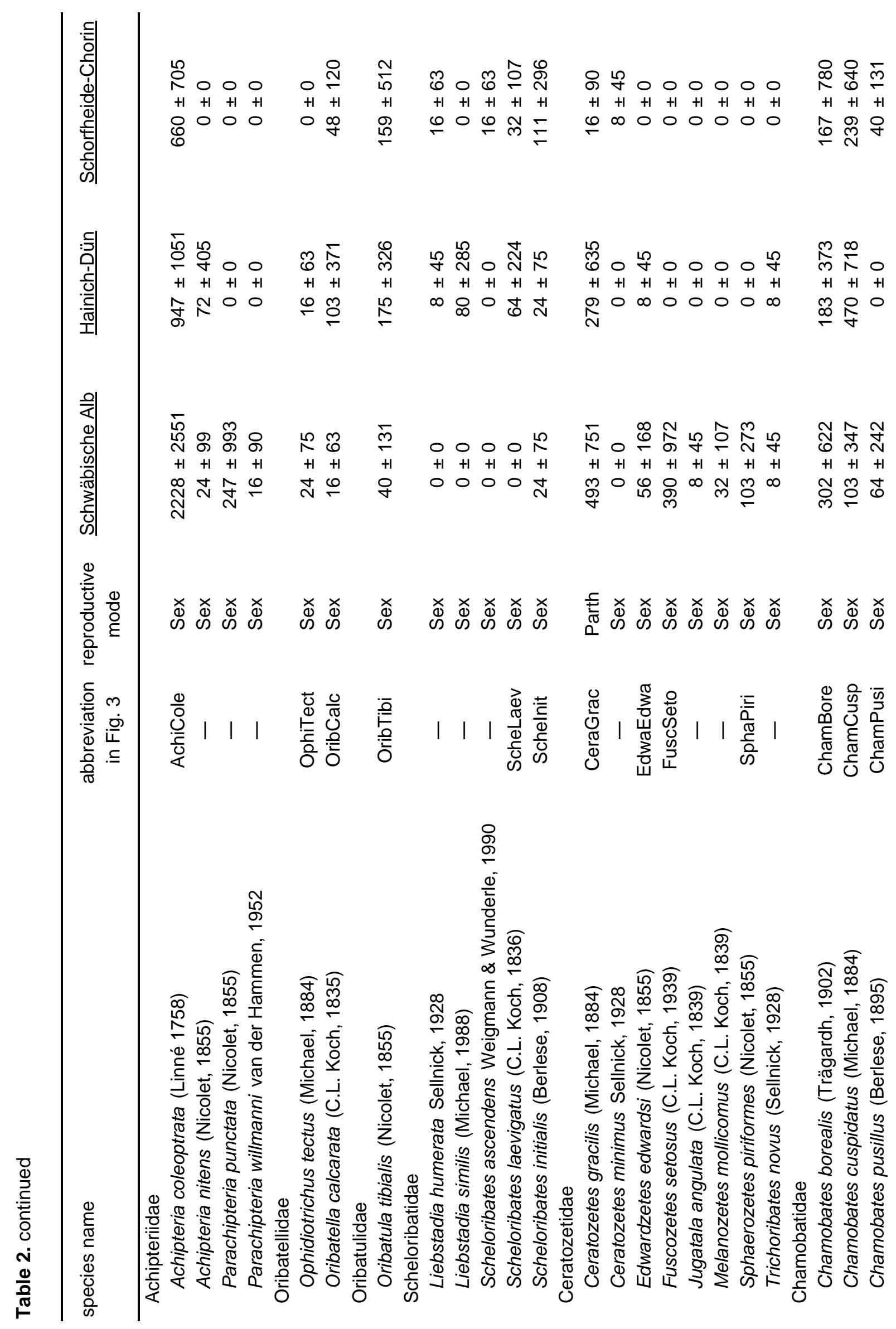




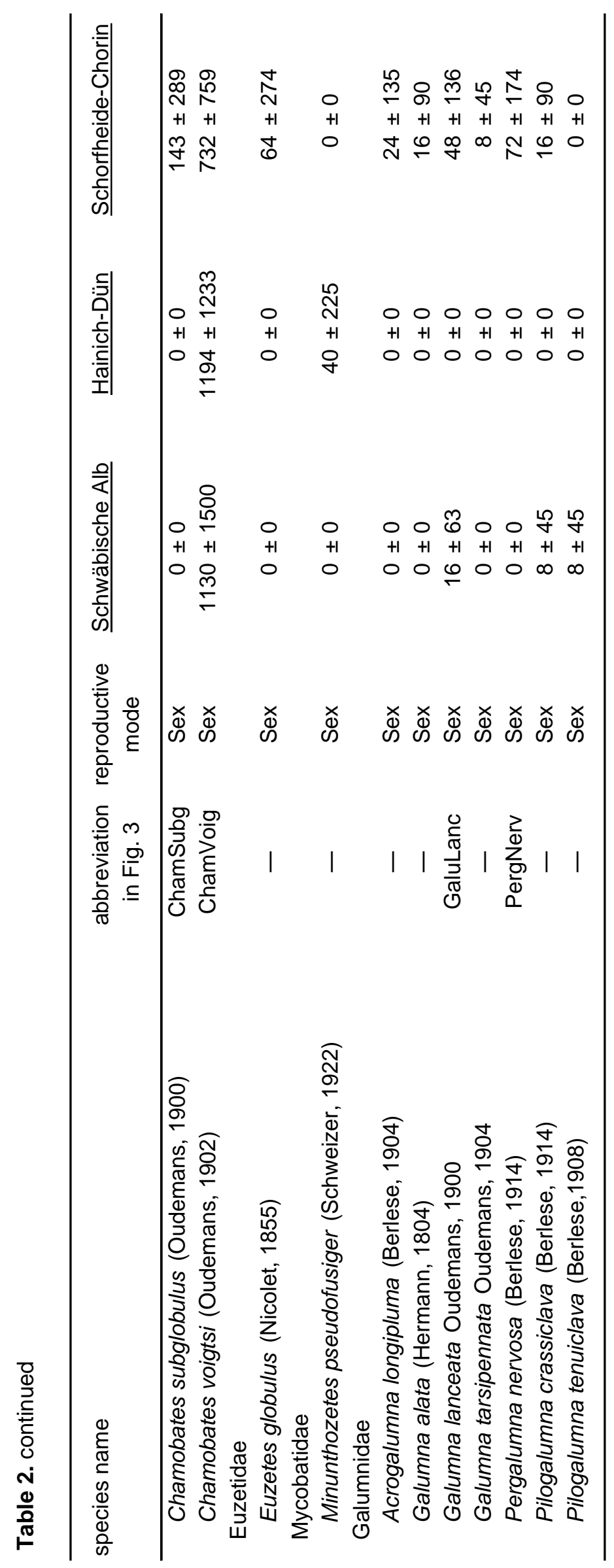




\section{Discussion}

\subsection{Density, species richness and community structure}

Oribatid mite densities did not differ between the three regions studied and ranged between 49,000 to $62,000 \mathrm{ind} / \mathrm{m}^{2}$ (averaged over all forest types), being in the range typically recorded from soils of mesophilic forests of the temperate zone (Maraun et al. 2003, Maraun and Scheu 2000). Remarkably, oribatid mite communities of the Hainich-Dün and Schwäbische Alb were dominated by Oppiidae, especially sexual species such as Oppiella falcata, Berniniella bicarinata, Berniniella conjuncta, Dissorhina ornata, Oppiella obsoleta, Quadroppia monstruosa which were rare or absent in the Schorfheide-Chorin. In contrast, parthenogenetic Oppiidae, e.g. Oppiella nova and Microppia minus, dominated in the SchorfheideChorin. Also, the parthenogenetic Desmonomata species Nanhermannia nana, Nothrus silvestris and Platynothrus peltifer were more abundant in the SchorfheideChorin than in the other regions.

Oribatid mite densities were generally higher in coniferous than in the beech forests, a pattern recorded previously (Lindo and Visser 2004; Sylvain and Buddle 2010; Walter and Proctor 2013). Differences in community structure between forest types were less pronounced than between regions and mainly separated coniferous forests from the three beech forests. Suctobelbella spp., Tectocepheus velatus and Brachychthoniidae dominated in coniferous forests whereas species of Oppiidae, Poronota and Phthiracaroidea were more abundant in beech forests. Similar patterns were reported earlier (Maraun and Scheu 2000). Oribatid mite community structure was surprisingly constant between 2008 and 2011, indicating low species turnover in time and suggesting that soil animal communities are remarkably stable. However, mainly due to the decline of the predominantly parthenogenetic Suctobelbidae oribatid mite density significantly varied between the two sampling dates in the Schorfheide-Chorin.

\subsection{Parthenogenesis and temporal fluctuations}

The relative abundance of parthenogenetic individuals varied significantly between forest types. Coniferous forests favoured parthenogenetic species presumably due to higher amounts of organic material accumulating on the forest floor as compared to beech forests. Higher amounts of organic material promote fungal growth resulting in increased resource availability (Blair et al. 1994). 
Accumulation of litter might be a consequence of low numbers of macrodecomposers such as earthworms due to lower $\mathrm{pH}$ of coniferous forest soils (Maraun and Scheu 2000). According to SRTS, higher amounts of resources, mediated by the absence or reduction of macrofauna activity, favours parthenogenetic reproduction. Generally, primary decomposers, in particular parthenogenetic species, such as Platynothrus peltifer, Nanhermannia nana, Nothrus palustris, Tectocepheus velatus, dominate in acidic coniferous forests, whereas sexual species dominate in tropical, subtropical and base-rich forests (Maraun et al. 2012; BM Fischer et al. 2014; Mumladze et al. 2015).

Furthermore, the dominance of parthenogenetic species varied significantly with region; densities in the Schorfheide-Chorin markedly exceeded those of the other two regions. A number of factors might be responsible for the more favourable conditions for parthenogenetic species in the Schorfheide-Chorin. On one hand, similar to coniferous forests, the sandy soils of the Schorfheide-Chorin are of low $\mathrm{pH}$ (M Fischer et al. 2010) which is associated with thick organic layers and low earthworm density (Klarner 2013). This indicates that, similar to coniferous forests, high amounts of resources favour parthenogenetic species. Additionally, the continental climate of the Schorfheide-Chorin with low precipitation and dry summers, likely is associated with high mortality due to density-independent factors, supporting the prediction of the SRTS that abiotic forcing favours parthenogenetic species. On the other hand, increasing elevation from north (Schorfheide-Chorin) to south (Schwäbische Alb) coincided with an increase in parthenogenetic species which is in agreement with studies investigating altitudinal gradients (Maraun et al. 2013; BM Fischer et al. 2014). It has been demonstrated that resource quality declines with altitude (Wilcke et al. 2008), thereby increasing resource control of detritivore species (Maraun et al. 2013). Again, this is consistent with the prediction of the SRTS that the advantage of sexual reproduction increases with increasing resource control, i.e. density-dependent factors. However, historical factors also may have contributed to the increased dominance of parthenogenetic species in the Schorfheide-Chorin, since, as compared to the Hainich-Dün and Schwäbische Alb, the Schorfheide-Chorin was more heavily glaciated and this may have favoured parthenogenetic species (Zaitsev et al. 2013). Parthenogenetically reproducing species vigorously invade new habitats due to faster reproduction and the ability to successfully colonize new habitats by single individuals, and therefore often 
dominate at early stages, but are replaced by sexually reproducing species at later stages of succession (Ryabinin and Pan'kov 1987; Norton and Palmer 1991). Since colonization of new habitats by oribatid mite communities is slow due to low dispersal ability (Lehmitz et al. 2010) and long generation times, establishment of climax communities in even small areas may take decades (Hågvar et al. 2009; Farská et al. 2014). Accordingly, the oribatid mite community of formerly glaciated regions such as the Schorfheide-Chorin still may not have reached its ultimate composition.

Temporal fluctuations of parthenogenetic species exceeded those of sexuals, supporting our hypothesis that parthenogenetic species are more heavily exposed to density-independent population control. Fluctuations in both parthenogenetic and sexual species were most pronounced in the Schorfheide-Chorin, presumably due to harsher climatic conditions in this region. Similar results were found when analysing mortality and recovery rates of parthenogenetic and sexual species in a drought experiment in Sweden (Lindberg and Bengtsson 2004). Oribatid mites were more sensitive to desiccation when reproducing via parthenogenesis but recovered more quickly reflecting stronger population variations in time in parthenogenetic species.

\subsection{Conclusion}

Overall, the results suggest that the structure of oribatid mite communities of forests in temperate regions varies significantly in space, but is rather stable in time. Temporal fluctuations in population density were more pronounced in parthenogenetic as compared to sexual species suggesting that the latter are more heavily controlled by density-dependent factors presumably predominantly by resource availability and quality. In contrast, parthenogenetic species are more heavily affected by density-independent factors, such as frost in winter and drought in summer, and flourish at sites were resources are plentiful and easily available such as coniferous forests and regions with more acidic soils and thick organic layers supporting prediction of the SRTS.

\section{Acknowledgements}

We thank the managers of the three Exploratories, Kirsten Reichel-Jung, Swen Renner, Katrin Hartwich, Sonja Gockel, Kerstin Wiesner, and Martin Gorke for their work in maintaining the plot and project infrastructure; Christiane Fischer and 
Simone Pfeiffer for giving support through the central office, Michael Owonibi for managing the central data base, and Markus Fischer, Eduard Linsenmair, Dominik Hessenmöller, Jens Nieschulze, Daniel Prati, Ingo Schöning, François Buscot, Ernst-Detlef Schulze, Wolfgang W. Weisser and the late Elisabeth Kalko for their role in setting up the Biodiversity Exploratories project. The work has been (partly) funded by the DFG Priority Program 1374 "Infrastructure-Biodiversity-Exploratories" (MA2461/7-2). Field work permits were issued by the responsible state environmental offices of Baden-Württemberg, Thüringen, and Brandenburg (according to §72 BbgNatSchG). We thank Georgia Erdmann, Bernhard Eitzinger, Bernhard Klarner, Olga Ferlian for assistance in the field. 


\section{References}

Beckmann M (1988) Die Entwicklung der Bodenmesofauna eines RuderalÖkosystems und ihre Beeinflussung durch Rekultivierung: 1.Oribatiden (Acari: Oribatei). Pedobiologia 31:391-408

Behan-Pelletier VM (1989) Limnozetes (Acari: Oribatida: Limnozetidae) of northeastern North America. Can Entomol 121:453-506

Behan-Pelletier VM, Bissett B (1994) Oribatida of Canadian peatlands. Mem Entomol Soc Canada 169:73-88

Bell G (1982) The masterpiece of nature: the evolution and genetics of sexuality. University of California Press, Berkeley

Blair JM, Parmelee RW, Wyman RL (1994) A comparison of the forest invertebrate communities of four types in the northeastern U.S.. Pedobiologia 38:146-160

Cianciolo JM, Norton RA (2006) The ecological distribution of reproductive mode in oribatid mites, as related to biological complexity. Exp Appl Acarol 40:1-25

Domes K, Scheu S, Maraun M (2007) Resources and sex: Soil re-colonization by sexual and parthenogenetic oribatid mites. Pedobiologia 51:1-11

Erdmann G, Floren A, Linsenmair KE, Scheu S, Maraun M (2006) Little effect of forest age on oribatid mites on the bark of trees. Pedobiologia 50:433-441

Erdmann G, Scheu S, Maraun M (2012) Regional factors rather than forest type drive the community structure of soil living oribatid mites (Acari, Oribatida). Exp Appl Acarol 57:157-169

Farská J, Prejzková K, Starý J, Rusek J (2014) Soil microarthropods in nonintervention montane spruce forest regenerating after bark-beetle outbreak. Ecol Res 29:1087-1096

Fischer BM, Meyer E, Maraun M (2014) Positive correlation of trophic level and proportion of sexual taxa of oribatid mites (Acari: Oribatida) in alpine soil systems. Exp Appl Acarol 63:465-79

Fischer BM, Schatz H, Maraun M (2010) Community structure, trophic position and reproductive mode of soil and bark-living oribatid mites in an alpine grassland ecosystem. Exp Appl Acarol 52:221-37

Fischer M, Bossdorf O, Gockel S, Hänsel F, Hemp A, Hessenmöller D, Korte G, Nieschulze J, Pfeiffer S, Prati D, Renner S, Schöning I, Schuhmacher U, Wells K, Buscot F, Kalko EKV, Linsenmair KE, Schulze ED, Weisser WW (2010) Implementing large-scale and long-term functional biodiversity research: The Biodiversity Exploratories. Basic Appl Ecol 11:473-485

Fisher RA (1930) The Genetical Theory of Natural Selection. Clarendon Press, Oxford

Hågvar S, Solhøy T, Mong CE (2009) Primary succession of soil mites (Acari) in a Norwegian glacier foreland, with emphasis on oribatid species. Arct Antarct Alp Res 41:219-227

Hamilton WD 1980 Sex versus non-sex versus parasite. Oikos 35:282-290 
Heethoff M, Domes K, Laumann M, Maraun M, Norton RA, Scheu S (2007) High genetic divergences indicate ancient separation of parthenogenetic lineages of the oribatid mite Platynothrus peltifer (Acari, Oribatida). J Evolution Biol 20:392-402

Illig J, Norton RA, Scheu S, Maraun M (2010) Density and community structure of soil- and bark-dwelling microarthropods along an altitudinal gradient in a tropical montane rainforest. Exp Appl Acarol 52:49-62

Jaenike $J$ (1978) A hypothesis to account for the maintenance of sex within populations. Evol Theory 3:191-194

Karg W (1967) Synökologische Untersuchungen von Bodenmilben aus forstwirtschaftlich und landwirtschaftlich genutzten Böden. Pedobiologia 7:198214

Klarner B (2013) Changes in trophic structure of decomposer communities with land use in Central European temperate forests. Dissertation, University of Göttingen.

Lehmitz R, Russell D, Hohberg K, Christian A, Xylander WER (2011) Wind dispersal of oribatid mites as a mode of migration. Pedobiologia 54:201-207

Lindberg N, Bengtsson J (2005) Population responses of oribatid mites and collembolans after drought. Appl Soil Ecol 28:163-174

Lindo Z, Visser S (2004) Forest floor microarthropod abundance and oribatid mite (Acari: Oribatida) composition following partial and clear-cut harvesting in the mixedwood boreal forest. Can J For Res 34:998-1006

Macfadyen A (1961) Improved funnel-type extractors for soil arthropods. J Anim Ecol 30:171-184

Maraun M, Fronczek S, Marian F, Sandmann D, Scheu S (2013) More sex at higher altitudes: Changes in the frequency of parthenogenesis in oribatid mites in tropical montane rain forests. Pedobiologia 56:185-190

Maraun M, Heethoff M, Scheu S, Norton RA, Weigmann G, Thomas RH (2003) Radiation in sexual and parthenogenetic oribatid mites (Oribatida, Acari) as indicated by genetic divergence of closely related species. Exp Appl Acarol 29:265-77

Maraun M, Norton RA, Ehnes RB, Scheu S, Erdmann G (2012) Positive correlation between density and parthenogenetic reproduction in oribatid mites (Acari) supports the structured resource theory of sexual reproduction. Evol Ecol Res 14:311-323

Maraun M, Salamon JA, Schneider K, Schaefer M, Scheu S (2003) Oribatid mite and collembolan diversity, density and community structure in a moder beech forest (Fagus sylvatica): effects of mechanical perturbations. Soil Biol Biochem 35:1387-1394

Maraun M, Scheu S (2000) The structure of oribatid mite communities (Acari, Oribatida): patterns, mechanisms and implications for future research. Ecography 23:374-383

Maynard Smith J (1968) Evolution in sexual and asexual populations. Am Nat 102:469-473

Maynard Smith J (1971) What use is sex? J Theor Biol 30:319-335 
Muller HJ (1964) The relation of recombination to mutational advance. Mutat Res $1: 2-9$

Mumladze L, Murvanidze M, Maraun M, Salakaia M (2015) Oribatid mite communities along an elevational gradient in Sairme gorge (Caucasus). Exp Appl Acarol 66:41-51

Norton RA, Behan-Pelletier VM (2009) Suborder Oribatida. In: Krantz GW, Walter DE (eds) A Manual of Acarology, 3rd edition, Texas Tech University Press, Lubbock, pp 124-232

Norton RA, Kethley J, Johnston DE, O'Connor B (1993) Phylogenetic perspectives on genetic systems and reproductive modes of mites. In: Wrensch DL, Ebbert MA (eds) Evolution and Diversity of Sex Ratio in Insect and Mites, Chapman and Hall Publ., New York, pp 8-99

Norton RA, Palmer S (1991) The distribution, mechanisms and evolutionary significance of parthenogenesis in oribatid mites. In: Schuster R, Murphy PW (eds) The Acari: Reproduction, Development and Life-History Strategies, Chapman and Hall Publ., London, pp 107-136

Norton RA, Sillman DY (1985) Impact of oily waste application on the mite community of an arable soil. Exp Appl Acarol 1:287-305

Palmer S, Norton RA (1991) Taxonomic, geographic and seasonal distribution of thelytokous parthenogenesis in the Desmonomata (Acari: Oribatida). Exp Appl Acarol 12:67-81

Ryabinin NA, Pan'kov AN (1987) The role of parthenogenesis in the biology of oribatid mites. Ekologiya (USSR) 4:62-64

Šmilauer P, Lepš J (2014) Multivariate Analysis of Ecological Data using CANOCO 5. Cambridge University Press, Cambridge

Schaefer I, Norton RA, Scheu S, Maraun M (2010) Arthropod colonization of land Linking molecules and fossils in oribatid mites (Acari, Oribatida). Mol Phylogenet Evol 57:113-121

Scheu S, Drossel B (2007) Sexual reproduction prevails in a world of structured resources in short supply. Proc R Soc B 274:1225-1231

Segers H (2008) Global diversity of rotifers (Rotifera) in freshwater. Hydrobiologia 595:49-59

Sylvain ZA, Buddle CM (2010) Effects of forest stand type on oribatid mite (Acari: Oribatida) assemblages in a southwestern Quebec forest. Pedobiologia 53: 321-325

Walter DE, Proctor HC (2013) Mites: Ecology, Evolution, and Behaviour, 2nd edn. Springer, Berlin

Weigmann G (2006) Hornmilben (Oribatida). In: Dahl, F. (ed), Die Tierwelt Deutschlands 76 Goecke \& Evers, Keltern

Weismann A (1889) Essays upon Heredity and Kindred Biological Problems, translated by Poulton EB, Schonland S, Shipley AE, Clarendon Press, Oxford

White MJD (1978) Modes of Speciation. Freeman, San Francisco 
Wilcke W, Oelmann Y, Schmitt A, Valarezo C, Zech W, Homeier J (2008) Soil properties and tree growth along an altitudinal transect in Ecuadorian tropical montane forest. J Plant Nutr Soil Sc 171:220-230

Zaitsev AS, Straalen NM, Berg MP (2013) Landscape geological age explains large scale spatial trends in oribatid mite diversity. Landscape Ecol 28:285-296 
ChAPTER 4

The effect of root-trenching on oribatid mite communities in temperate forests

Christian Bluhm, Stefan Scheu, Mark Maraun

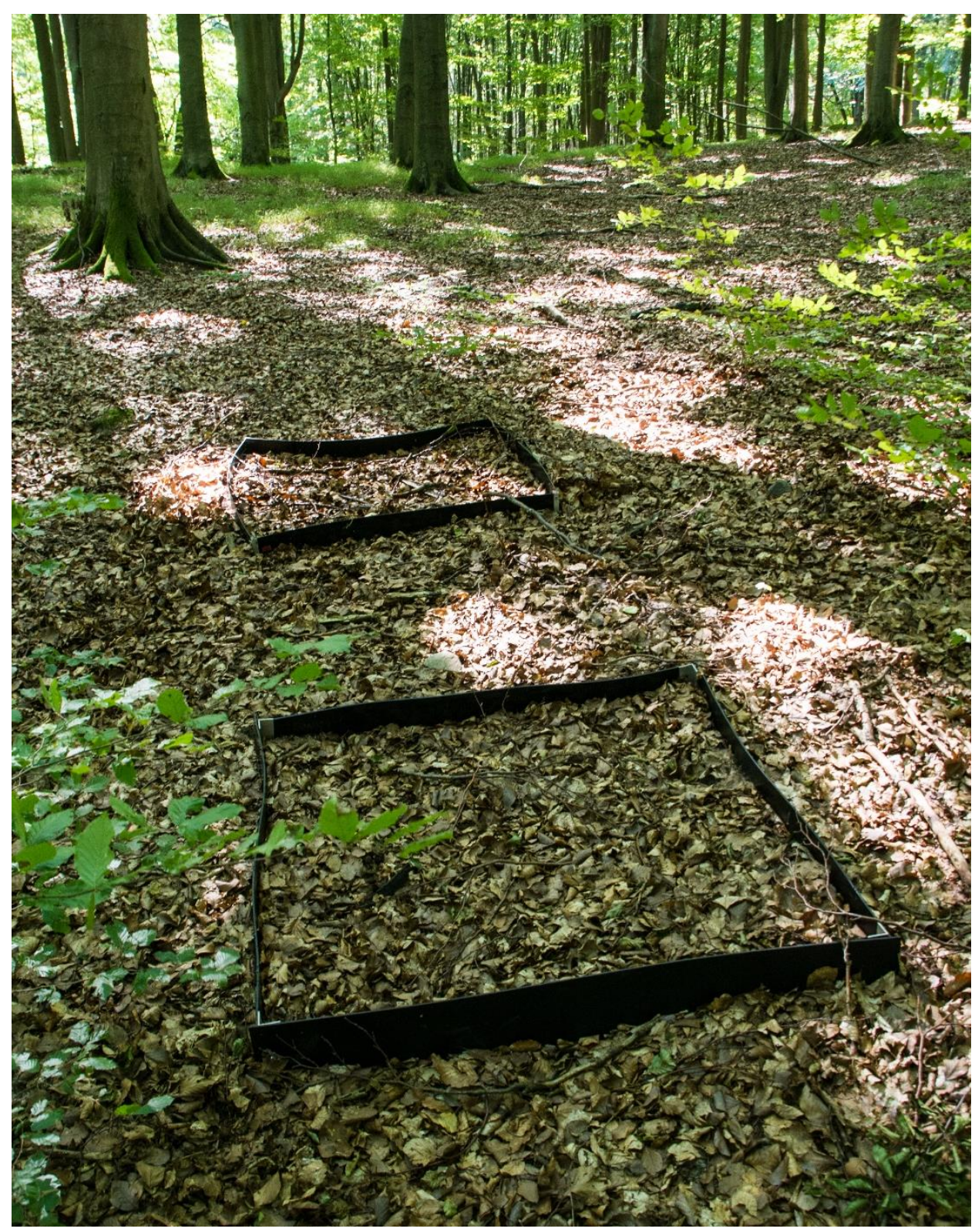




\begin{abstract}
Recently, evidence for the importance of root-derived carbon input for soil animal food webs has been provided, however, the exact pathway how the carbon enters the below-ground food web is still unknown. In the present study, we investigated density and community structure of oribatid mites after cutting plant root mediated carbon input by root-trenching in deciduous and coniferous forests of two regions in Germany (Hainich-Dün, Schorfheide-Chorin). We hypothesized that those oribatid mite species which are predominantly fueled by the root-derived carbon pathway decrease in abundance whereas those primary fueled by the litter pathway, such as primary decomposers remain unaffected. We furthermore expected soil-living species to be more affected than litter-living species as fine roots and ectomycorrhizal fungi predominantly colonize the upper mineral soil. One year after the root-trenching, total oribatid mite density tended to decrease in Hainich-Dün but remained unaffected in Schorfheide-Chorin. In Hainich-Dün, in accordance with our hypothesis, root-trenching predominantly reduced densities of soil-living oribatid mites which was in contrast to Schorfheide-Chorin where only litter-living species were affected. Oribatid mite community structure was not significantly affected by root-trenching. Overall, the results suggest that only few (if any) oribatid mite species exclusively exploit root-derived carbon resources, however, some species presumably directly or indirectly benefit from root resources including primary decomposers. Furthermore, the results suggest that the relevance of root-derived carbon varies with soil structure as indicated by the different response in the two investigated regions, being more intense where litter accumulation is low. Generally, the rather weak response to the elimination of root-derived carbon input probably was related to soil organic matter resources buffering reduced resource input by roots and by roots cut by trenching and serving as additional food for the decomposer food web.
\end{abstract}

Key words: Oribatida; root-trenching; root-derived resources; temperate forests 


\section{Introduction}

Traditionally, the input of leaf litter has been assumed to be the major carbon source for soil animal food webs (Schlesinger 1977; Cebrian 1999), however, recent studies have demonstrated that the input of root-derived carbon has been largely underestimated (Pollierer et al. 2007; Gilbert et al. 2014). By using stable isotopes (i.e. ${ }^{13} \mathrm{C}$ ), carbon fluxes could be followed from trees into the soil system indicating that many soil animals incorporate substantial amounts of root-derived carbon. However, the exact pathway how this carbon enters the below-ground food web still is unknown (Pollierer et al. 2007).

Depending on the plant species involved and also on season, $10-63 \%$ of the photosynthetically fixed carbon is allocated to the roots (Kuzyakov and Domanski 2000; Litton et al. 2007) and part of this carbon enters the soil food web via different pathways. Beside feeding directly on roots (e.g. by nematodes and insect larvae; Bonkowski et al. 2009), root-derived carbon presumably enters the soil food web via animals feeding on mycorrhizal fungi or via feeding on microorganisms that incorporated root exudate carbon (Högberg et al. 2010; Ruf et al. 2006). Root exudates serve as an easily digestible carbon resource for microorganisms and are preferred compared to recalcitrant leaf litter (Farrar et al. 2003; van Hees et al. 2005). Microorganisms quickly assimilate labile carbon resources and thereby reach much higher density than in bulk soil (Kuzyakov and Blagodatskaya 2015). When consumed, microorganisms transfer the root-derived carbon to higher trophic levels (Pollierer et al. 2012).

The amount of root exudates was estimated to be approximately $3-5 \%$ of the carbon fixed by photosynthesis (Pinton et al. 2001). Probably, a larger amount of carbon enters the soil system by mycorrhizal fungi, estimated to be in the range of 5-7 \% of the net primary production (Hobbie 2006; Ekblad et al. 2013). Mycorrhizal fungi improve the uptake of nutrients, especially nitrogen and phosphorus, into the plant by forming extensive hyphal networks thereby increasing the soil volume exploited by roots (Smith and Read 2008). In return, mycorrhizal fungi obtain carbon compounds produced by the plant, making the fungus independent from external carbon sources (Treseder et al. 2006). By using in-growth bags, the production rates of extramatrical mycelium of mycorrhizal fungi in the upper $10 \mathrm{~cm}$ of forest soils was estimated to be $160 \mathrm{~kg}$ dry matter ha-1 $\mathrm{y}^{-1}$ (Ekblad et al. 2013). The biomass of the total extramatrical ectomycorrhizal mycelium has been estimated to comprise $32 \%$ 
of the total microbial biomass (Högberg and Högberg 2002), suggesting that it serves as important food resource for soil animals.

A soil animal group that likely acquires carbon from the root pathway is oribatid mites (Acari), a widely distributed taxon of the soil mesofauna. Their densities peak in boreal forest soils where they reach up to 400,000 ind. $\mathrm{m}^{-2}$, but usually range between $30,000-100,000$ ind. $\mathrm{m}^{-2}$ in mesophilic forests of the temperate region (Persson et al. 1980; Huhta et al. 1986; Schaefer and Schauermann 1990; Maraun and Scheu 2000). Their dietary spectrum comprises lichens, algae and litter but is dominated by fungi (Siepel and Ruiter-Dijkman1993; Schneider et al. 2004; Maraun et al. 2011). However, it is unknown to what extend their fungal diet includes mycorrhizal fungi. When given the choice between different species of saprotrophic and mycorrhizal fungi in laboratory food choice experiments the three oribatid mite species investigated (Nothrus silvestris, Oribatula tibialis and Carabodes femoralis) consumed mycorrhizal fungi to a high extent (Schneider et al. 2005). However, it remains unclear if the results of laboratory experiments are applicable to the complex conditions in the field. Due to the small size of soil animals and the opaqueness of their habitat, direct observations on the feeding habits of soil mites in the field are difficult. An indirect way to measure the significance of root-derived carbon for soil biota is to cut the flux of root carbon into the soil system by treegirdling or root-trenching (Högberg et al. 2001). Although these methods have been widely used for estimations on microbial contributions to soil respiration, few studies investigated the response of soil animals (Hanson et al. 2000). Assuming that rootderived resources are important, the density of soil animals should decrease in the rhizosphere of girdled tress or inside of trenched forest floor. Notably, such experiments may allow distinguishing species relying on the root-derived carbon vs. the litter carbon pathway.

In spruce and pine forests in northern Sweden, Protura were negatively affected, whereas most Collembola were not or positively affected by tree-girdling (Malmström and Persson 2011). In a mixed forest of Scots pine and Norway spruce in central Finland root-trenching resulted in increased densites of Enchytraeidae and Nematoda, did not alter that of Collembola and detrimentally affected that of Oribatida (Siira-Pietikäinen et al. 2001). However, in a girdling experiment in northern Sweden the response of oribatid mites markedly varied between species (Remén et al. 2008). While the density of some species decreased, that of other 
species remained unaffected or increased. Moreover, the effects differed between spruce and pine forests indicating that the type of forest affects carbon allocation into the soil system. Beside tree identity the amount of carbon allocated from the tree to its roots also depends on tree age, soil properties and climatic conditions (Kuzyakov and Domanski 2000), probably resulting in different responses of soil animals to manipulations of the input of root-derived resources.

In the present study, we investigated density and community structure of oribatid mites by eliminating the carbon input via plant roots in deciduous and coniferous forests of two regions in Germany. We hypothesized that densities of species relying on root-derived carbon decrease in trenched as compared to control plots. Further, we expected this effect to be less pronounced in the litter layer (as compared to upper mineral soil) as the fungal community in litter is dominated by saprotrophic rather than mycorrhizal fungi (Lindahl et al. 2007; Rosling et al. 2003). Further, we hypothesized that primary decomposer species are little affected by root-trenching since their resource is independent of mycorrhizal fungi and the input of root-derived resources.

\section{Materials and Methods}

\subsection{Study sites and sampling design}

The experimental plots were established in two regions in Germany at the sites of the "Biodiversity-Exploratories", a large-scale and long-term biodiversity project (Fischer et al. 2010). The regions include (1) the Schorfheide-Chorin (3-140 m a.s.I.) located in the lowlands of Northeastern Germany, characterized by postglacial geomorphological structures and (2) the Hainich-Dün (285-550 $\mathrm{m}$ a.s.I.) situated in the hilly lands of Central Germany, featuring large continuous areas of deciduous woodlands. Mean annual temperatures for Schorfheide-Chorin and Hainich-Dün are 8-8.5 and $6.5-8^{\circ} \mathrm{C}$ with mean annual precipitation of $500-600$ and $500-800 \mathrm{~mm}$, respectively. The soil consists mainly of Cambisols in the Schorfheide-Chorin and Luvisols in the Hainich-Dün with pH ranging between $3.00 \pm 0.19$ and $4.59 \pm 0.67$, respectively. Bedrock is glacial till in Schorfheide-Chorin and Triassic limestone in Hainich-Dün. For more details on the study sites see Fischer et al. (2010).

Within each region the study sites are composed of four differently managed forest types: coniferous forests (Pinus sylvestris in the Schorfheide-Chorin and Picea abies in the Hainich-Dün) planted as age-class forests 70 years ago, young 
and old beech forests planted as age-class forests 30 and 70 years ago, respectively, and unmanaged, natural beech forests, left out of management for at least 60 years, including trees being 120 to 150 years old. Each forest type was replicated four times in each region.

\subsection{Establishment and maintenance of root-trenching plots}

Between September and October 2011, root-trenching plots were established at 16 sites each in Schorfheide-Chorin and Hainich-Dün. Roots were cut in an area of $1.2 \times 1.2 \mathrm{~m}$ to a depth of $40-50 \mathrm{~cm}$ using a chainsaw, spade and pickaxe. Then $60 \mathrm{~cm}$ high polyethylene barriers were inserted into the slits to prevent ingrowth of roots into the trenched areas. To improve trenching aluminum linings were inserted at the corners closing gaps between adjacent barriers. In addition to barriers in soil, the root trenching areas were equipped with plastic barriers extending $20 \mathrm{~cm}$ above the ground. Control plots also were equipped with respective barriers above the ground to control for possible side effects of barriers above the ground. Herbaceous plants in root-trenching plots were clipped three times a year to minimize input of rootderived carbon. To avoid potential effects of shading and associated changes in microclimatic conditions, herbaceous plants were also cut in control plots.

\subsection{Sampling and determination of species}

In October 2012, one year after the plots were established, two samples of $5 \mathrm{~cm}$ depth were taken from root-trenched and control plots using a soil corer $(\varnothing 5 \mathrm{~cm})$; for statistical analysis the two samples were pooled. All samples were separated into soil and litter layer. The litter layer comprised undecomposed or weakly decomposed leaves; the soil layer included F- and H-material (if present) and mineral soil (Ah layer). Soil animals were extracted by heat (Macfadyen 1961) and stored in $70 \%$ ethanol until determination. Except for Brachychthoniidae, Suctobelbella and Phthiracarus, oribatid mites were determined to species level using Weigmann (2006). Juvenile oribatid mites were counted.

\subsection{Statistical analysis}

Oribatid mite density and diversity were analyzed by repeated measures analysis of variance (ANOVA) with the fixed factors treatment (trench, control), forest type (young beech, old beech, natural beech, coniferous) and layer (soil, litter) as a repeated factor using $R$ version 2.14.1 ( $R$ Development Core Team 2011). Data on 
oribatid mite density were log-transformed to improve homoscedasticity. To test for significance of the three factors on oribatid mite community structure the multivariate datasets consisting of 69 species in the Hainich-Dün and 61 species in the Schorfheide-Chorin were reduced to six dimensions using non-metric multidimensional scaling (NMDS) in CANOCO 5.02 (Microcomputer Power, Ithaca, New York; Šmilauer and Lepš 2014). Subsequently, the six dimensions of the NMDS were used in STATISTICA 11 (Statsoft, Tulsa, USA) for Discriminant Function Analysis (DFA) to identify treatment effects. Finally, Detrended Correspondence Analysis (DCA) with all species of the respective region was performed using CANOCO 5.02 to relate the structure of oribatid mite communities to the factors treatment, forest type and layer. Data were log-transformed before the analyses.

\section{Results}

\subsection{Effect of root-trenching on total oribatid mite density and species richness}

Overall, more than 11,500 oribatid mite individuals of 93 species were found; 4720 (69 species) in Hainich-Dün and 6850 (61 species) in Schorfheide-Chorin.

Root-trenching tended to reduce total oribatid mite densities in the Hainich-Dün $\left(33,120 \pm 21,947\right.$ and $42,001 \pm 20,226$ ind. $/ \mathrm{m}^{2}$, respectively) but not in the Schorfheide-Chorin $\left(55,370 \pm 53,184\right.$ and 53,651 $\pm 41,764 \mathrm{ind} . / \mathrm{m}^{2}$, respectively; Tables 1, 2). In both regions, densities were significantly higher in litter $(22,863 \pm$ 14,713 and $42,073 \pm 36,211$ ind. $/ \mathrm{m}^{2}$ in Hainich-Dün and Schorfheide-Chorin, respectively) than in soil $\left(14,698 \pm 15,833\right.$ and $12,438 \pm 17,718$ ind./ $\mathrm{m}^{2}$ in HainichDün and Schorfheide-Chorin, respectively), but the difference between the layers was much larger in Schorfheide-Chorin. In Schorfheide-Chorin differences in total oribatid mite densities between the layers also significantly differed between forest types, being higher in pine forests $\left(48,160 \pm 16,724\right.$ and $923 \pm 1027$ ind. $/ \mathrm{m}^{2}$ in litter and soil, respectively) than in young $\left(47,301 \pm 37,907\right.$ ind. $/ \mathrm{m}^{2}$ and $21,136 \pm 15,328$ ind. $/ \mathrm{m}^{2}$ in litter and soil, respectively), old (34,059 $\pm 25,362$ ind. $/ \mathrm{m}^{2}$ and 12,701 \pm $19,938 \mathrm{ind} . / \mathrm{m}^{2}$ in litter and soil, respectively) and natural $\left(38,770 \pm 57,338 \mathrm{ind} . / \mathrm{m}^{2}\right.$ and 14,992 $\pm 22,609$ ind. $/ \mathrm{m}^{2}$ in litter and soil, respectively) beech forests.

Diversity, i.e. the average number of species per sample, was significantly lower in soil (8.2 \pm 5.2 and $4.4 \pm 3.6$ in Hainich-Dün and Schorfheide-Chorin, respectively) 
than in litter (12.1 \pm 5.4 and $14.2 \pm 3.8$ in Hainich-Dün and Schorfheide-Chorin, respectively) in both regions but was not affected by root-trenching (Table 1).

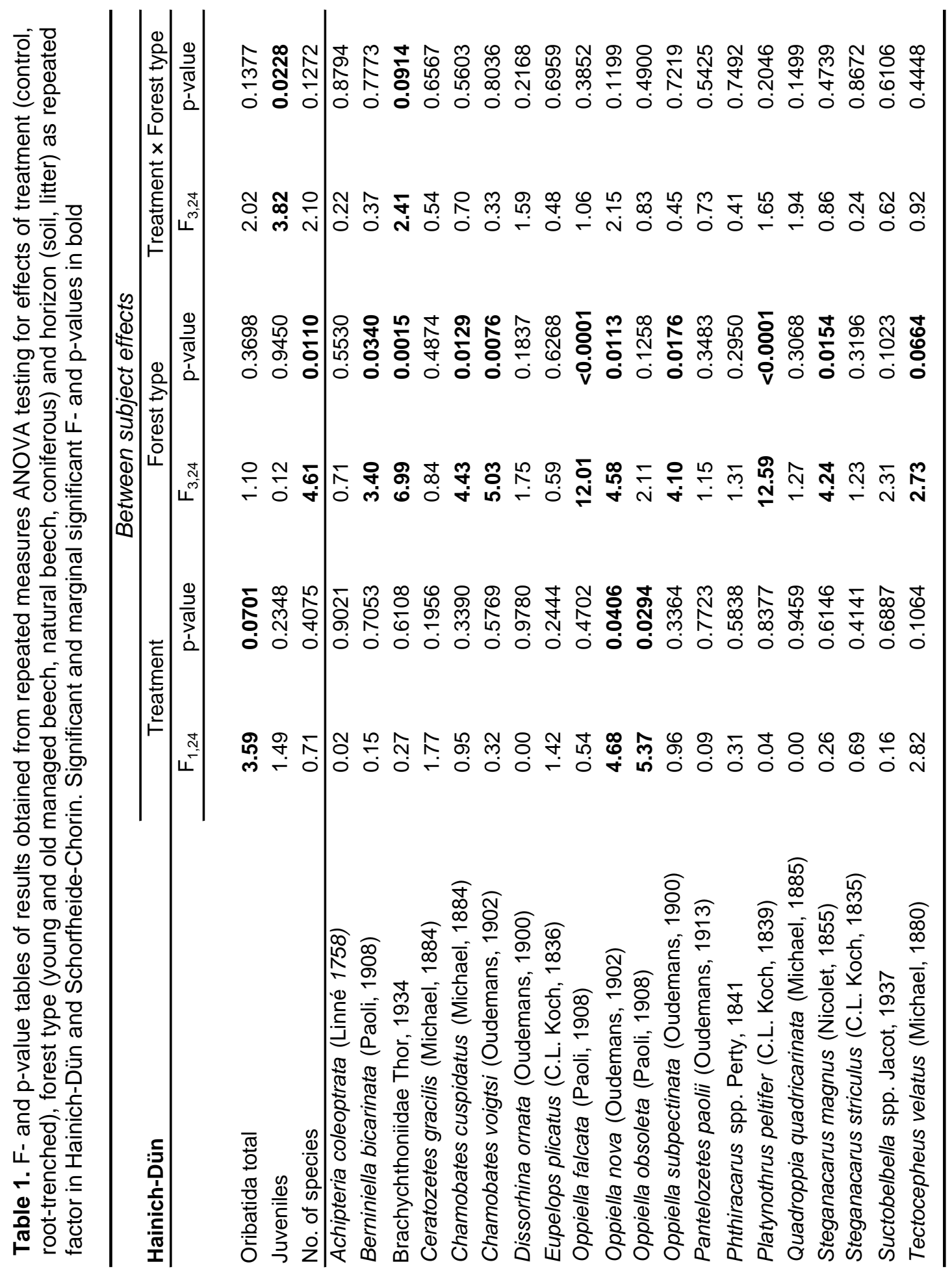




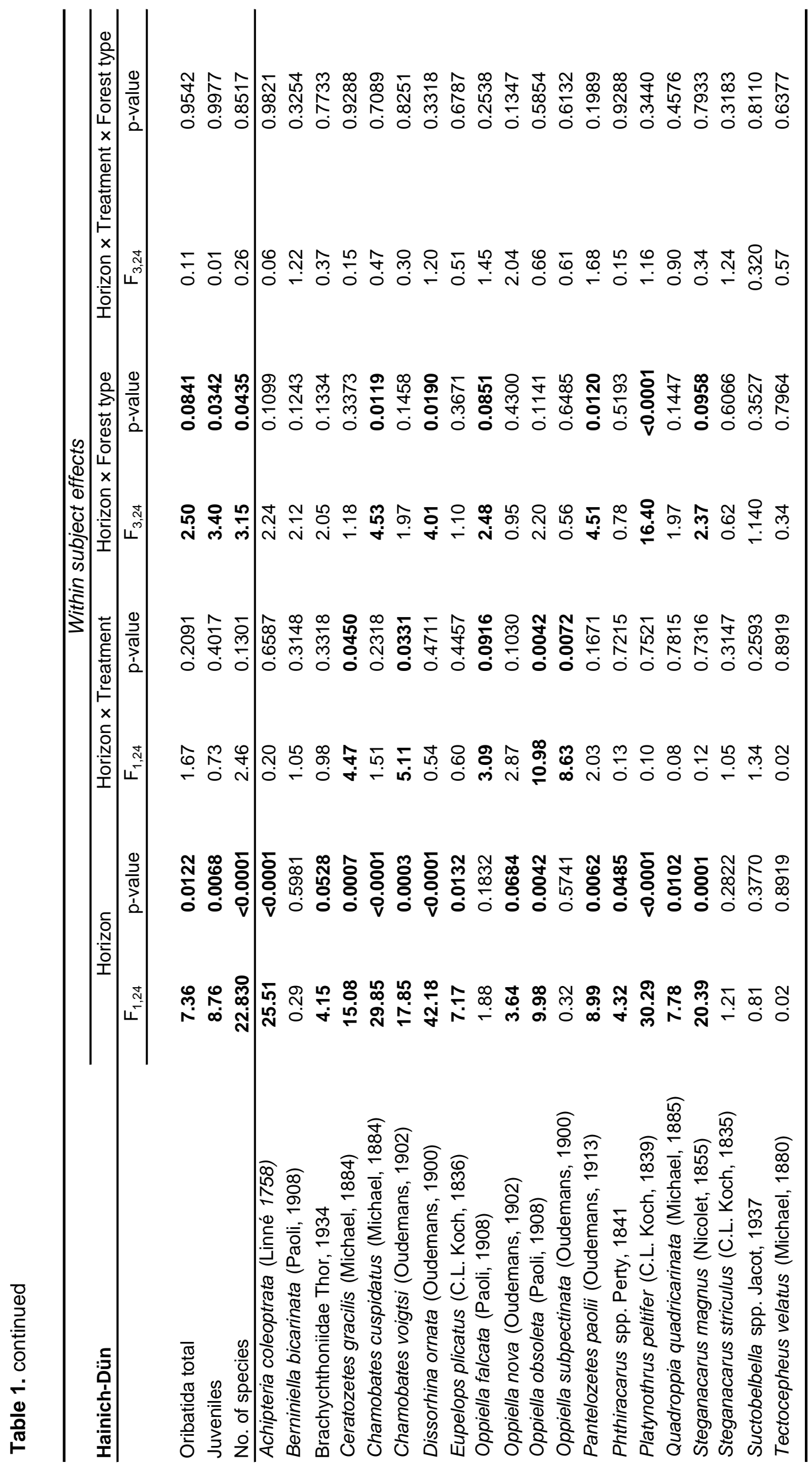




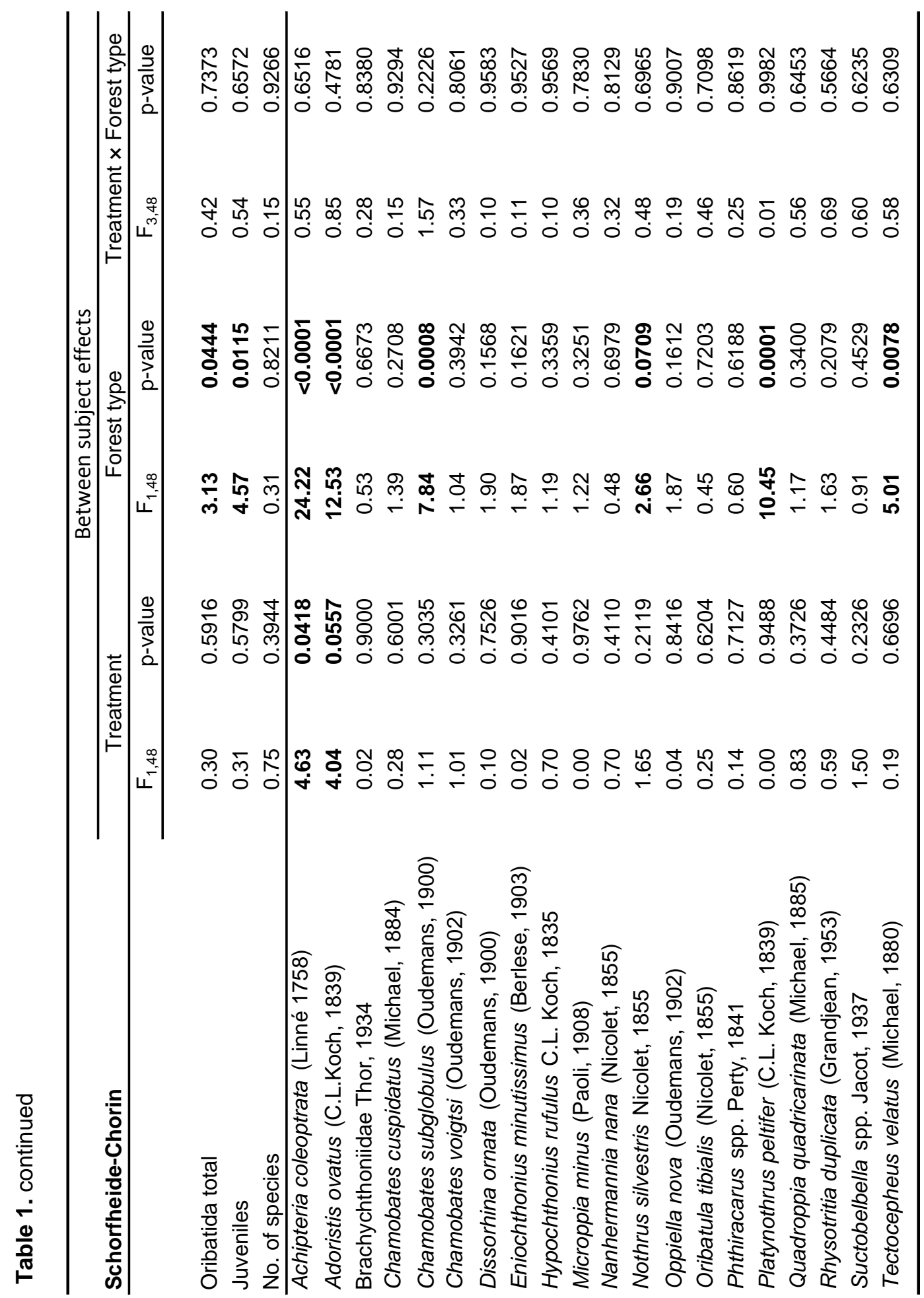




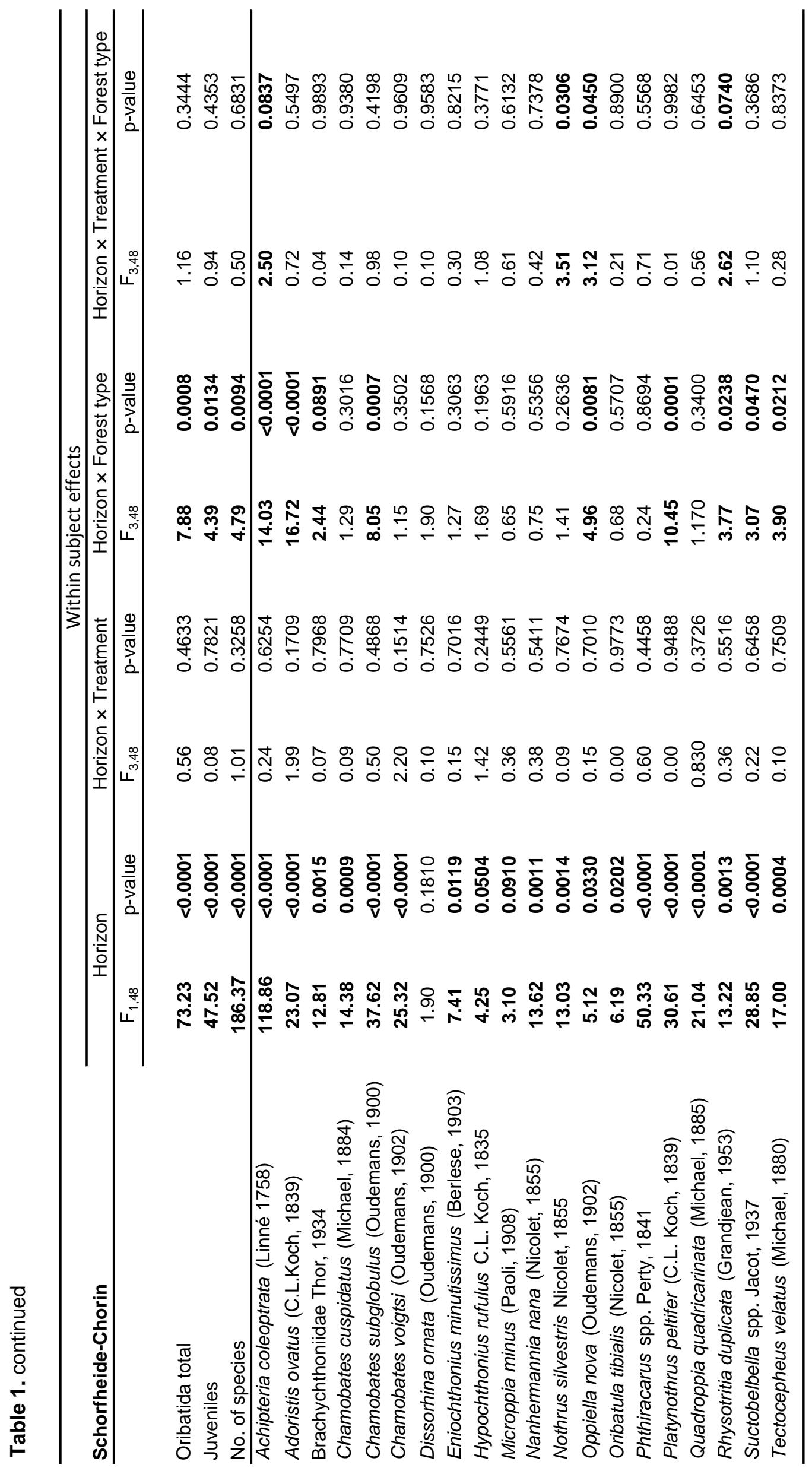




\subsection{Effect of root-trenching on abundant oribatid mite species}

The 20 most abundant species accounted for 89 and $91 \%$ of total oribatid mite individuals in the Hainich-Dün and Schorfheide-Chorin, respectively, with Suctobelbidae and Oppiidae (55\% and 48\%, respectively) dominating in both regions (Table 2). The other species were not further investigated since their densities were too low for statistical analyses.

In the Hainich-Dün, four species significantly occurred more often (or tended to occur more often) in soil (Oppiella nova, Oppiella obsoleta, Ceratozetes gracilis and Pantelozetes paolii), ten species/taxa significantly occurred more often in litter (Chamobates voigtsi, Steganacarus magnus, Achipteria coleoptrata, Eupelops plicatus, Dissorhina ornata, Quadroppia quadricarinata, Brachychthoniidae Phthiracarus spp., Platynothrus peltifer and Chamobates cuspidatus) and six species were indifferent in this respect (Oppiella subpectinata; Suctobelbella spp., Steganacarus striculus, Oppiella falcata, Tectocepheus velatus and Berniniella bicarinata; Table 1). In the Schorfheide-Chorin, only one species tended to occur more often in soil (Microppia minus), one species was indifferent in this respect (Dissorhina ornata), and the 18 other species/taxa significantly occurred more often in litter.

In the Hainich-Dün, seven of the 20 most abundant species/taxa were significantly or in trend affected by root-trenching, whereas the other 13 species remained unaffected. While root-trenching significantly reduced densities of $O$. nova irrespective of the layer (5507 $\pm 14,593$ ind. $/ \mathrm{m}^{2}$ and $477 \pm 623 \mathrm{ind} . / \mathrm{m}^{2}$ in control and trench, respectively), it significantly reduced densities of $O$. obsoleta, $C$. voigtsi and C. gracilis, $O$. subpectinata and tended to reduce densities of $O$. falcata only in soil but not in litter (treatment $\times$ layer interaction; Fig. 1a). Root-trenching further tended to reduce densities of Brachychthoniidae in spruce forests (9167 $\pm 13,505 \mathrm{ind} . / \mathrm{m}^{2}$ and $1337 \pm 1416$ ind. $/ \mathrm{m}^{2}$ in control and trench, respectively) but had no effect on densities in young (127 ind. $/ \mathrm{m}^{2} \pm 255$ ind. $/ \mathrm{m}^{2}$ and $127 \pm 147 \mathrm{ind} . / \mathrm{m}^{2}$ in control and trench, respectively) old (191 \pm 244 ind. $/ \mathrm{m}^{2}$ and $1210 \pm 1183 \mathrm{ind} . / \mathrm{m}^{2}$ in control and trench, respectively) and natural beech forests $\left(127 \pm 255 \mathrm{ind} . / \mathrm{m}^{2}\right.$ and $255 \pm 509$ ind. $/ \mathrm{m}^{2}$ in control and trench, respectively; treatment $\times$ forest type interaction; Table 1). 
(a)
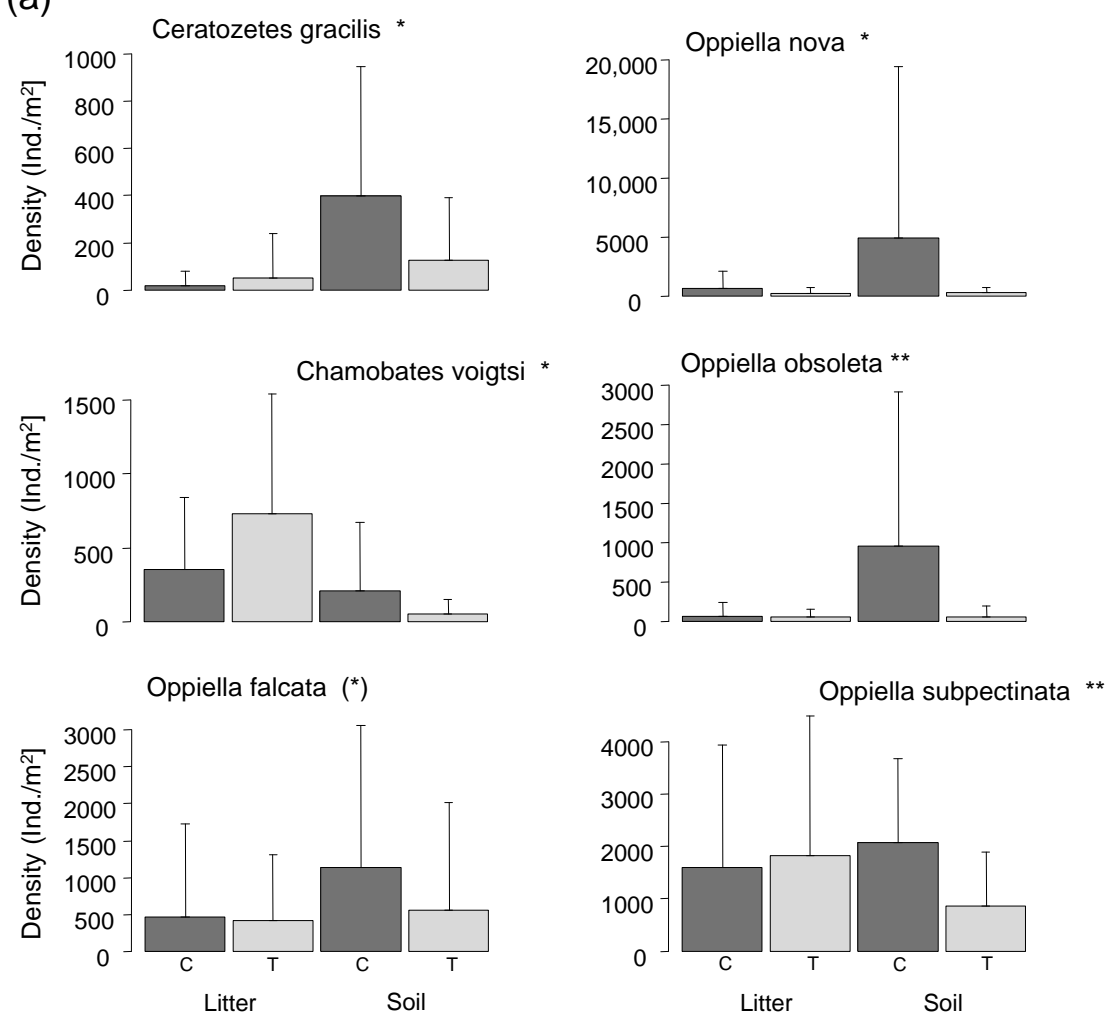

(b) Achipteria coleoptrata $\left(^{\star}\right)$
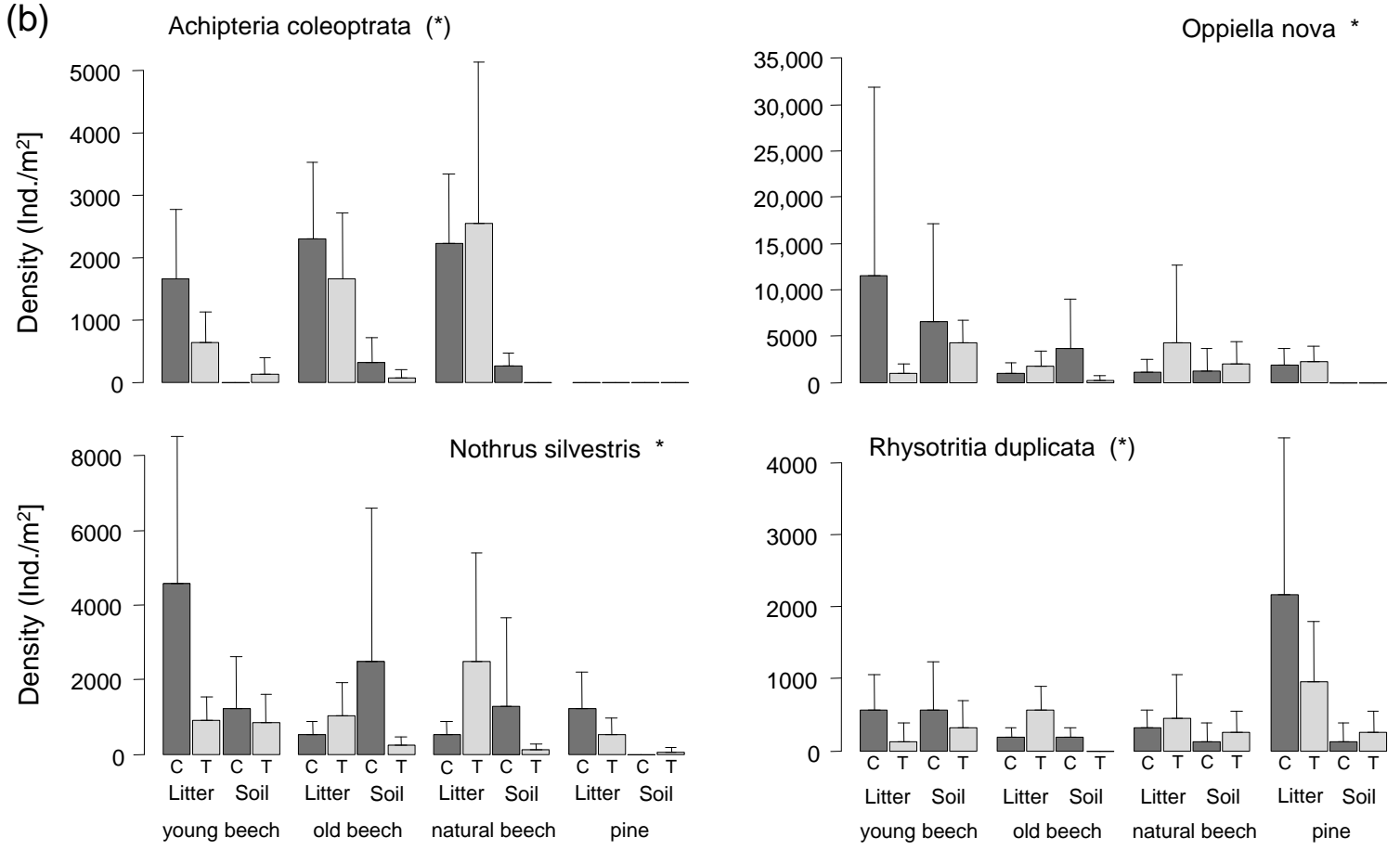

Fig. 1. Densities of oribatid mite species being affected by root-trenching in a) soil and litter in Hainich-Dün and b) soil and litter in four different forest types in Schorfheide-Chorin. $\mathrm{C}=$ control; $\mathrm{T}$ = root-trenched; Soil = soil layer; Litter =litter layer; young beech = young managed beech forest; old beech = old managed beech forest; beech natural = unmanaged natural beech forest; Pine = pine forest. 
In the Schorfheide-Chorin, five of the 20 species/taxa were significantly or in trend affected by root-trenching. Root-trenching tended to reduce densities of Adoristes ovatus which almost exclusively occurred in litter of spruce forests (414 \pm 663 ind./ $\mathrm{m}^{2}$ and $207 \pm 639$ ind. $/ \mathrm{m}^{2}$ in control and trench, respectively). Root-trenching also significantly affected densities of $N$. silvestris and $O$. nova and tended to affect densities of $A$. coleoptrata and Rhysotritia duplicata but the effect differed between forest types and layers (treatment $\times$ forest type $\times$ layer interaction; Table 1 ; Fig. 1 b). A. coleoptrata exclusively occurred in the three beech forests $\left(1210 \pm 970 \mathrm{ind} . / \mathrm{m}^{2}\right.$, $2165 \pm 1225 \mathrm{ind} . / \mathrm{m}^{2}$ and $2515 \pm 1808 \mathrm{ind} . / \mathrm{m}^{2}$ in young, old and natural beech forests, respectively) and had much higher densities in litter (1377 $\pm 1455 \mathrm{ind} . / \mathrm{m}^{2}$ ) than in soil $\left(95 \pm 202 \mathrm{ind} . / \mathrm{m}^{2}\right)$. Root-trenching only reduced densities of this species in litter in young beech forests, litter and soil in old beech forests and soil in natural beech forests (treatment $\times$ forest type $\times$ layer interaction Table 1, 2; Fig. 1b). $N$. silvestris occurred significantly more often in litter $\left(1464 \pm 2098 \mathrm{ind} . / \mathrm{m}^{2}\right)$ than in soil (780 $\left.\pm 1763 \mathrm{ind} . / \mathrm{m}^{2}\right)$ and densities decreased from young $\left(3756 \pm 4092 \mathrm{ind} . / \mathrm{m}^{2}\right)$ to old $\left(2133 \pm 3128 \mathrm{ind} . / \mathrm{m}^{2}\right)$ to natural beech $\left(2196 \pm 2650 \mathrm{ind} . / \mathrm{m}^{2}\right)$ to pine forests (891 $\left.\pm 782 \mathrm{ind} . / \mathrm{m}^{2}\right)$. Root-trenching reduced densities of $N$. silvestris in both in litter and soil in young beech forests, only in litter in pine forests but reduced densities in soil and increased densities in litter in old and natural beech forests (treatment $\times$ forest type $\times$ layer interaction; Table 1, 2; Fig. 1b). Densities of $O$. nova were significantly higher in young beech forests $\left(5809 \pm 11,059\right.$ ind. $\left./ \mathrm{m}^{2}\right)$ than in old beech forests $\left(1639 \pm 2882 \mathrm{ind} . / \mathrm{m}^{2}\right)$, natural beech forests $\left(2149 \pm 4296 \mathrm{ind} . / \mathrm{m}^{2}\right)$ and pine forests $\left(1035 \pm 1512 \mathrm{ind} . / \mathrm{m}^{2}\right)$. While root-trenching reduced densities in young beech forests in both litter and soil, it only reduced densities in soil but increased densities in litter in old beech forests. In natural forests root-trenching increased densities whereas in pine forests it had no effect in both litter and soil (treatment $x$ forest type $\times$ layer interaction; Table 1, 2; Fig. 1b). R. duplicata occurred in similar densities in soil and litter in young (350 $\pm 425 \mathrm{ind} . / \mathrm{m}^{2}$ and $\left.446 \pm 523 \mathrm{ind} . / \mathrm{m}^{2}\right)$, old (382 \pm 304 ind. $/ \mathrm{m}^{2}$ and $95 \pm 132$ ind. $/ \mathrm{m}^{2}$ ) and natural beech forests (382 \pm 430 ind. $/ \mathrm{m}^{2}$ and 191 $\left.\pm 264 \mathrm{ind} . / \mathrm{m}^{2}\right)$ but in higher densities in litter than in soil in pine forests $(1560 \pm 1658$ and ind. $\left./ \mathrm{m}^{2} 191 \pm 264 \mathrm{ind} . / \mathrm{m}^{2}\right)$. Root-trenching reduced densities in litter and soil in young beech forests, in soil in old beech forests and in litter in pine forests but had no or slightly positive effects in litter in old beech forests, in soil and litter in natural 
beech forests and in soil in pine forests (treatment $\times$ forest type $\times$ layer interaction; Table 1, 2; Fig. 1b).

\section{3 $\underline{\text { Community composition }}$}

Oribatid mite communities differed significantly between layers (DFA: Wilks' lambda $=0.32, F_{6,56}=19.66, p<0.0001$ ) and forest types in the Hainich-Dün (DFA: Wilks' lambda $=0.19, \mathrm{~F}_{18,153}=6.72, \mathrm{p}<0.0001 ;$ Tab. 3) as well as in the Schorfheide-Chorin (DFA for layers: Wilks' lambda $=0.35, F_{6,53}=16.65, p<0.0001$; DFA for forest types: Wilks' lambda $=0.38, F_{18,144}=3.30, p<0.0001$; Tab. 3; Fig. 2a,b). Root-trenching neither affected community composition in the Hainich-Dün (DFA: Wilks' lambda $=0.99, F_{6,56}=0.14, p=0.99$ ) nor in the Schorfheide-Chorin (DFA:Wilks' lambda $=0.89, F_{6,53}=1.15, p=0.35$ ). 


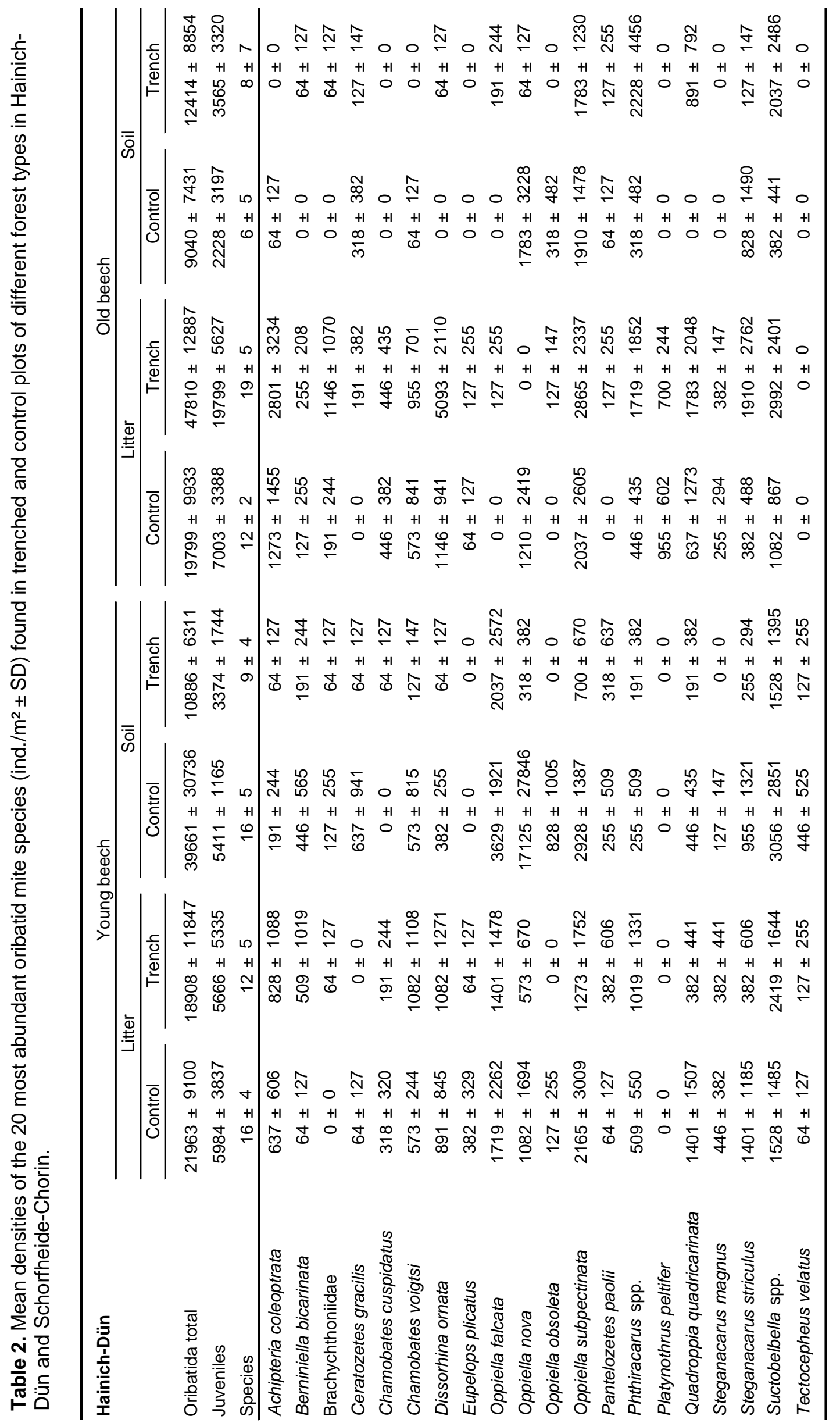




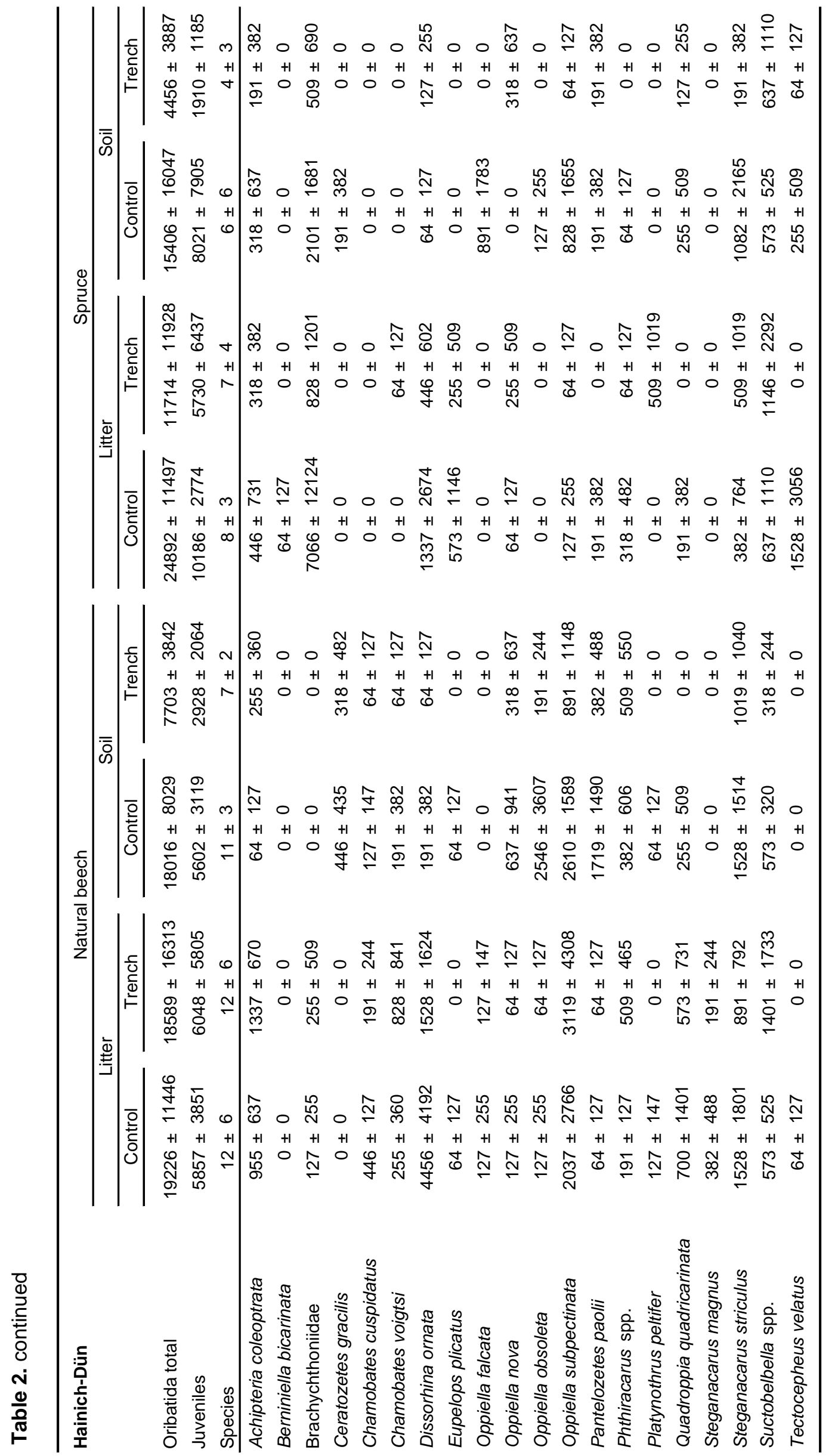




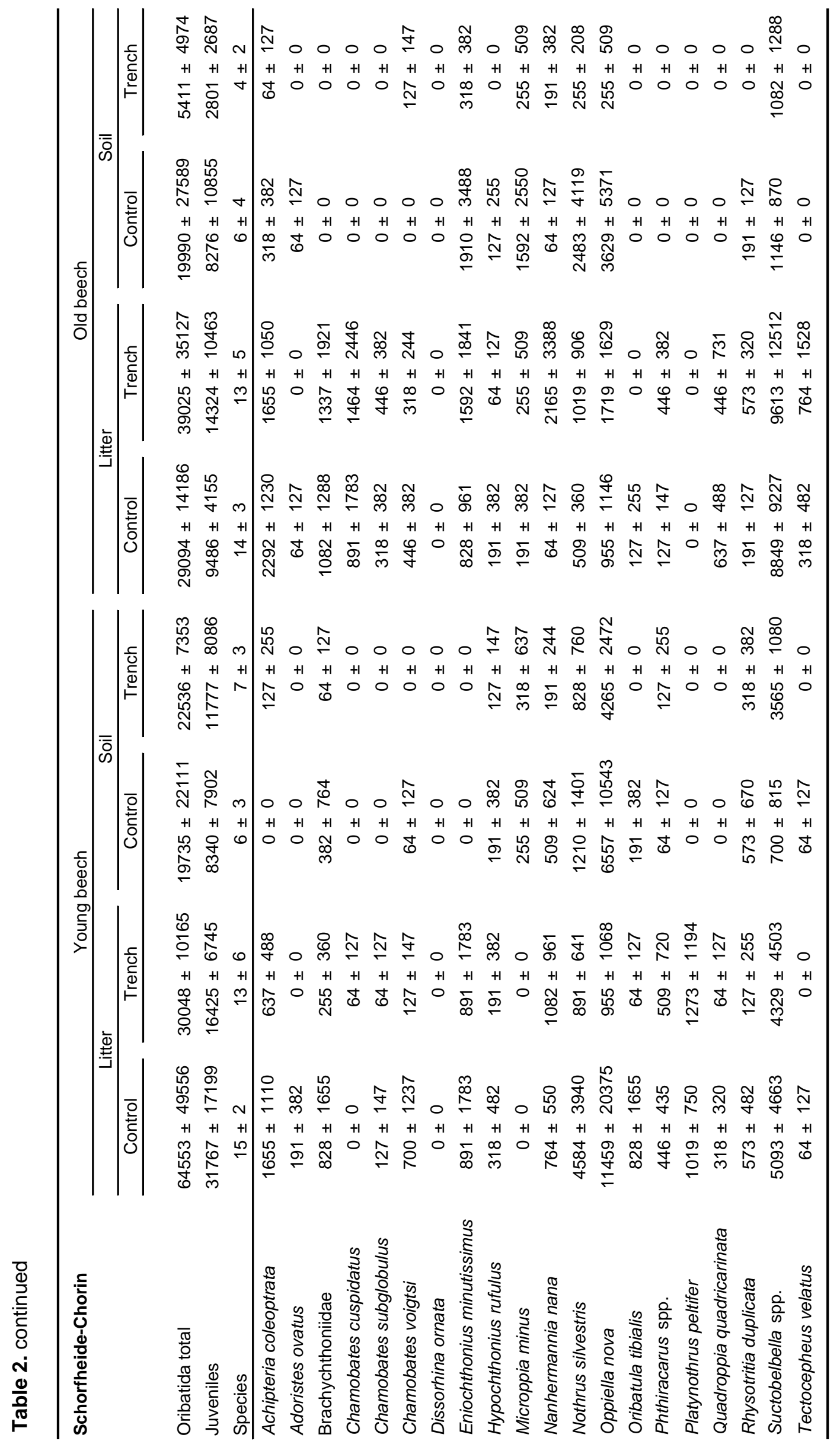




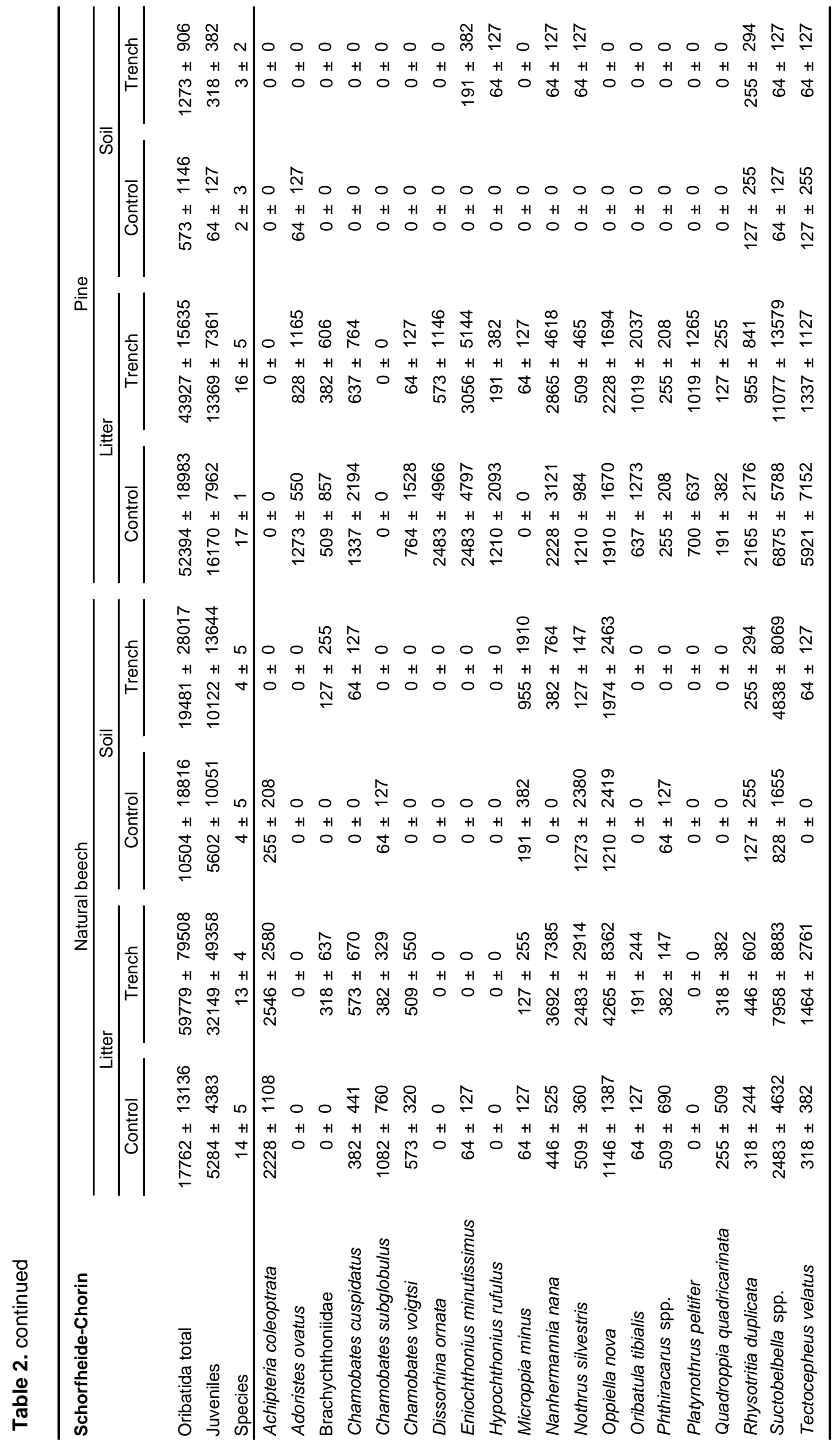


Table 3. Squared Mahalanobis Distances and significance levels of Discriminant Function Analysis (DFA) between oribatid mite communities of four forest types in Hainich-Dün and SchorfheideChorin. young beech = young managed beech forest; old beech = old managed beech forest; beech natural $=$ unmanaged natural beech forest; Pine $=$ pine forest.

Hainich-Dün

\begin{tabular}{ccccc} 
forest type & spruce & young beech & old beech & natural beech \\
\hline spruce & - & $13.93^{* * *}$ & $11.97^{* * *}$ & $10.61^{* * *}$ \\
young beech & $13.93^{* * *}$ & - & $1.32^{\text {n.s. }}$ & $3.16^{* *}$ \\
old beech & $11.97^{* * *}$ & $1.32^{\text {n.s. }}$ & - & $1.54^{\text {n.s. }}$ \\
natural beech & $10.61^{* * *}$ & $3.16^{* *}$ & $1.54^{\text {n.s. }}$ & - \\
\hline
\end{tabular}

\section{Schorfheide-Chorin}

\begin{tabular}{ccccc} 
forest type & pine & young beech & old beech & natural beech \\
\hline pine & - & $3.32^{* *}$ & $6.02^{* * *}$ & $6.90^{* * *}$ \\
young beech & $3.32^{* *}$ & - & $2.41^{*}$ & $2.68^{* *}$ \\
old beech & $6.02^{* * *}$ & $2.41^{*}$ & - & $0.22^{\text {n.s. }}$ \\
natural beech & $6.90^{* * *}$ & $2.68^{* *}$ & $0.22^{\text {n.s. }}$ & -
\end{tabular}

(a)

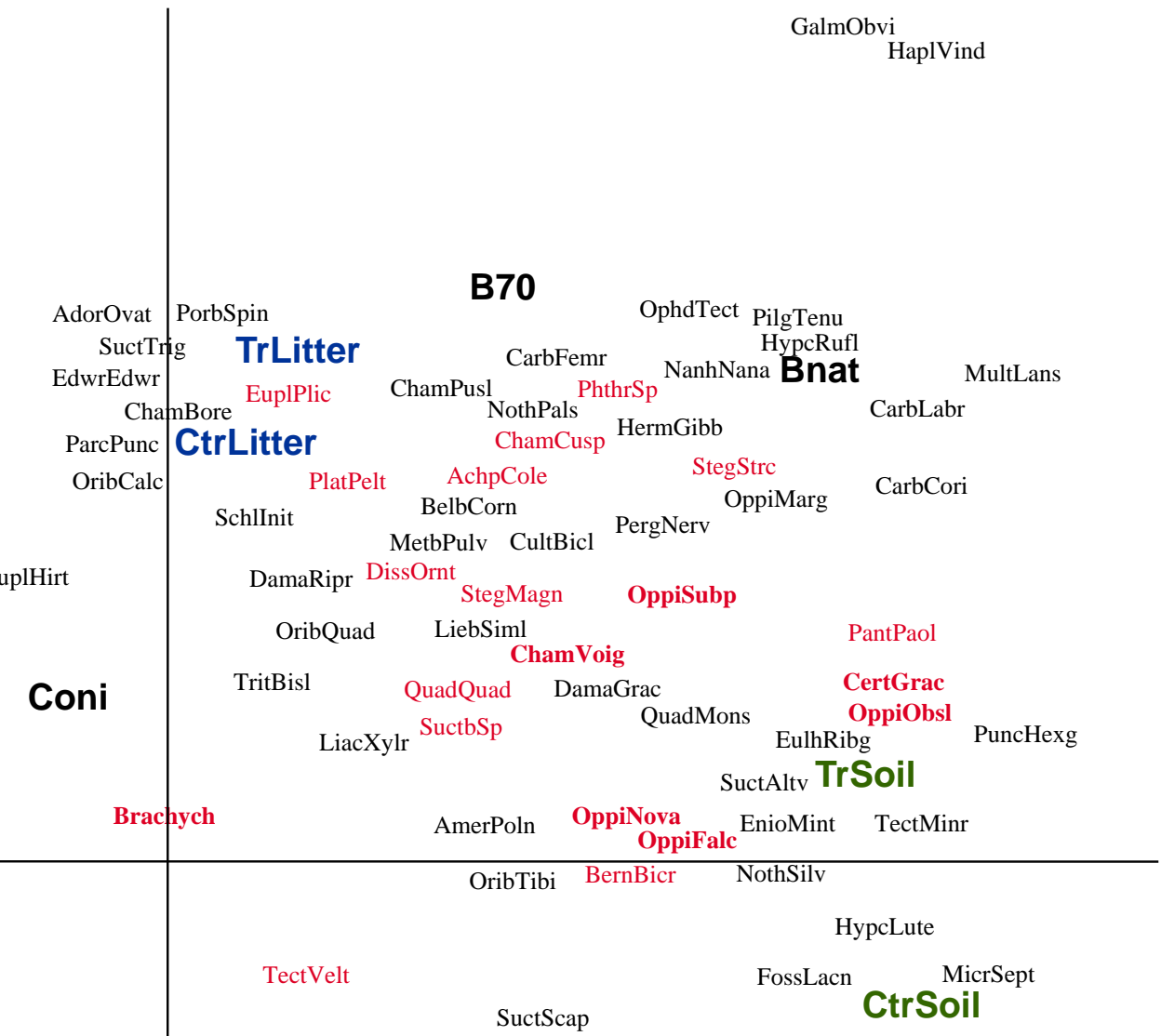




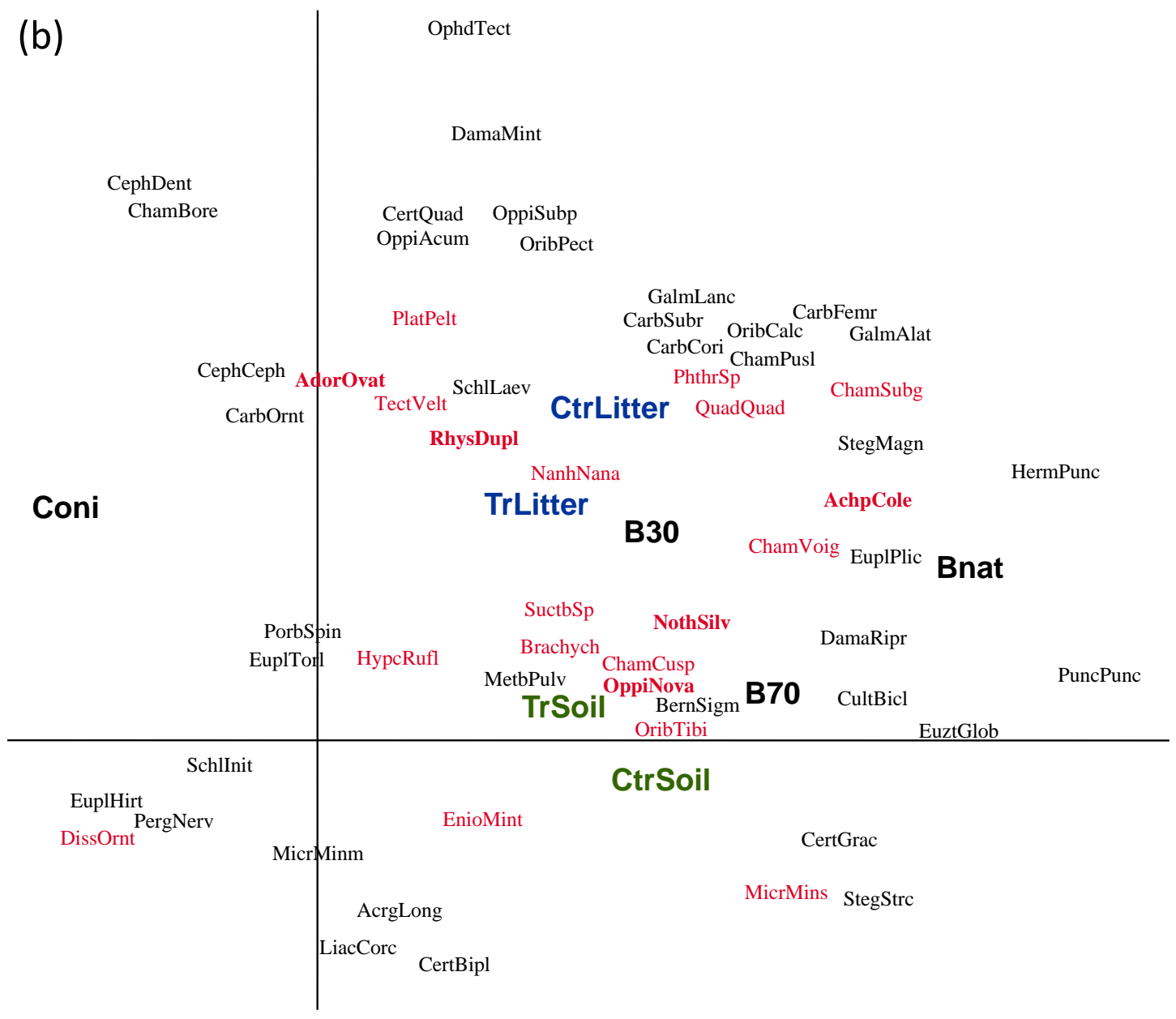

Fig. 2. Detrended Correspondence Analysis (DCA) of oribatid mite species in soil and litter of control and root-trenched plots in four different forest types in (a) Hainich-Dün (Length of gradient 3.9; eigenvalues of 0.46 and 0.24 for the first and second axis, respectively) and (b) Schorfheide-Chorin (Length of gradient 3.8; eigenvalues of 0.34 and 0.20 for the first and second axis, respectively). B30 = young managed beech forest; $\mathrm{B} 70=$ old managed beech forest; Bnat = unmanaged natural beech forest; Coni $=$ coniferous forest; Soil $=$ soil horizon; Litter = litter horizon; Ctr = control; $\mathrm{Tr}=$ roottrenched. The 20 most abundant species per region are marked red. Bold species were significantly or by trend affected by root-trenching. Full names of species and their abbreviations: Achipteria coleoptrata = AchpCole; Acrogalumna longipluma = AcrgLong; Adoristes ovatus = AdorOvat; Amerus polonicus $=$ AmerPoln; Belba corynopus $=$ BelbCorn; Berniniella bicarinata $=$ BernBicr; Berniniella sigma $=$ BernSigm; Brachychthoniidae = Brachych; Carabodes coriaceus $=$ CarbCori; Carabodes femoralis = CarbFemr; Carabodes labyrinthicus $=$ CarbLabr; Carabodes ornatus = CarbOrnt; Carabodes subarcticus $=$ CarbSubr; Cepheus cepheiformis = CephCeph; Cepheus dentatus = CephDent; Ceratoppia quadridentata = CertQuad; Ceratozetes gracilis = CertGrac; Chamobates borealis = ChamBore; Chamobates cuspidatus = ChamCusp; Chamobates pusillus = ChamPusl; Chamobates subglobulus = ChamSubg; Chamobates voigtsi = ChamVoig; Cultroribula bicultrata $=$ CultBicl; Damaeobelba minutissima $=$ DamaMint; Damaeus gracilipes $=$ DamaGrac; Damaeus riparius $=$ DamaRipr; Dissorhina ornata $=$ DissOrnt; Edwardzetes edwards $i=$ EdwrEdwr; Eulohmannia ribagai $=$ EulhRibg; Eniochthonius minutissimus = EnioMint; Eupelops hirtus = EuplHirt; Eupelops plicatus = EuplPlic; Eupelops torulosus = EuplTorl; Euzetes globulus = EuztGlob; Fosseremus laciniatus = FossLacn; Galumna alata = GalmAlat; Galumna lanceata = GalmLanc; Galumna obvia = GalmObvi; Haplozetes vindobonensis = HaplVind; Hermannia gibba = HermGibb; Hermanniella punctulata = HermPunc; Hypochthonius luteus = HypcLute; Hypochthonius rufulus = HypcRufl; Liacarus coracinus = LiacCorc; Liacarus $x y l a r i a e=$ LiacXylr; Liebstadia similis = LiebSiml; Metabelba pulverosa $=$ MetbPulv; Microppia minus = MicrMins; Microtritia minima $=$ MicrMinm; Microzetes septentrionalis $=$ MicrSept; Multioppia laniseta $=$ MultLans; Nanhermannia nana $=$ NanhNana; Nothrus palustris $=$ NothPals; Nothrus silvestris $=$ NothSilv; Ophidiotrichus tectus $=$ OphdTect; Oppiella acuminata = OppiAcum; Oppiella falcata = OppiFalc; Oppiella marginedentata = 
OppiMarg; Oppiella nova $=$ OppiNova; Oppiella obsoleta $=$ OppiObsl; Oppiella subpectinata $=$ OppiSubp; Oribatella calcarata = OribCalc; Oribatella quadricornuta $=$ OribQuad; Oribatula tibialis $=$ OribTibr; Oribella pectinata $=$ OribPect; Pantelozetes paolii $=$ PantPaol; Parachipteria punctata $=$ ParcPunc; Paratritia baloghi $=$ ParaBalo; Pergalumna nervosa $=$ PergNerv; Phthiracarus spp. $=$ PhthrSp; Pilogalumna tenuiclava = PilgTenu; Platynothrus peltifer = PlatPelt; Porobelba spinosa = PorbSpin; Punctoribates hexagonus = PuncHexg; Punctoribates punctum = PuncPunc; Quadroppia monstruosa = QuadMons; Quadroppia quadricarinata = QuadQuad; Rhysotritia duplicata = RhysDupl; Scheloribates ascendens = SchlAscn; Scheloribates initialis = Schllnit; Scheloribates laevigatus = SchlLaev; Steganacarus magnus = StegMagn; Steganacarus striculus = StegStrc; Suctobelba altvateri = SuctAltv; Suctobelba scapellata = SuctScap; Suctobelba trigona = SuctTrig; Suctobelbella spp. = SuctbSp; Tectocepheus minor = TectMinr; Tectocepheus velatus = TectVelt; Tritegeus bisulcatus $=$ TritBis

\section{Discussion}

In Hainich-Dün, as hypothesized, root-trenching more strongly affected soil-living than litter-living oribatid mite species. Here, densities of five $(O$. obsoleta, $O$. subpectinata, $O$. falcata, $C$. gracilis and $C$. voigtsi) of the seven species being affected by root-trenching were only reduced in soil and the other two in both litter and soil, but none of them only in litter. This supports our hypothesis since fine roots and mycorrhizal fungi are concentrated in the upper centimeters of the soil (Genney et al. 2006; Lindahl et al. 2007). Densities of $O$. nova, the most abundant species in Schorfheide-Chorin and second most abundant in Hainich-Dün, were reduced by root-trenching in both regions but depended on the forest type and layer in Schorfheide-Chorin. Similar responses were observed in a study from northern Sweden where densities of $O$. nova significantly declined to $8-18 \%$ of control plots following girdling of trees in spruce forests (Remén et al. 2008). In a study from northern Canada, beside one Liochthonius and one Suctobelbella species, only densities of $O$. nova, the dominant species in the forests investigated, significantly decreased after clear cutting (Lindo and Visser 2004). This suggests that $O$. nova benefits from the presence of mycorrhizal fungi, which was corroborated in two mesocosm experiments (Setälä 2000; Remén et al. 2010). However, as Remén et al. (2008) already stated, although strongly favored by the presence of mycorrhizal fungi it is unlikely that this ubiquitous species is specialized on this food resource since it occurs in habitats where mycorrhizal fungi are only available in small amounts or not at all (Skubała1995, Krivolutsky and Lebedeva 2004; Penttinen et al. 2008). Additionally, O. nova (among other Oppiidae) exhibits relatively high stable isotope signatures $\left({ }^{15} \mathrm{~N}\right)$ contradicting the assumption that they predominantly feed on (ectomycorrhizal) fungi (Schneider et al. 2004, Maraun et al. 2011). Presumably, $O$. nova is part of the root-exudation food chain and might feed on 
nematodes or protists consuming bacteria of the rhizosphere rather than feeding directly on mycorrhizal fungi. However, separating the mycorrhizal and the root exudation pathway is difficult since mycorrhizal colonization and root exudation are intercorrelated (Setälä 2000).

In Hainich-Dün, but not in Schorfheide-Chorin, densities of Brachychthoniidae tended to decrease following trenching but only in coniferous forests where they occurred in highest numbers. As a result of their small body size, species of Brachychthoniidae often were neglected and their trophic interrelationships are little understood. In agreement with results of this study, Remén (2008) found that densities of Brachychthoniidae significantly decreased after girdling in a spruce forest in of one of three study regions indicating that the availability of belowground carbon affects their densities.

In contrast, in Schorfheide-Chorin only five species, which dominated in the litter, were affected by root-trenching. Among those, contrary to our expectations, $A$. coleoptrata and $R$. duplicata, classified as primary decomposers in several studies, and $A$. ovatus, living inside of coniferous needles as juveniles, negatively responded to root-trenching (Lions and Gourbière 1988; Siepel and Ruiter-Dijkman1993; Schneider et al. 2004). Since the putative food resource (litter) was not directly affected by our experimental design, this suggests that the negative effect of roottrenching on these species is rather indirect, possibly mediated by fungal mycelium channeling carbon resources into the litter. Whatever pathway was involved, our results indicate that primary decomposers also indirectly benefit from the input of root-derived carbons.

The less pronounced effect of root-trenching in the Schorfheide-Chorin than in the Hainich-Dün suggests that root-derived carbon is of less importance in this region. This is supported by low abundance of oribatid mites in soil of the Schorfheide-Chorin (24\% of total; average of control plots) compared to HainichDün ( $48 \%$ of total; average of control plots) indicating lower resource availability at the depth layer where fine root and mycorrhizal biomass is highest (Genney et al. 2006; Lindahl et al. 2007). On the other hand, forests of the Schorfheide-Chorin have thicker litter layers with higher densities of oribatid mites as compared to the Hainich-Dün suggesting that root exudate pathways are generally less important in systems with thick litter layers (Klarner et al. 2014). 
Although densities of some species were reduced, oribatid mite community composition was not significantly affected by root-trenching in both regions. This finding is in line with a study from central Finland where total oribatid mite densities decreased while the community structure remained unaffected after root-isolation in a coniferous forest stand (Siira-Pietikäinen et al. 2001). The fact that community structure does not change when belowground carbon input is inhibited points to a lack of specialized species for these resources. All species appear to have a certain degree of trophic plasticity (Corral-Hernández et al. 2015), being not completely dependent on belowground carbon, even though some might directly or indirectly benefit from its presence.

Generally, when assuming that a large part of the soil animal food web is fueled by root derived-carbons the response of oribatid mites to root-trenching was rather weak (Pollierer et al. 2007; Gilbert et al. 2014). On the one hand, the effect following root-trenching might be buffered by internal carbon resources of coarse roots which still supplies the mycorrhizal fungi covering the fine roots.

In fact, it has been shown that ectomycorrhizal fungi survive for several seasons after roots have been cut, and that ectomycorrhizal fungi community structure but not biomass changes (Bauhus and Bartsch 1996; Pena et al. 2010). A complete dieback of ectomycorrhizal fungi takes two to three growing seasons (Hagerman et al. 1999). Furthermore, ectomycorrhizal fungi at least in part are capable to live as saprotrophic organisms attacking soil organic matter, therefore, not only relying on carbon input of their plant hosts (Ponge 1990). Overall, this suggests that it takes several years until the oribatid mite community fully experiences the loss of root derived resources in trenched plots. Further, as a general problem of root-trenching experiments, decomposition of cut roots results in increased resource availability and promotes growth of saprotrophic fungi (Hanson 2000) which may also benefit from the release of competition with ectomycorrhizal fungi (Gadgil and Gadgil 1975). In soil, generalistic feeders are common and also oribatid species predominantly rely on a number of food resources. In a gut content investigation of oribatid mites, none of the twelve species investigated ingested only a single type of food resource, but the proportion of different food materials varied between species (Anderson 1975). Within species, their diet also changed with season and habitat indicating trophic plasticity (Anderson 1975, Corral-Hernández et al. 2015). This trophic plasticity complicates understanding to what extent oribatid mites feed on root- 
derived carbon resources under natural conditions since they can switch to rootindependent resources, e.g. saprotrophic fungi, when the possibly otherwise preferred root-derived resources become less abundant.

\section{Acknowledgements}

We thank the managers of the three Exploratories, Kirsten Reichel-Jung, Swen Renner, Katrin Hartwich, Sonja Gockel, Kerstin Wiesner, and Martin Gorke for their work in maintaining the plot and project infrastructure; Christiane Fischer and Simone Pfeiffer for giving support through the central office, Michael Owonibi for managing the central data base, and Markus Fischer, Eduard Linsenmair, Dominik Hessenmöller, Jens Nieschulze, Daniel Prati, Ingo Schöning, François Buscot, Ernst-Detlef Schulze, Wolfgang W. Weisser and the late Elisabeth Kalko for their role in setting up the Biodiversity Exploratories project. The work has been (partly) funded by the DFG Priority Program 1374 "Infrastructure-Biodiversity-Exploratories" (MA2461/7-2). Field work permits were issued by the responsible state environmental offices of Baden-Württemberg, Thüringen, and Brandenburg (according to $\S 72$ BbgNatSchG). We thank Bernhard Eitzinger, Christoph Digel, David Ott, Bernhard Klarner and Olga Ferlian for assistance in the field. 


\section{References}

Anderson J (1975) Succession, diversity and trophic relationships of some soil animals in decomposing leaf litter. J Anim Ecol 44:475-495

Bauhus J, Bartsch N (1996) Fine-root growth in beech (Fagus sylvatica) forest gaps. Can J For Res 26:2153-2159

Bonkowski M, Villenave C, Griffiths B (2009) Rhizosphere fauna: the functional and structural diversity of intimate interactions of soil fauna with plant roots. Plant Soil 321:213-233

Cebrian J (1999) Patterns in the fate of production in plant communities. Am Nat 154:449-468

Corral-Hernández E, Maraun M, Iturrondobeitia JC (2015) Trophic structure of oribatid mite communities from six different oak forests (Quercus robur). Soil Biol Biochem 83:93-99

Ekblad A, Wallander H, Godbold DL, Cruz C, Johnson D, Baldrian P, Björk, RG, Epron D, Kieliszewska-Rokicka B, Kjøller R, Kraigher H, Matzner E, Neumann J, Plassard C (2013) The production and turnover of extramatrical mycelium of ectomycorrhizal fungi in forest soils: role in carbon cycling. Plant Soil 366:1-27

Farrar J, Hawes M, Jones D, Lindow S (2003) How roots control the flux of carbon to the rhizosphere. Ecology 84:827-837

Fischer M, Bossdorf O, Gockel S, Hänsel F, Hemp A, Hessenmöller D, Korte G, Nieschulze J, Pfeiffer S, Prati D, Renner S, Schöning I, Schuhmacher U, Wells K, Buscot F, Kalko EKV, Linsenmair KE, Schulze ED, Weisser WW (2010) Implementing large-scale and long-term functional biodiversity research: The Biodiversity Exploratories. Basic Appl Ecol 11:473-485

Gadgil RL, Gadgil PD (1975) Suppression of litter decomposition by mycorrhizal roots of Pinus radiata. New Zeal J For Sci 5:33-41

Genney DR, Anderson IC, Alexander IJ, Alexander I (2006) Fine-scale distribution of pine ectomycorrhizas and their extramatrical mycelium. New Phytol 170:381-390

Gilbert KJ, Fahey TJ, Maerz JC, Sherman RE, Bohlen P, Dombroskie JJ, Groffman PM, Yavitt JB (2014) Exploring carbon flow through the root channel in a temperate forest soil food web. Soil Biol Biochem 76:45-52

Hagerman SM, Jones MD, Bradfield GE, Gillespie M, Durall DM (1999) Effects of clear-cut logging on the diversity and persistence of ectomycorrhizae at a subalpine forest. Can J For Res 29:124-134

Hanson PJ, Edwards NT, Garten CT, Andrews JA (2000) Separating root and soil microbial contributions to soil respiration: A review of methods and observations. Biogeochemistry 48:115-146

Hobbie EA (2006) Carbon allocation to ectomycorrhizal fungi correlates with belowground allocations in culture studies. Ecology 87:563-569

Högberg MN, Briones M (2010) Quantification of effects of season and nitrogen supply on tree below-ground carbon transfer to ectomycorrhizal fungi and other soil organisms in a boreal pine forest. New Phytol 187:485-493 
Högberg MN, Högberg P (2002) Extramatrical ectomycorrhizal mycelium contributes one-third of microbial biomass and produces, together with associated roots, half the dissolved organic. New Phytol 154:791-795

Huhta V, Hyvonen R, Kaasaiainen P, Koskenniemi A, Muona J, Mäkelä I, Sulander M, Vilkamaa P (1986) Soil fauna of Finnish coniferous forests. Ann Zool Fenn 23:345-360

Klarner B, Ehnes RB, Erdmann G, Eitzinger B, Pollierer MM, Maraun M, Scheu S (2014) Trophic shift of soil animal species with forest type as indicated by stable isotope analysis. Oikos 123:1173-1183

Krivolutsky DA, Lebedeva NV (2004) Oribatid mites (Oribatei) in bird feathers: Passeriformes. Acta Zool Lituan 14:19-38

Kuzyakov Y, Blagodatskaya E (2015) Microbial hotspots and hot moments in soil: Concept \& review. Soil Biol Biochem 83:184-199

Kuzyakov Y, Domanski G (2000) Carbon input by plants into the soil: Review. J Plant Nutr Soil Sci 163:421-431

Lindahl B, Ihrmark K, Boberg J, Trumbore SE, Högberg P, Stenlid J, Finlay RD (2007) Spatial separation of litter decomposition and mycorrhizal nitrogen uptake in a boreal forest. New Phytol 173:611-620

Lindo Z, Visser S (2004) Forest floor microarthropod abundance and oribatid mite (Acari: Oribatida) composition following partial and clear-cut harvesting in the mixedwood boreal forest. Can J For Res 34:998-1006

Lions JC, Gourbière F (1988) Populations adultes et immatures d'Adoristes ovatus (Acarien, Oribate) dans les aiguilles de la litière d' Albies alba. Rev Écol Biol Sol, 25:343-352

Litton CM, Raich JW, Ryan MG (2007) Carbon allocation in forest ecosystems. Glob Change Biol 13:2089-2109

Macfadyen A (1961) Improved funnel-type extractors for soil arthropods. J Anim Ecol 30:171-184

Malmström A, Persson T (2011) Responses of Collembola and Protura to tree girdling - some support for ectomycorrhizal feeding. Soil Org 83:279-285

Maraun M, Erdmann G, Fischer BM, Pollierer MM, Norton RA, Schneider K, Scheu $S$ (2011) Stable isotopes revisited: Their use and limits for oribatid mite trophic ecology. Soil Biol Biochem 43:877-882

Maraun M, Scheu S (2000) The structure of oribatid mite communities (Acari, Oribatida): patterns, mechanisms and implications for future research. Ecography 23:374-383

Pena R, Offermann C, Simon J, Naumann PS, Gessler A, Holst J, Dannenmann M, Mayer H, Kögel-Knabner I, Polle A (2010) Girdling affects ectomycorrhizal fungal (EMF) diversity and reveals functional differences in EMF community composition in a beech forest. Appl Environ Microb 76:1831-41

Penttinen R, Siira-Pietikäinen A, Huhta V (2008) Oribatid mites in eleven different habitats in Finland. Integr Acarol 2:237-244 
Persson T, Bååth E, Clarholm M, Lundkvist H, Söderström BE, Sohlenius B (1980) Trophic structure, biomass dynamics and carbon metabolism of soil organisms in a Scots pine forest. In: Persson T (ed.) Structure and function of northern coniferous forests - an ecosystem study, Ecol Bull 32:419-459

Pinton R, Varanini Z, Nannipieri P (2001) The rhizosphere. Marcel Dekker Inc., New York, USA

Pollierer MM, Dyckmans J, Scheu S, Haubert D (2012) Carbon flux through fungi and bacteria into the forest soil animal food web as indicated by compoundspecific ${ }^{13} \mathrm{C}$ fatty acid analysis. Funct Ecol 26:978-990

Pollierer MM, Langel R, Körner C, Maraun M, Scheu S (2007) The underestimated importance of belowground carbon input for forest soil animal food webs. Ecol Lett 10:729-36

Ponge JF (1990) Ecological study of a forest humus by observing a small volume. Eur J Forest Pathol 20:290-303

Remén C, Fransson P, Persson T (2010) Population responses of oribatids and enchytraeids to ectomycorrhizal and saprotrophic fungi in plant-soil microcosms. Soil Biol Biochem 42:978-985

Remén C, Persson T, Finlay R, Ahlström K (2008) Responses of oribatid mites to tree girdling and nutrient addition in boreal coniferous forests. Soil Biol Biochem 40:2881-2890

Rosling A, Landeweert R, Lindahl BD, Larsson KH, Kuyper TW, Taylor AFS, Finlay RD (2003) Vertical distribution of ectomycorrhizal fungal taxa in a podzol soil profile. New Phytol 159:775-783

Ruf A, Kuzyakov Y, Lopatovskaya $O$ (2006) Carbon fluxes in soil food webs of increasing complexity revealed by ${ }^{14} \mathrm{C}$ labelling and ${ }^{13} \mathrm{C}$ natural abundance. Soil Biol Biochem 38:2390-2400

Schaefer M, Schauermann J (1990). The soil fauna of beech forests: comparison between a mull and a moder soil. Pedobiologia 314:299-314

Schlesinger WH (1977) Carbon balance in terrestrial detritus. Ann Rev Ecol Syst 8:51-81

Schneider K, Migge S, Norton RA, Scheu S, Langel R, Reineking A, Maraun M (2004) Trophic niche differentiation in soil microarthropods (Oribatida, Acari): evidence from stable isotope ratios $\left({ }^{15} \mathrm{~N} /{ }^{14} \mathrm{~N}\right)$. Soil Biol Biochem $36: 1769-1774$

Schneider K, Renker C, Maraun M (2005) Oribatid mite (Acari, Oribatida) feeding on ectomycorrhizal fungi. Mycorrhiza 16:67-72

Setälä H (2000) Reciprocal interactions between Scots pine and soil food web structure in the presence and absence of ectomycorrhiza. Oecologia 125:109118

Siepel H, de Ruiter-Dijkman EM (1993) Feeding guilds of oribatid mites based on their carbohydrase activities. Soil Biol Biochem25:1491-1497

Siira-Pietikäinen A, Haimi J, Kanninen A, Pietikäinen J, Fritze H (2001) Responses of decomposer community to root-isolation and addition of slash. Soil Biol Biochem 33:1993-2004 
Skubała P (1995) Moss mites (Acarina: Oribatida) on industrial dumps of different ages. Pedobiologia 184:170-184

Šmilauer P, Lepš J (2014) Multivariate Analysis of Ecological Data using CANOCO 5. Cambridge University Press, Cambridge

Smith S, Read D (2008) Mycorrhizal Symbiosis. Academic Press, London

Treseder K, Torn M, Masiello C (2006) An ecosystem-scale radiocarbon tracer to test use of litter carbon by ectomycorrhizal fungi. Soil Biol Biochem 38:10771082

Van Hees PAW, Jones DL, Finlay R, Godbold DL, Lundström US (2005) The carbon we do not see-the impact of low molecular weight compounds on carbon dynamics and respiration in forest soils: a review. Soil Biol Biochem 37: 1-13

Weigmann G (2006) Hornmilben (Oribatida). In: Dahl, F. (ed), Die Tierwelt Deutschlands 76 Goecke \& Evers, Keltern 


\section{ChaPter 5}

\section{General Discussion}

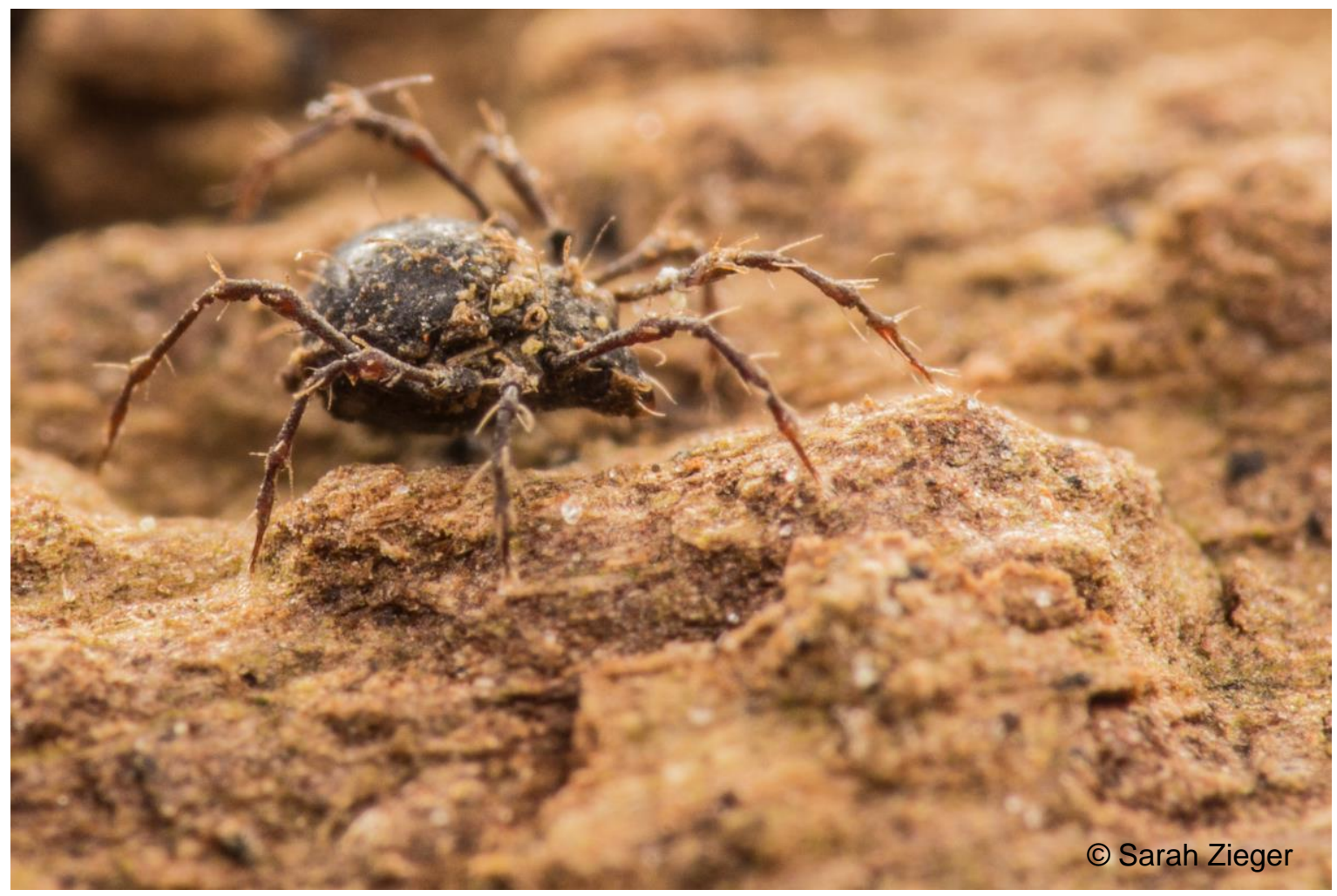


Soil animal communities are shaped by a complex interplay of abiotic and biotic factors that affect their community structure on different spatial and temporal scales (Levin 1992). Regional factors such as climate and landscape history operate on a larger scale than local factors such as habitat structure, availability of resources or predation and competition (Cornell and Lawton 1992). However, the mechanisms which structure species assemblages within a habitat are still debated with mainly two opposing ecological theories. Deterministic theories state that communities are predictable and are composed of species being best adapted to certain environmental conditions. More specifically, niche differentiation models base the coexistence of species on dissimilarities of traits thereby avoiding competitive exclusion, whereas the environmental filtering model posits that communities are composed of species with similar tolerances and requirements representing a subset from a regional species pool (Tscharntke et al. 2012). Neutral theories, in contrast, posit that species are ecologically identical and that communities are randomly shaped by local extinction and immigration events and therefore are unpredictable (Hubbell 2001; Leibold and McPeek 2006; Adler et al. 2007; Kraft et al. 2015). Accordingly, the deterministic models predict that communities of similar habitats in different regions are more similar than communities of different habitats in the same regions while the opposite is true for neutral models.

In this Thesis I investigated oribatid mite (Oribatida, Acari) communities in the framework of the DFG funded integrative project "Biodiversity-Exploratories". The experimental design of the "Biodiversity Exploratories" provides the opportunity to investigate community patterns on both regional and local scales. The project encompasses three regions (Schorfheide-Chorin, Hainich-Dün and Schwäbische Alb) that are located on a north-south gradient and differ in climatic conditions and soil properties (M Fischer et al. 2010). Within each region the impact of different forest types (young and old managed beech forests, natural beech forests and managed coniferous forests) on biodiversity patterns is one of the central questions being addressed by the project since land-use change is assumed to be a major driver of biodiversity and ecosystem functioning (Sala et al. 2000; Blüthgen et al. 2012). On a more local scale, we investigated oribatid mite communities from dead wood (Chapter 2) and soil (Chapter 3 and 4) which represent different microhabitats within forest types and regions. The availability of resources probably is a main factor structuring local communities which is clearly illustrated by the 
trophic distinctness of arboreal and edaphic oribatid mite communities (Proctor et al. 2002; Schneider et al. 2004; Erdmann et al. 2007). Using natural variations in stable isotope ratios we investigated the trophic diversity of oribatid mites on early decaying dead wood (Chapter 2) and related it to community structure. In soil, animal communities are assumed to be fuelled by two fundamentally different pathways: the litter- and the root-based pathway. Recent studies provided evidence that root-derived carbon is incorporated into soil animals to a high extent (Pollierer et al. 2007; Gilbert et al. 2014). In Chapter 4 we assessed the impact of root-derived resources on oribatid mite communities by disrupting the carbon flux into soil via root-trenching. In Chapter 3, we additionally included a temporal scale by comparing soil communities from two dates. Temporal community patterns may allow insight into the processes affecting soil animal communities.

Along these spatial and temporal scales, we investigated oribatid mite density, species richness, community structure and the proportions of parthenogenetically reproducing species. By comparing distribution patterns of oribatid mite species/genera we can assess the significance of the factors region, forest type and microhabitat for community assemblages. Differences between the same forest types and microhabitats in different regions were interpreted as being affected by regional factors such as climate, soil properties or landscape history whereas differences between different forest types and microhabitats within a region were interpreted as being affected by local factors e.g. habitat structure or availability of resources.

\section{Factors structuring communities}

\subsection{Microhabitats}

Oribatid mite densities and overall diversity were higher in soil (116 species; 30,000-120,000 ind./m²; Chapter 3 and 4) than on the bark of dead wood (83 species; 5000-10,000 ind. $/ \mathrm{m}^{2}$; Chapter 2). This finding contradicts results of other studies where density and diversity of dead wood communities exceeded those of soil communities (Skubała 2008; Sokołowska et al. 2009, Skubała and Marzec 2013). However, the decay stage of the logs and the unit by which densities are compared (surface area vs. dry weight of substrate) probably affects the results and complicates direct comparisons. The bark structure (rough vs. smooth) did not affect oribatid mite densities on the bark of dead wood which contrasts with results from 
the bark of living trees (Nicolai 1993) and also from soil (Peterson and Luxton 1982, Schaefer and Schauermann 1990, Hanson 2000) where increased structure has shown to be beneficial. Species richness, however, was significantly higher on structured oak bark than on smooth beech bark corresponding with previous studies (Nicolai 1986). Highly structured bark probably provides more niches than smooth, homogenous bark allowing more species to coexist.

Contrary to arboreal communities which are largely distinct from those in soil (Aoki 1973; Proctor et al. 2002; Lindo and Stevenson 2007), our findings suggest that oribatid mite communities of early decaying dead wood mainly consist of soil living and some arboreal oribatid mite species but only of a small number of dead wood specialists and thereby rather represents a transitional than a specific microhabitat. By using natural abundances of stable isotopes $\left({ }^{13} \mathrm{C}\right.$ and $\left.{ }^{15} \mathrm{~N}\right)$ we could also show that - similarly to soil - the majority of species on early decaying dead wood are fungivorous. However, the communities on the bark of dead wood differed from those in soil in several aspects. Most notably, Oppiidae and Quadroppiidae (e.g., Dissorhina ornata, Oppiella subpectinata, Oppiella falcata, Microppia minus, Quadroppia quadricarinata, Q. monstruosa) which numerically dominated soil and litter associated habitats in our (Chapter $\mathbf{3}$ and $\mathbf{4}$ ) and previous studies (Wunderle 1992; Maraun and Scheu 2000, Lindo and Stevenson 2007; Penttinen et al. 2008) in temperate forest soils (often in the range of $>40 \%$ of total oribatid mite densities) only occurred in low densities. In our studies for example, the ubiquitous Oppiella nova on dead wood reached only about $1 \%$ of its abundance in soil, regardless of the region and forest type. Similarly, also the taxa Suctobelbidae and Brachychthoniidae, usually dominant in soil, rarely occurred on dead wood. The comparable low abundances of these taxa suggest that they rather represent "sink populations" frequently invading the logs from the ambient substrate than selfsustaining populations. In Chapter 4 densities of some of those species (e.g., $O$. nova, $O$. falcata, $O$. subpectinata, $O$. obsoleta) were reduced by root-trenching indicating that they benefit from root-derived resources. Additionally, some other species/taxa negatively affected by root-trenching such as Brachychthoniidae, Ceratozetes gracilis, Chamobates voigtsi, Rhysotritia duplicata, Achipteria coleoptrata and Nothrus silvestris were also absent or occurred in very low densities on dead wood as compared to soil. These taxa presumably also benefit directly or indirectly from root-derived resources. 
In contrast, various species on the bark of dead wood were rare or not present in soil of the same forest type and region, e.g., Cymbaeremaeus cymba, Micreremus brevipes, Camisia segnis, Camisia horrida, Eueremaeus oblongus, Phauloppia Iucorum, Phauloppia rauschenensis, Carabodes labyrinthicus and Zygoribatula exilis. These species typically occur in arboreal habitats (Wunderle 1992; Erdmann et al. 2006) and either represent relicts from the arboreal communities inhabiting the stems before the trees were felled or invaded the logs from the surrounding trees as the bark and the epiphytic cover on the logs provides a similar habitat.

However, in contrast to arboreal habitats where some of these species, particularly C. labyrinthicus, M. brevipes and C. cymba, clearly dominate the community (Nicolai 1986; Wunderle 1992; Erdmann et al. 2006), densities of arboreal species on the bark of dead wood were low and did not greatly contribute to overall density. Dead wood probably only represents a temporal habitat for these species which might in part be attributed to the decline of lichens, a food resource for many arboreal species including $C$. labyrinthicus (see stable isotope analysis Chapter 2). The general decline of arboreal species on dead wood indicates that deterministic niche-based processes are operating. Only Zygoribatula exilis, a typical but subdominant arboreal species of lower trunk regions, was among the most numerous species on dead wood (Wunderle 1992; Huhta et al 2012). This species, among several others, such as Parachipteria punctata, Minunthozetes pseudofusiger; Melanozetes mollicomus, is primarily associated with the moss cover irrespective to the substrate it is attached to (Wunderle 1992). Despite the close association of many oribatid mite species with moss we found only one species, namely $M$. mollicomus, using moss as a food resource which was evidenced by stable isotope signatures in our study (Chapter 2) and previous studies (Shaldybina 1967; Wunderle 1992; Erdmann et al. 2007; Fischer et al. 2014). For most other moss-associated oribatid mite species mosses probably represents a habitat providing favourable microclimatic conditions for e.g., egg deposition or shelter.

Furthermore, we found some species that can be considered specific of dead wood as they have their highest abundance there and only sporadically occur in soil or in arboreal habitats. In our study (Chapter 2) the most characteristic species of dead wood were Autogneta longilamellata, Liebstadia humerata and Siculobata leontonycha which frequently occurred on logs across all regions and forest types 
and were virtually absent in samples from soil. These species were also considered as specific of dead wood by other studies (Christensen 1980; Wunderle et al. 1990; Skubałaand Maslak 2009, Behan-Pelletier 2015) and were also recorded from sporocarps of wood decaying fungi (Maraun et al. 2014). In our study, stable isotope signatures indicated that all three species feed on fungi, but it remains unclear if the specificity to dead wood is related to presence of certain species of fungi or rather to favourable microclimatic conditions. The latter species, S. leontonycha, was frequently found to phoretically disperse on scolytid beetles (Lieutier 1978; Norton 1980; Knee et al. 2013; Penttinen et al. 2013) and it is assumed that this species inhabits the galleries of their hosts (Weigmann 2006). The high habitat specificity of this species is probably also related to this trait. Furthermore, although not highly abundant in our study, most Carabodes species may be regarded as dead wood adapted since their juveniles tunnel in fruiting bodies of wood fungi (e.g., Fomes and Fomitopsis) which restricts their occurrence to habitats where these fungi occur (Matthewman and Pielou 1971; Hågvar and Steen 2013; Maraun et al. 2014).

Despite these differences between soil and dead wood, many species occurred frequently in both habitats indicating a high degree of generalism in oribatid mites with respect to resources and microclimatic conditions. Due to the low number of obligate dead wood species we regarded the bark of early decaying dead wood as a transitional habitat, although the composition of soil living, arboreal and dead wood species is unique. However, the community of dead wood might become increasingly distinct to other habitats in later stages of decay (Skubała 2008).

\subsection{Regional effects}

Regional factors strongly affected oribatid mite community composition in both soil and dead wood habitats resulting in regionally distinct communities. Although most species were recorded from two or all three regions, dominances of species markedly differed between regions. For example, Oppiidae which were dominant throughout all soil habitats were primarily represented by the sexually reproducing Oppiella subpectinata, Oppiella falcata and Berniniella bicarinata in the Schwäbische Alb whereas the two parthenogenetic species Oppiella nova and Microppia minus clearly dominated in the Schorfheide-Chorin. In the Hainich-Dün dominances of these species were intermediate and additionally Dissorhina ornata occurred in higher densities (Chapter 3 and 4). A similar pattern was found for 
Carabodes where the bark of dead wood was dominated by different species of this genus in each region (Chapter 2).

The few species almost exclusively occurring in one region were mostly rare, but characteristically shaped the regional communities. Oribatid mites communities in the Schwäbische Alb were characterised by some species of the Ceratozetidae, namely Melanozetes mollicomus, Sphaerozetes piriformis, Edwardzetes edwardsi and Fuscozetes setosus, and also Damaeobelba minutissima, Steganacarus herculeanus, Hermaniella punctulata and Parachipteria punctata, whereas communities of the Schorfheide-Chorin were characterized by Acrogalumna Iongipluma, Berniniella sigma, Cepheus cepheiformis, Chamobates subglobulus, Eupelops torulosus, Euzetes globules, Microtritia minima, Pergalumna nervosa, Porobelba spinosa, Rhysotritia duplicata, and Nothrus silvestris, which exclusively occurred here or had a clear centre of distribution in this region. The Hainich-Dün had less characteristic species (Fosseremaeus laciniatus, Liebstadia similis, Neotrichoppia confinis, Tectocepheus minor and Zygoribatula exilis) possibly due its central geographic position. Since the bark of dead wood was highly interspersed with soil species the regional impact was also present in this microhabitat to a certain degree indicating neutral effects for the colonization of the logs. The presence of some and the absence of other soil and arboreal species on dead wood can, however, also be interpreted as environmental filtering.

Since forest types and logs are largely similar in each region we attribute differences in community structure between regions to regional factors including climate, soil related factors and landscape history. The climate of both the HainichDün and the Schwäbische Alb are oceanic and the soils exhibit high pH values as a consequence of the calcareous bedrock and loess. Resemblance in climatic conditions and soil characteristics of the Hainich-Dün and Schwäbische Alb are presumably reflected in similar oribatid mite communities in soil and also on the bark of dead wood. Exclusively occurring species in the Schwäbische Alb may in part represent subalpine/alpine species, e.g. Sphaerozetes piriformis, Edwardzetes edwardsi, Steganacarus herculeanus and Suctobelba altvateri (Schuster 1960; Borcard et al. 1995; Materna 2000; Schatz and Wilhalm 2013; Weigmann 2006).

In contrast, the Schorfheide-Chorin is characterized by a continental climate and a glacial history expressed by sandy, acidic and nutrient poor soils, and we suggest that community distinctness to the other regions is primarily attributed to these 
factors. Mediated by acidic soils, higher overall densities in soils in this region (Chapter 3 and 4) may be a consequence of lower earthworm activity (Klarner 2013) which has been shown to be detrimental to oribatid mite communities (Maraun et al. 1999; McLean and Parkinson 2000; Migge-Kleian et al. 2006; Eisenhauer et al. 2007). Accordingly, densities did not differ significantly between the regions on the bark of dead wood (Chapter 2). However, in comparison to the Hainich-Dün and Schwäbische Alb oribatid mite densities in soil fluctuated more over time in this region which might be related to higher mortality rates caused by more pronounced abiotic extremes; i.e. in 2011 total oribatid mite densities were only half of the densities in 2008 (Chapter 3).

Differences in soil structure between regions were also expressed by vertical distributions of oribatid mites. In the Schorfheide-Chorin the difference between litter and soil layer was most pronounced with on average more than three-fold higher densities in the former ( $76 \%$ and $24 \%$, respectively), while in the Hainich-Dün densities in both layers were similar (52\% and $48 \%$, respectively) (Chapter 4). The low abundance of oribatid mites in the soil layer of the Schorfheide-Chorin indicates lower availability of resources where fine root and mycorrhizal biomass is highest (Genney et al. 2006; Lindahl et al. 2007). Accordingly, we found less species to be affected and a lower overall effect on oribatid mite densities by root-trenching in the Schorfheide-Chorin as compared to the Hainich-Dün which suggests a lower importance of root-derived resources in this region. On the other hand, total densities in the Schorfheide-Chorin on average exceeded those of the Hainich-Dün, presumably due to thicker litter layers (Klarner et al. 2014) suggesting that the soil food web in this region is shifted more towards the litter pathway.

\subsection{Forest type effects}

The effect of forest type on oribatid mite communities was moderate and overridden by regional factors. Oribatid mite communities between the three different beech forests were generally similar among each other and major forest type effects mainly occurred between communities of beech forests and those of coniferous forests.

Few species/taxa had a marked preference for coniferous forest, e.g. Fuscozetes setosus, Sphaerozetes pirifomis, Brachychthoniidae, Chamobates borealis, Tectocepheus velatus and Adoristes ovatus, or for deciduous forests, e.g. Berniniella bicarinata, Microppia minus, Steganacarus magnus and Steganacarus 
herculeanus. Preferences of species for a certain forest type may be due to differences in the thickness of humus layer (coniferous $>$ deciduous), $\mathrm{pH}$-value (coniferous < deciduous), the degree of disturbance by earthworms (coniferous < deciduous), seasonal microclimatic/abiotic changes (coniferous $<$ deciduous), fungal communities or chemical composition of leaf litter but is in most cases not well understood (Strenzke 1952; Maraun and Scheu 2000). At least one species, $A$. ovatus, appears to be adapted to coniferous forests since immatures and adults of this species exclusively tunnel in coniferous needles (Lions and Gourbière 1988).

However, most species distribution patterns among forest types were ambiguous, i.e. preferences for a forest type were inconsistent between habitats, regions or sampling date. For example, Achipteria coleoptrata had 4-5 fold higher densities in coniferous forests soils in the Schwäbische Alb, similar densities in soils across all forest types in the Hainich-Dün and was absent in coniferous forests but occurred in all beech forests soils in the Schorfheide-Chorin. Similarly, Dissorhina ornata had higher or similar densities in beech as compared to coniferous forests in the Schwäbische Alb and Hainich-Dün but almost exclusively occurred in coniferous forest in the Schorfheide-Chorin. In the Hainich-Dün, Oppiella nova mainly occurred in coniferous forests in 2008, but was equally abundant in all forest types in 2011. Platynothrus peltifer had similar densities in forest types in soils of the SchorfheideChorin but was more abundant in coniferous forests than in the beech forests on the bark of dead wood. The occurrence of most species on a variety of forest types again points to high degree of generalism among oribatid mites.

\section{Parthenogenesis in oribatid mites}

The proportion of parthenogenetically reproducing species is exceptionally high ( 8-9\%) in oribatid mites (Norton and Palmer 1991, Heethof et al. 2009). Due to cooccurrence of sexual and parthenogenetic species in the same habitats they represent ideal model organisms to test predictions of ecological and evolutionary theories on the maintenance of sex. A recent model, the 'Structured Resource Theory of Sexual Reproduction' (SRTS), assumes sexual species to be favoured in environments where resources are scarce or difficult to access and population growth is primarily limited by density-dependent factors such as competition and predation (Scheu and Drossel 2007). On the contrary, species reproducing by parthenogenesis are favoured in environments where resources are plenty and do not limit population growth. Instead population growth is limited by density- 
independent factors such as desiccation, frost or flooding so that populations never reach densities high enough that competition for resources plays a major role. In these environments the more efficient resource use by more diverse offspring of sexual species is outperformed by higher reproductive output of parthenogenetically reproducing species. In the following, we compare these theoretical predictions of the SRTS with distribution patterns of parthenogenetically reproducing species/individuals we found throughout the chapters of this thesis.

First, the proportion of parthenogenetically individuals/species was much lower on the bark of dead wood (3-20\%; Chapter 2) than in soil (40-80\%; Chapter 3 and 4). Many parthenogenetically reproducing species and genera which dominate in soil (e.g., Oppiella nova, Microppia minus, Quadroppia quadricarinata, Suctobelbella and Desmonomata such as Platynothrus peltifer or Nothrus spp.) were scarce or absent on dead wood - similar to arboreal habitats. The lack of coevolution with dead organic matter might in part explain a higher prevalence of parthenogenetic species among detritivores predominantly occurring in soil. In contrast, many arboreal species feeding on living resources such as lichens and mosses that are well protected against predators by chemical repellents (Reutimann and Scheidegger 1986; Lawrey 1987) benefit from sexual reproduction. However, in soil habitats as well as dead wood habitats the main food resource is fungi (Luxton 1972; Siepel and de Ruiter-Dijkman 1993; Schneider et al. 2004; Maraun et al. 2011; Chapter 2) which presumably produce secondary metabolites in both habitats to similar amounts. This suggests that the difference between both habitats primarily is not based on the type of resource but its amount. Much lower densities in dead wood indicate that communities are more heavily resource limited than soil communities which would, according to the SRTS, result in higher proportions of sexual species/individuals (Maraun et al. 2012). Since fungal biomass presumably increases over the course of decaying stages it would be interesting to analyse if the proportion of parthenogenetic species continuously increases during wood decomposition.

Second, proportions of parthenogenetic species significantly decreased in soil communities from the Schorfheide-Chorin (ø 75\%) to the Hainich-Dün (ø 54\%) and the Schwäbische Alb (ø 46\%). A similar trend occurred on dead wood where also the Schorfheide-Chorin had higher proportions (ø 13\%) than the Schwäbische Alb (ø $7.5 \%)$ and the Hainich-Dün (ø 4\%). The dominance of parthenogenetic species 
in the Schorfheide-Chorin may in part be attributed to its young landscape history of this formerly heavily glaciated region. In a recent study from the Netherlands the number of parthenogenetic species decreased along soils of increasing geological age (Zaitsev et al. 2013). Presumably, better colonisation abilities confer parthenogenetic species an advantage in early successional stages but are replaced by sexual species in later stages of succession (Norton and Palmer 1991) - a process which even on small areas can take decades (Hågvar et al. 2009; Farská et al. 2014). Furthermore, among the three regions the Schorfheide-Chorin has the thickest leaf litter layer which probably is a result of low earthworm activity (Klarner 2013). According to the SRTS an increase in the availability of resources fosters the proportion of parthenogenetic species. Higher mortality rates as a consequence of more pronounced abiotic extremes in this region might additionally shift the community towards species reproducing parthenogenetically (Scheu and Drossel 2007). The fact that a similar pattern was found on the bark of dead wood is probably an artefact of neutral distribution processes since a large fraction of the community was composed of soil living oribatid mites.

Third, the proportion of parthenogenetically reproducing individuals significantly differed between forest types in both soil and on dead wood with a higher percentage in coniferous forests (average of 68 and 14\%, respectively) than in the three beech forests (average of 54 and $5 \%$, respectively). Coniferous forests have more organic material due to a reduction of earthworm activity (Klarner 2013). In contrast to beech forests, the amount of resources in coniferous forests is constant throughout the year; thus variations in resource availability are less pronounced. In agreement with the SRTS, we assume that, similar to the regional effect, higher availability and stability of resources in coniferous forests as compared to beech forests favours parthenogenetic reproduction (Scheu and Drossel 2007). We consider the same pattern on the bark of dead wood to be caused by stochastic colonisation processes from soil.

Fourth, the proportion of parthenogenetically reproducing oribatid mites increased from the litter layer to the soil layer (Chapter 4). This finding is in line with previous results (Luxton 1982, Ryabinin and Pan'kov 1987) but still not well understood. Dominance of parthenogenetic species in rather abiotically stable soil layers are apparently in conflict with the high prevalence of parthenogenetic species in highly disturbed habitats. Norton and Palmer (1991) referred to the biotic- 
uncertainty theory which states that sexually reproducing species have an advantage in biologically complex and unpredictable habitats like the litter layer while the opposite is true for parthenogenetically reproducing species in comparable depauperated deeper soil layers. However, this theory was rejected in a comprehensive metadata study where no negative correlation of parthenogenetic species with biotic complexity was found (Cianciolo and Norton 2006).

Fifth, temporal fluctuations of parthenogenetically reproducing species were significantly higher than those of sexual species (Chapter 3). Theoretically, in habitats where populations are predominantly regulated by density-independent factors, advantages of a more efficient resource use by diverse progeny of sexual reproduction diminishes and is outperformed by faster reproducing parthenogenetic species. By contrast, in habitats where density dependent-factors, such as resource limitation, competition and predation, regulate population densitiesthe advantage of a more diverse progeny outweigh the lower reproductive output and favours sexual species (Scheu and Drossel 2007). More pronounced temporal fluctuations of parthenogenetic as compared to sexual species therefore support assumptions of the SRTS that parthenogenetically reproducing species are primarily controlled by density-independent factors and predominantly occur where resources are plentiful, replenish quickly and death rates due to abiotic factors are high.

\section{Conclusions}

Due to their small size and ubiquitous occurrence oribatid mites are ideal model organisms to investigate ecological and evolutionary patters along a large range of spatial and temporal scales. The results of our studies suggest that communities of oribatid mites are driven by both deterministic and neutral processes being consistent with previous studies. Predictable regional communities as well as differences between habitats and forest types across regions point to deterministic processes shaping species assemblages. The high proportion of soil-living species on dead wood and the low forest type specificity in contrast indicate neutral effects for the species composition. Neutral dispersal is also supported by the corresponding pattern of proportions of parthenogenetic individuals between the regions in soil and on dead wood. Both deterministic and neutral processes appear not to be opposing but to go hand in hand operating simultaneously on different scales. 
The distribution of parthenogenetic and sexual oribatid mite species displayed interesting and predictable ecological patterns and is worth to investigate when attempting to resolve the cause and maintenance of sexual reproduction. The SRTS generally provides a good explanatory power for understanding actual patterns for the occurrence of parthenogenetic species/individuals, although not all patterns found could be explained satisfyingly (e.g., vertical distribution in soil). A critical point, however, is the assessment of resource availability within a habitat which was mostly inferred indirectly by total densities or the amount of organic material. Also, the abiotic stress for oribatid mites which is, aside with resources, regarded as a main factor for the occurrence of parthenogenetic species is difficult to assess. Continuing research on the trophic structure of oribatid mites by resource manipulation experiments, stable isotope or fatty acid analysis and the investigation of oribatid mite species along environmental gradients will not only add to a more detailed view on community composition but also to the understanding of distribution patterns of parthenogenetic species. 


\section{References}

Adler PB, HilleRisLambers J, Levine JM (2007) A niche for neutrality. Ecol Lett 10:95-104

Aoki J-I (1973) Soil mites (oribatids) climbing trees. In: Daniel M, Rosicky B (eds) Proceedings of the 3rd International Congress of Acarology, Prague. Junk B.V. Publishers, The Hague, pp 59-65

Behan-Pelletier VM (2015) Sexual dimorphism in Autogneta, with description of three new species from North America and new diagnosis of the genus (Acari, Oribatida, Autognetidae). Zootaxa 3946:55-78

Blüthgen N, Dormann CF, Prati D, Klaus V, Kleinebecker T, Hölzel N, Alte F, Boch S, Gockel S, Hemp A, Müller J, Nieschulze J, Renner SC, Schöning I, Schuhmacher U, Socher SA, Wells K, Birkhofer K Buscot F, Oelmanne Y, Rothenwöhrer C, Scherber C, Tscharntke T, Weiner CN, Fischer M, Kalko EKV, Linsenmair KE, Schulze ED, Weisser W (2012) A quantitative index of land-use intensity in grasslands: Integrating mowing, grazing and fertilization. Basic Appl Ecol 13:207-220

Borcard D, Geiger W, Matthey W (1995) Oribatid mite assemblages in a contact zone between a peat-bog and a meadowin the Swiss Jura (Acari, Oribatei): influence of landscape structures and historical processes. Pedobiologia 39:318-330

Christensen O (1980) Aspects of the distribution pattern of Liebstadia humerata in a Danish oak forest. Pedobiologia 20:24-30

Cianciolo JM; Norton RA (2006) The ecological distribution of reproductive mode in oribatid mites, as related to biological complexity. Exp Appl Acarol 40:1-25

Cornell HV, Lawton JH (1992) Species interactions, local and regional processes, and limits to the richness of ecological communities: a theoretical perspective. J Anim Ecol 61:1-12

Eisenhauer N, Partsch S, Parkinson D, Scheu S (2007) Invasion of a deciduous forest by earthworms: Changes in soil chemistry, microflora, microarthropods and vegetation. Soil Biol Biochem 39:1099-1110

Erdmann G, Floren A, Linsenmair KE, Scheu S, Mark M (2006) Little effect of forest age on oribatid mites on the bark of trees. Pedobiologia 50:433-441

Erdmann G, Otte V, Langel R, Scheu S, Maraun M (2007) The trophic structure of bark-living oribatid mite communities analysed with stable isotopes $\left({ }^{15} \mathrm{~N},{ }^{13} \mathrm{C}\right)$ indicates strong niche differentiation. Exp Appl Acarol 41:1-10

Farská J, Prejzková K, Starý J, Rusek J (2014) Soil microarthropods in nonintervention montane spruce forest regenerating after bark-beetle outbreak. Ecol Res 29:1087-1096

Fischer BM, Meyer E, Maraun M (2014) Positive correlation of trophic level and proportion of sexual taxa of oribatid mites (Acari: Oribatida) in alpine soil systems. Exp Appl Acarol 63:465-479 
Fischer M, Bossdorf O, Gockel S, Hänsel F, Hemp A, Hessenmöller D, Korte G, Nieschulze J, Pfeiffer S, Prati D, Renner S, Schöning I, Schuhmacher U, Wells K, Buscot F, Kalko EKV, Linsenmair KE, Schulze ED, Weisser WW (2010) Implementing large-scale and long-term functional biodiversity research: The Biodiversity Exploratories. Basic Appl Ecol 11:473-485

Genney DR, Anderson IC, Alexander IJ (2006) Fine-scale distribution of pine ectomycorrhizas and their extramatrical mycelium. New Phytol 170:381-390

Gilbert KJ, Fahey TJ, Maerz JC, Sherman RE, Bohlen P, Dombroskie JJ, Groffman PM, Yavitt JB (2014) Exploring carbon flow through the root channel in a temperate forest soil food web. Soil Biol Biochem 76:45-52

Hågvar S, Steen R (2013) Succession of beetles (genus Cis) and oribatid mites (genus Carabodes) in dead sporocarps of the red-banded polypore fungus Fomitopsis pinicola. Scand J For Res 28:436-444

Hågvar S, Solhøy T, Mong CE (2009) Primary succession of soil mites (Acari) in a Norwegian glacier foreland, with emphasis on oribatid species. Arct Antarct Alp Res 41:219-227

Hansen R (2000) Effects of habitat complexity and composition on a diverse litter microarthropod assemblage. Ecology 81:1120-1132

Heethoff M, Norton R, Scheu S, Maraun M (2009) Parthenogenesis in oribatid mites (Acari, Oribatida). Evolution without sex. In: Schön I, Martens K, Van Dijk P (eds) Lost sex. The Evolutionary Biology of Parthenogenesis. Springer, New York, pp 241-257

Hubbell SP (2001) The unified neutral theory of biodiversity and biogeography. Princeton University Press, Princeton, USA

Huhta V, Siira-Pietikäinen A, Penttinen R (2012) Importance of dead wood for soil mite (Acarina) communities in boreal old-growth forests. Soil Org 84:499-512

Klarner B (2013) Changes in trophic structure of decomposer communities with land use in Central European temperate forests. Dissertation, University of Göttingen

Klarner B, Ehnes RB, Erdmann G, Eitzinger B, Pollierer MM, Maraun M, Scheu S (2014) Trophic shift of soil animal species with forest type as indicated by stable isotope analysis. Oikos 123:1173-1183

Knee W, Forbes MR, Beaulieu F (2013) Diversity and host use of mites (Acari: Mesostigmata, Oribatida) phoretic on bark beetles (Coleoptera: Scolytinae): Global generalists, local specialists? Entomol Soc Am 106:339-350

Kraft NJB, Adler PB, Godoy O, James EC, Fuller S, Levine JM (2015) Community assembly, coexistence and the environmental filtering metaphor. Funct Ecol 29:592-599

Lawrey JD (1987) Nutritional ecology of lichen/moss arthropods. In: Slansky Jr. F, Rodriguez JG (eds) Nutritional Ecology of Insects, Mites, Spiders and related Invertebrates. John Wiley \& Sons, London, pp 209-233

Leibold MA, McPeek MA (2006) Coexistence of the niche and netural perspectives in community ecology. Ecology 87:1399-1410

Levin S (1992) The problem of pattern and scale. Ecology 73:1943-1967 
Lieutier F (1978) Les acariens associés a Ips typographus et Ips sedentatus (Coleoptera: Scolytidae) en région parisienne et les variations de leur populations au cours du cycle annuel. Bull Ecol 9:307-321

Lindahl B, Ihrmark K, Boberg J, Trumbore SE, Högberg P, Stenlid J (2007) Spatial separation of litter decomposition and mycorrhizal nitrogen uptake in a boreal forest. New Phytol 173:611-20

Lindo Z, Stevenson SK (2007) Diversity and distribution of oribatid mites (Acari: Oribatida) associated with arboreal and terrestrial habitats in interior cedarhemlock forests, British Columbia, Canada. Northwest Sci 81:305-315

Lions JC, Gourbière F(1988) Populations adultes et immatures d'Adoristes ovatus (Acarien: Oribate) dans les aiguilles de la litière d'Albies alba. Rev Écol Biol Sol 25:343-352

Luxton M (1972) Studies on the oribatid mites of a Danish beech wood soil. Pedobiologia 12:434-463

Luxton M (1982) The biology of mites from beech woodland soil. Pedobiologia 23:18

Maraun M, Augustin D, Müller J, Bässler C, Scheu S (2014) Changes in the community composition and trophic structure of microarthropods in sporocarps of the wood decaying fungus Fomitopsis pinicola along an altitudinal gradient. Appl Soil Ecol 84:16-23

Maraun M, Alphei J, Bonkowski M, Buryn R, Migge-Kleian S, Peter M, Schaefer M, Scheu S (1999) Middens of the earthworm Lumbricus terrestris (Lumbricidae): microhabitats for micro-and mesofauna in forest soil. Pedobiologia 43:276-287

Maraun M, Erdmann G, Fischer BM, Pollierer MM, Norton RA, Schneider K, Scheu $S$ (2011) Stable isotopes revisited: Their use and limits for oribatid mite trophic ecology. Soil Biol Biochem 43:877-882

Maraun M, Norton RA, Ehnes RB, Scheu S, Erdmann G (2012) Positive correlation between density and parthenogenetic reproduction in oribatid mites (Acari) supports the structured resource theory of sexual reproduction. Evol Ecol Res 14:311-323

Maraun M, Scheu S (2000) The structure of oribatid mite communities (Acari, Oribatida): patterns, mechanisms and implications for future research. Ecography 23:374-383

Materna J (2000) Oribatid communities (Acari: Oribatida) inhabiting saxicolous mosses and lichens in the Krkonoše Mts. (Czech Republic). Pedobiologia 44, 40-62

Matthewman W, Pielou D (1971) Arthropods inhabiting the sporophores of Fomes fomentarius (Polyporaceae) in Gatineau Park, Quebec. Can Entomol 103:775847

McLean MA, Parkinson D (1998) Impacts of the epigeic earthworm Dendrobaena octaedra on oribatid mite community diversity and microarthropod abundances in pine forest floor: a mesocosm study. Appl Soil Ecol 7:125-136

Migge-Kleian S, McLean MA, Maerz JC, Heneghan L (2006) The influence of invasive earthworms on indigenous fauna in ecosystems previously uninhabited by earthworms. Biol Invasions 8:1275-1285 
Nicolai V (1986) The bark of trees: thermal properties, microclimate and fauna. Oecologia 69:148-160

Nicolai V (1993) The arthropod fauna on the bark of deciduous and coniferous trees in a mixed forest of the Itasca State Park, MN, USA. Spixiana 16:61-69

Norton RA (1980) Observations on phoresy by oribatid mites (Acari: Oribatei). Int $J$ Acarol 6:121-130

Norton R, Palmer SC (1991) The distribution, mechanisms and evolutionary significance of parthenogenesis in oribatid mites. In: Schuster R, Murphy PW (eds) The Acari: Reproduction, Development and Life-History Strategies. Chapman and Hall Publ., London, pp 107-136

Penttinen R, Siira-Pietikäinen A, Huhta V (2008) Oribatid mites in eleven different habitats in Finland. Integr Acarology 2:237-244

Penttinen R, Viiri H, Moser JC (2013) The mites (Acari) associated with bark beetles in the Koli National Park in Finland. Acarologia 53:3-15

Petersen H, Luxton M (1982) A comparative analysis of soil fauna populations and their role in decomposition processes. Oikos 39:288-388

Pollierer MM, Langel R, Körner C, Maraun M, Scheu S (2007) The underestimated importance of belowground carbon input for forest soil animal food webs. Ecol Lett 10:729-736

Proctor HC, Montgomery KM, Rosen KE, Kitching RL (2002) Are tree trunks habitats or highways? A comparison of oribatid mite assemblages from hoop-pine bark and litter. Aust J Entomol 41:294-299

Reutimann P, Scheidegger C (1986) Importance of lichen secondary products in food choice of two oribatid mites (Acari) in an alpine meadow ecosystem. $J$ Chem Ecol 13:363-369

Ryabinin NA and Pan'kov AN (1987) The role of parthenogenesis in the biology of the oribatid mites. Ekologiya 62-64

Sala OE, Chapin FS,Armesto JJ,Berlow E,Bloomfield J,Dirzo R,Huber-Sanwald E,Huenneke LF,Jackson RB,Kinzig A,Leemans R,Lodge DM,Mooney HA, Oesterheld M, Poff NLR, Sykes MT, Walker BH, Walker M, DH Wall (2000) Global Biodiversity Scenarios for the Year 2100. Science 287:1770-1774

Schaefer M, Schauermann J (1990) The soil fauna of beech forests: comparison between a mull and a moder soil. Pedobiologia 34:299-314

Schatz H, Wilhalm T (2013) Tag der Artenvielfalt 2012 in Ridnaun (Gemeinde Ratschings, Südtirol, Italien). Gredleriana 13, 139-194

Scheu S, Drossel B (2007) Sexual reproduction prevails in a world of structured resources in short supply. Proc Biol Sci 274:1225-1231

Schneider K, Migge-Kleian S, Norton RA, Scheu S, Langel R, Reineking A, Maraun M (2004) Trophic niche differentiation in soil microarthropods (Oribatida, Acari): evidence from stable isotope ratios $\left({ }^{15} \mathrm{~N} /{ }^{14} \mathrm{~N}\right)$. Soil Biol Biochem 36:1769-1774

Schuster R (1960) On the ecology and distribution of soil mites (Oribatei) at the eastern edge of the Alps, especially in Styria. Mitteilungen des Naturwissenschaftlichen Vereines für Steiermark 90:132-149 
Shaldybina EA (1967) The biology of Melanozetes mollicomus (Koch). Zoologicheskii zhurnal 46:1659-1667

Siepel H, Ruiter-Dijkman E (1993). Feeding guilds of oribatid mites based on their carbohydrase activities. Soil Biol Biochem 25:1491-1497

Skubała P (2008) Oribatid fauna ion Norway Spruce stumps. Are there saproxylic oribatid species? In: Bertrand M, Kreiter S, Migeon A, Navajas M, Tixier MS, Vial $L$ (eds) Integrative Acarology. Proceedings of the $6^{\text {th }}$ European Congress, European Association of Acarologists, pp 250-260

Skubała P, Marzec A (2013) Importance of different types of beech dead wood for soil microarthropod fauna. Pol J Ecol 61:545-560

Skubała P, Maslak M (2009) Succession of oribatid fauna (Acari, Oribatida) in fallen spruce trees: Deadwood promotes species and functional diversity.In: Sabelis MW, Bruin J (eds) Trends in Acarology: Proceedings of the $12^{\text {th }}$ International Congress. Springer, Berlin, pp 123-128

Sokołowska M, Duras M, Skubała P (2009) Oribatid mites communities (Acari: Oribatida) in dead wood of protected areas under strong anthropogenic pressure. In: Tajovský K, Schlaghamerský J, Pižl V (eds) Contribution to Soil Zoology in Central Europe III, České, Budějovice, pp 151-155

Strenzke K (1952) Untersuchungen über Tiergemainschaften des Bodens: Die Oribatiden und ohre Synusien in den Böden Norddeutschlands. Zoologica 104:1-80

Tscharntke T, Tylianakis JM, Rand T, Didham RK, Fahrig L, Batáry P, Bengtsson J, Clough Y, Crist TO, Dormann CF, Ewers RM, Fründ J, Holt RD, Holzschuh A, Klein AM, Kleijn D, Kremen C, Landis D, Laurance W, Lindenmayer D, Scherber C, Sodhi N, Steffan-Dewenter I, Thies C, van der Putten WH, Westphal C(2012) Landscape moderation of biodiversitypatterns and processes - eight hypotheses. Biol Rev Camb Philos Soc 87:661-685

Weigmann G (2006) Hornmilben (Oribatida). In: Dahl F (ed) Die Tierwelt Deutschlands 76. Goecke \& Evers, Keltern, pp 1-520

Wunderle I, Beck L, Woas S (1990) Ein Beitrag zur Taxonomie und Ökologie der Oribatulidae und Scheloribatidae (Acari, Oribatei) in Südwestdeutschland. Andrias 7:15-60

Wunderle I (1992) Die Oribatiden-Gemeinschaften (Acari) der verschiedenen Habitate eines Buchenwaldes. Carolinea 50:79-144

Zaitsev AS, Straalen NM, Berg MP (2013) Landscape geological age explains large scale spatial trends in oribatid mite diversity. Landscape Ecol 28:285-296 


\section{DANKSAGUNG}

Mein größter Dank gebührt Mark Maraun für seine hervorragende Betreuung. Während der gesamten Zeit habe ich mich bei dir immer gut aufgehoben gefühlt. Ich danke dir zudem für die vielen anregenden oribatologischen Fachgespräche und deiner ansteckenden Begeisterung durch die man sich nach Verlassen deines Büros immer motivierter fühlt als vor dem Betreten.

Stefan Scheu möchte ich für die schnellen, akribischen und konstruktiven Korrekturen der Manuskripte und für die Hilfestellung zu Problemen jeglicher Art danken.

Bei Olga Ferlian, Bernhard Klarner, Georgia Erdmann, David Ott und besonders Bernhard Eitzinger möchte ich mich für die schönen Erinnerungen während der gemeinsamen Feldarbeiten und für die fachlichen Diskussionen bedanken.

Ein großes Dankeschön geht an Christel Fischer, Andrea Lambertz, Susanne Böning-Klein, Ingrid Kleinhans, Elisabeth Opielka, Guido Humpert, Dieter Nünchert und Bernd Messerschmidt für die Vorsortierungen der Proben, die Bereitstellung sämtlichen Equipments, die Abwicklung bürokratischer Angelegenheiten und für die sonstige technische Unterstützung.

Dem Exploratorienteam danke ich für die Koordination des Projektes und der vielseitigen Hilfestellung vor Ort.

Dana Augustin und Fabian Willert danke ich für die nette Atmosphäre im gemeinsamen Büro, bei der ich trotz mancher Tiefpunkte immer gerne zur Arbeit gekommen bin. Ihr seid würdige Nachfolger für Olga, der ich hiermit auch nochmal für die schöne Zeit als Bürokollege danken möchte.

Meiner Freundin und Kollegin Sarah Zieger danke ich für die emotionale Unterstützung und für die Hilfe bei der Bewältigung von Problemen des alltäglichen Wissenschaftlerdaseins.

Meinen Eltern möchte ich ganz herzlich für die finanzielle und moralische Unterstützung während meiner gesamten Studienzeit danken.

Meinen Freunden danke ich für die gemeinsame Zeit außerhalb des Oribatidenuniversums.

Zu guter Letzt danke ich der gesamten Arbeitsgruppe für die gute Arbeitsatmosphäre. 
Geistige Nahrung ist wie jede andere; es ist angenehmer und zuträglicher, sie mit einem Löffel als mit einer Schaufel zu nehmen

(Mark Twain) 


\section{List OF PUblications}

Bluhm C, Scheu S, Maraun M (2015) Oribatid mite communities on the bark of dead wood vary with log type, surrounding forest and regional factors. Appl Soil Ecol 89:102-112

Bluhm C, Scheu S, Maraun M (2016) Temporal fluctuations in oribatid mites indicate that density-independent factors favour parthenogenetic reproduction. Exp Appl Acarol 68:387-407

\section{THESIS DECLARATIONS}

Declaration of the author's own contribution to manuscripts with multiple authors

Chapters 2 and 3 comprise manuscripts that have been published in peer-reviewed journals. Chapter 4 comprises a manuscript that is in preparation for submission.

Chapter 2, Chapter 3, Chapter 4: I am the first author of this manuscript and significantly contributed to the study design, collected and analysed the data, wrote the manuscript and created figures, tables and appendices. All co-authors contributed to finalizing the manuscripts.

\section{Plagiarism declaration}

I declare that I have written this doctoral thesis independently. All persons contributing to the manuscripts have been named so. All sentences or passages quoted from other people's work have been specifically acknowledged by clear cross-referencing. I have not submitted this thesis in any form for another degree at any university or institution.

Christian Bluhm

Göttingen, April 2016 